\title{
A Review of Terpenes from Marine-Derived Fungi: 2015-2019
}

\author{
Minghua Jiang ${ }^{1,2,+} \mathbb{D}$, Zhenger $W u^{1,+}$, Heng Guo ${ }^{1}$, Lan Liu ${ }^{1,2,3}$ and Senhua Chen $1,2,3, *(\mathbb{D})$ \\ 1 School of Marine Sciences, Sun Yat-sen University, Guangzhou 510006, China; \\ jiangmh23@mail2.sysu.edu.cn (M.J.); wuzher@mail2.sysu.edu.cn (Z.W.); hengeguo163@163.com (H.G.); \\ cesllan@mail.sysu.edu.cn (L.L.) \\ 2 South China Sea Bio-Resource Exploitation and Utilization Collaborative Innovation Center, \\ Guangzhou 510006, China \\ 3 Southern Laboratory of Ocean Science and Engineering (Guangdong, Zhuhai), Zhuhai 519000, China \\ * Correspondence: chensenh@mail.sysu.edu.cn; Tel.: +86-020-84725459 \\ + These authors contributed equally to this work.
}

Received: 9 May 2020; Accepted: 16 June 2020; Published: 18 June 2020

\begin{abstract}
Marine-derived fungi are a significant source of pharmacologically active metabolites with interesting structural properties, especially terpenoids with biological and chemical diversity. In the past five years, there has been a tremendous increase in the rate of new terpenoids from marine-derived fungi being discovered. In this updated review, we examine the chemical structures and bioactive properties of new terpenes from marine-derived fungi, and the biodiversity of these fungi from 2015 to 2019 . A total of 140 research papers describing 471 new terpenoids of six groups (monoterpenes, sesquiterpenes, diterpenes, sesterterpenes, triterpenes, and meroterpenes) from 133 marine fungal strains belonging to 34 genera were included. Among them, sesquiterpenes, meroterpenes, and diterpenes comprise the largest proportions of terpenes, and the fungi genera of Penicillium, Aspergillus, and Trichoderma are the dominant producers of terpenoids. The majority of the marine-derived fungi are isolated from live marine matter: marine animals and aquatic plants (including mangrove plants and algae). Moreover, many terpenoids display various bioactivities, including cytotoxicity, antibacterial activity, lethal toxicity, anti-inflammatory activity, enzyme inhibitor activity, etc. In our opinion, the chemical diversity and biological activities of these novel terpenoids will provide medical and chemical researchers with a plenty variety of promising lead compounds for the development of marine drugs.
\end{abstract}

Keywords: terpenoid; biological activity; chemical diversity; marine natural product; marine fungi

\section{Introduction}

Marine-derived fungi are a significant source of pharmacologically active metabolites with interesting structural properties [1-5]. Terpenoids, which possess chemical structure diversity [6], are important secondary metabolites of marine-derived fungi and have diverse bioactivities $[7,8]$, such as cytotoxic, antibacterial, antifungal, antiviral, anti-inflammatory, and enzyme inhibitor activities. Two past reviews have covered the isolation, chemical structures, and biological activities of terpenoids from marine-derived fungi-one published by Rainer Ebel [7] in 2011 and another by Peter Proksch [8] in 2015. The field of marine natural products is currently in a golden age of microbially derived compound discovery [9]; there has been a tremendous increase in the rate of new terpenoids from marine-derived fungi being discovered in the last five years. Hence, an updated review is needed, covering the literature published from 2015 to 2019. In this review, we focus not only on the diversity of the chemical structures and bioactive properties of the new terpenes isolated from marine-derived 
fungi during the last five years but also on the biodiversity of these fungi. A total of 140 research papers describing 471 new terpenoids from marine fungi were included in this analysis. Steroids and simple isopentenyl (C5)-substituted alkaloids, polyketides, peptides, and shikimates, and their derivates, were excluded from this review.

\section{The Characteristics of Terpenoids from Marine Fungi}

The new terpenoids from marine fungi can be divided into six groups based on their chemical structures and biogenetic pathways: monoterpenes, sesquiterpenes, diterpenes, sesterterpenes, triterpenes, and meroterpenes. The pie chart in Figure 1 details the proportions of the different terpenes from marine fungi discovered in the last five years. Sesquiterpenes $(188,40 \%)$, meroterpenes $(165,35 \%)$, and diterpenes $(75,16 \%)$ comprise the largest proportions of terpenes from marine fungi, followed by sesterterpenes $(29,6 \%)$, monoterpenes $(11,2 \%)$, and triterpenes $(3,1 \%)$. The number of new terpenoids found in marine fungi increased rapidly from 2010-2014 [8] to 2015-2019 (on average, an increase from 40 discoveries a year to 95 a year).

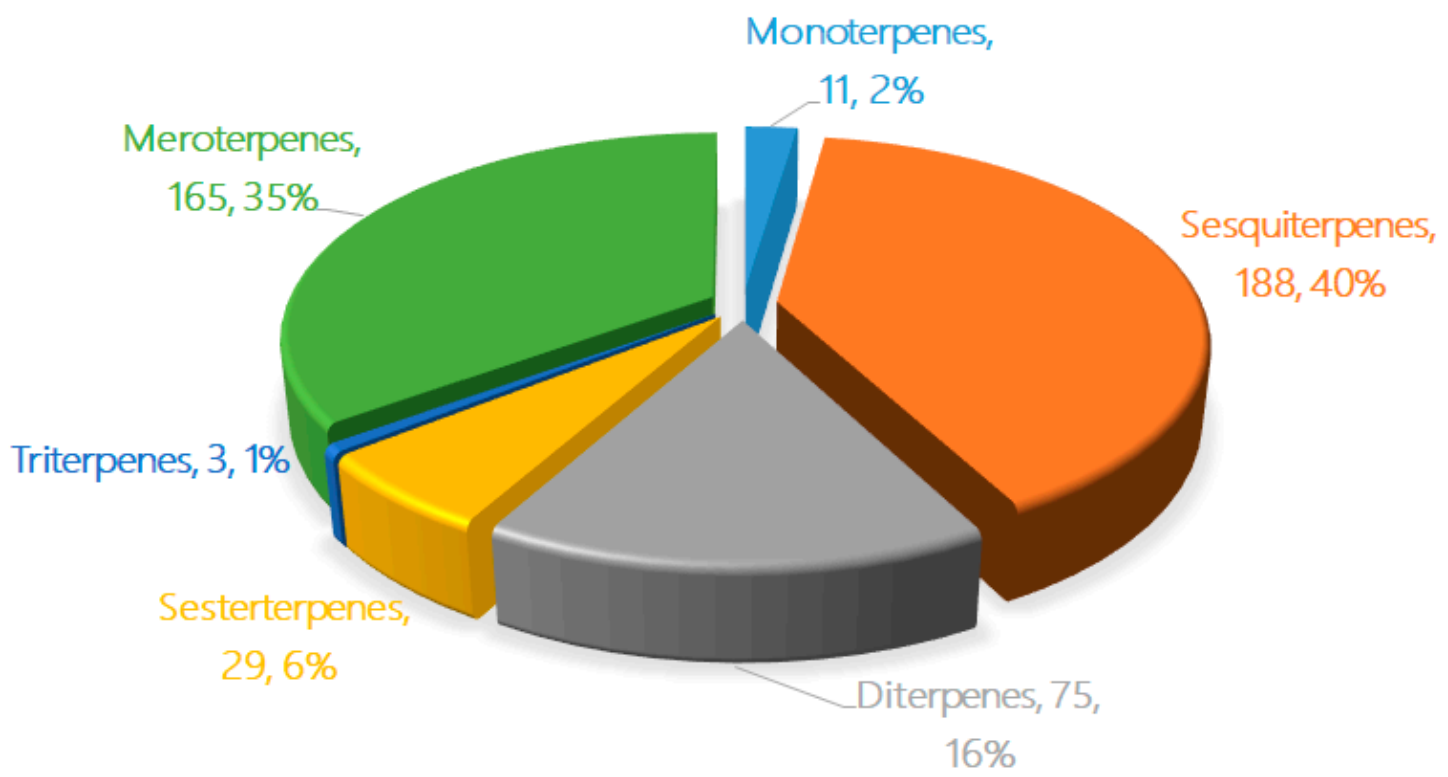

Figure 1. The proportions of different terpenes from marine fungi discovered in the last five years.

About 471 new terpenes were derived from a diverse range of marine fungi (127 strains, including three strains of unidentified fungi) belonging to 34 genera (Acremonium, Alternaria, Arthrinium, Aspergillus, Auxarthron, Botryotinia, Chondrostereum, Cochliobolus, Coriolopsis, Curvularia, Diaporthe, Epicoccum, Eupenicillium, Eutypella, Graphostroma, Leptosphaerulina, Lophiostoma, Mucor, Myrothecium, Nectria, Neosartorya, Paraconiothyrium, Penicillium, Pestalotiopsis, Pleosporales, Pseudallescheria, Rhinocladiella, Scopulariopsis, Stachybotrys, Talaromyces, Thielavia, Tinctoporellus, Trichoderma, and Trichothecium). Penicillium (23\%, 108), Aspergillus (21\%,99), and Trichoderma $(10 \%, 49)$ each represent more than $10 \%$ of the total and are the dominant producers of terpenoids, whose amounts together comprise more than half of the total. There are nine genera of fungi in the range of $2 \%-6 \%$ (10-29 compounds), including Eutypella $(6.0 \%, 29)$, Talaromyces (3.2\%, 15), Stachybotrys (3.2\%, 15), Alternaria $(2.8 \%, 13)$, Chondrostereum $(2.8 \%, 13)$, Diaporthe $(2.3 \%, 11)$, Graphostroma $(2.3 \%, 11)$, Rhinocladiella $(2.1 \%, 10)$, and Acremonium $(2.1 \%, 10)$. The remaining 22 genera of fungi together make up approximately $19 \%$, while each genus comprises less than $2 \%$ ( $\leq 9$ compounds), as shown in Figure 2. 


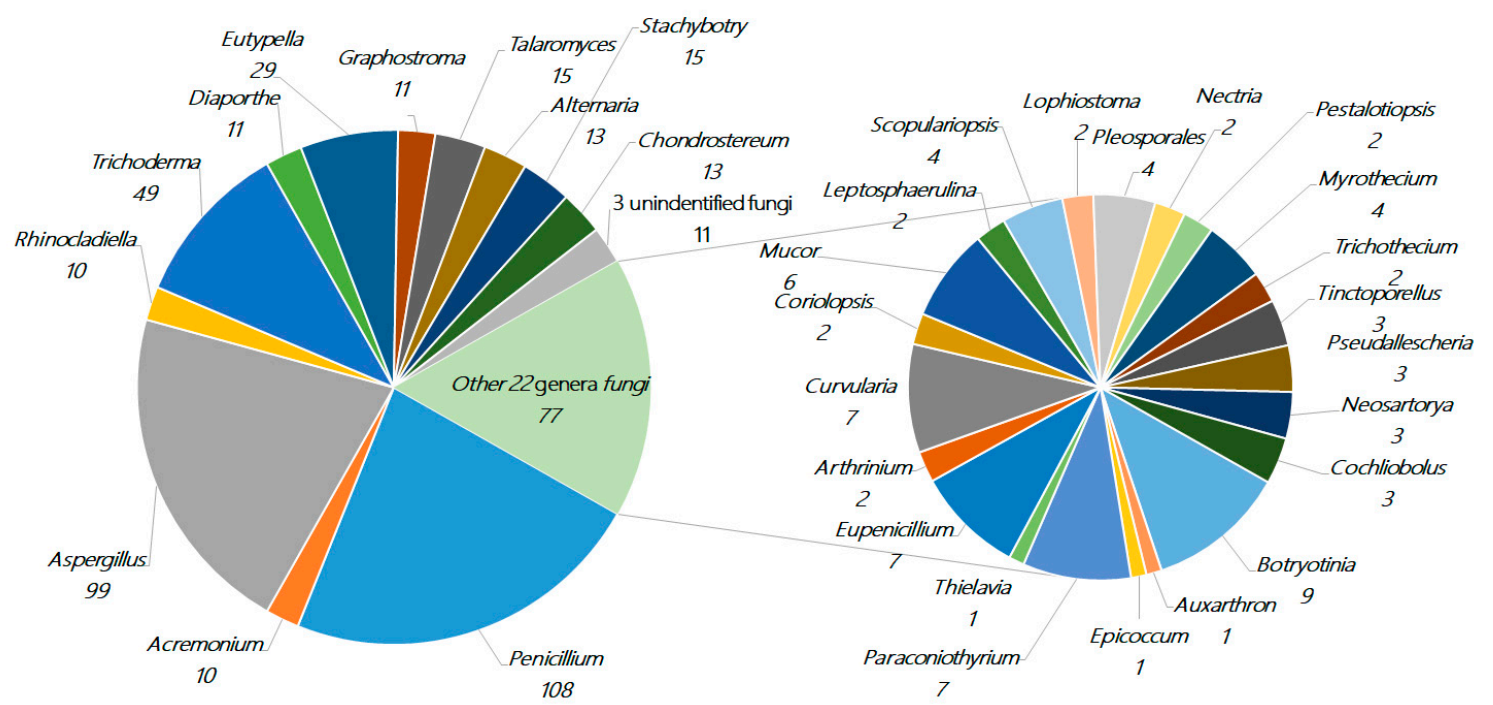

Figure 2. The terpenoids from marine fungi in this review divided by the origin of the genus.

When examining the habitats/sources of these terpenoid-rich marine fungi (Figure 3), were found that $33 \%$ of the compounds were isolated from marine environments (i.e., deep-sea sediments (15\%)) and other marine sediments (shallow sea or coast, 11\%), while the remaining compounds were obtained from living matter, such as marine animals (27\%) and aquatic plants (including mangrove plants) (38\%). Within the individual groups, algae (20\%), mangrove habitats (19\%), deep-sea sediments (15\%), other marine sediments $(11 \%)$, sponges $(9 \%)$, coral $(6 \%)$, and echinoderms $(4 \%)$ were the most predominant sources of fungi. A newly emerging source is the extreme environment, i.e., deep-sea sediments (15\%) and hydrothermal vents $(3 \%)$, which can produce structurally unique metabolites.

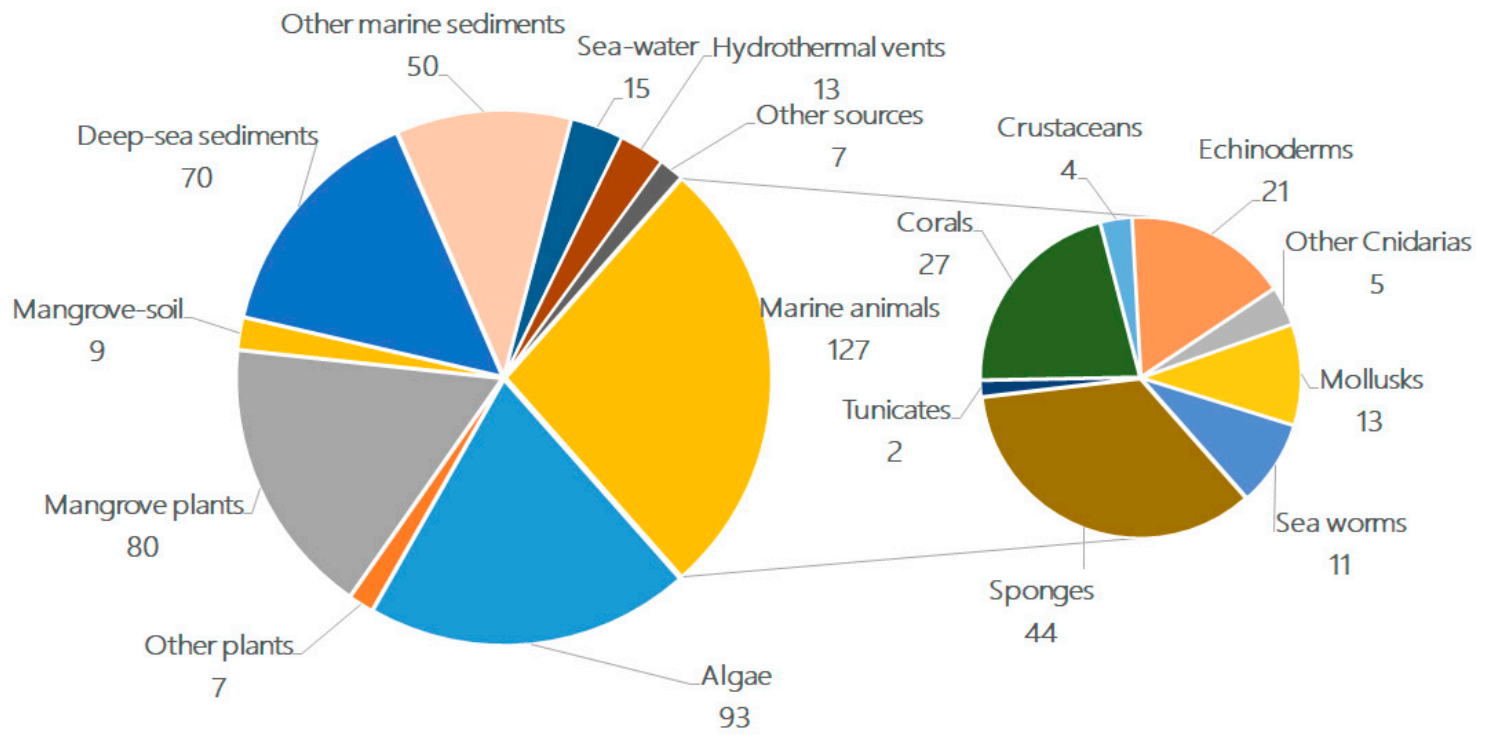

Figure 3. The terpenoids from marine fungi were divided by their sources (habitats); 471 terpenoids were isolated from 127 species of fungi in 127 habitats.

In the bioassays of the 471 new terpenoids from marine fungi, most of the isolated novel terpenoids were evaluated as having one or more bioactivity (Figures 4 and 5). An equivalent of $30 \%$ of the terpenoids displayed biological activities, including cytotoxicity, antibacterial activity, antifungal activity, antiviral activity, lethal toxicity activity, anti-inflammatory activity, enzyme inhibitor activity, and other activities (242 active/707 test of terpenoids). In total, 22\% of the compounds displayed cytotoxicity (up to 54 compounds), followed by lethal toxicity $(20 \%, 48)$, anti-inflammatory $(19 \%, 45)$, 
antibacterial $(15 \%, 37)$, protease enzyme inhibition $(13 \%, 30)$, antiviral $(4 \%, 10)$, and antifungal $(3 \%, 8)$ activities (Figure 4). When comparing the special activities of the new terpenoids, the lethal toxicity (mainly including the toxicity of marine phytoplankton, marine zooplankton, and plant seedlings) (70.6\%, 20/67), enzyme inhibitor activity (40.5\%, 44/74), anti-inflammatory activity $(37.8 \%, 45 / 119)$, and cytotoxicity $(30.5 \%, 54 / 177)$ of each terpenoid should be given more attention in the search for new drug leads (Figure 5).

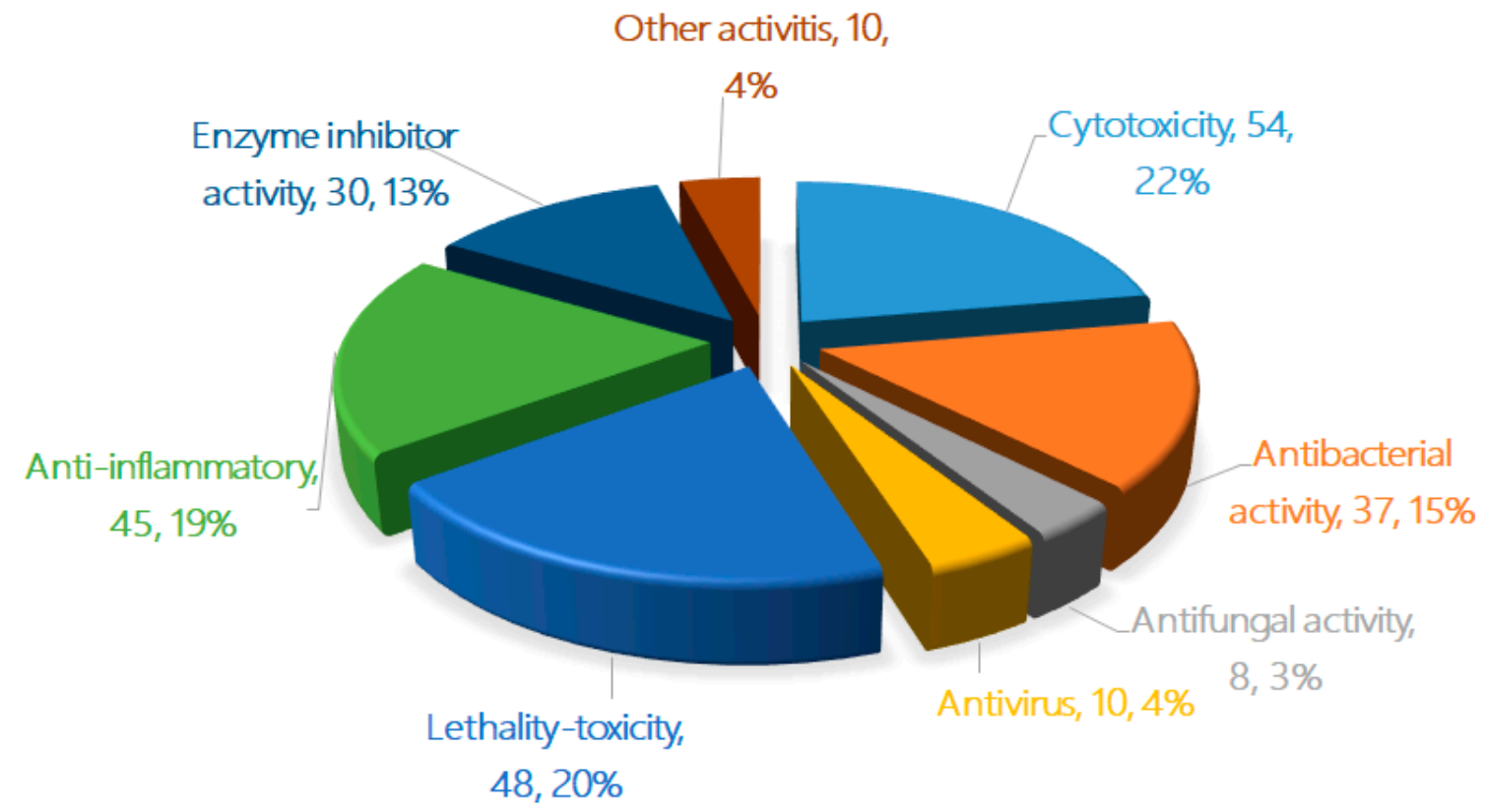

Figure 4. The percentage represents the proportion of one activity compared to the whole occurrence of activities of bioactive terpenoids from marine fungi.

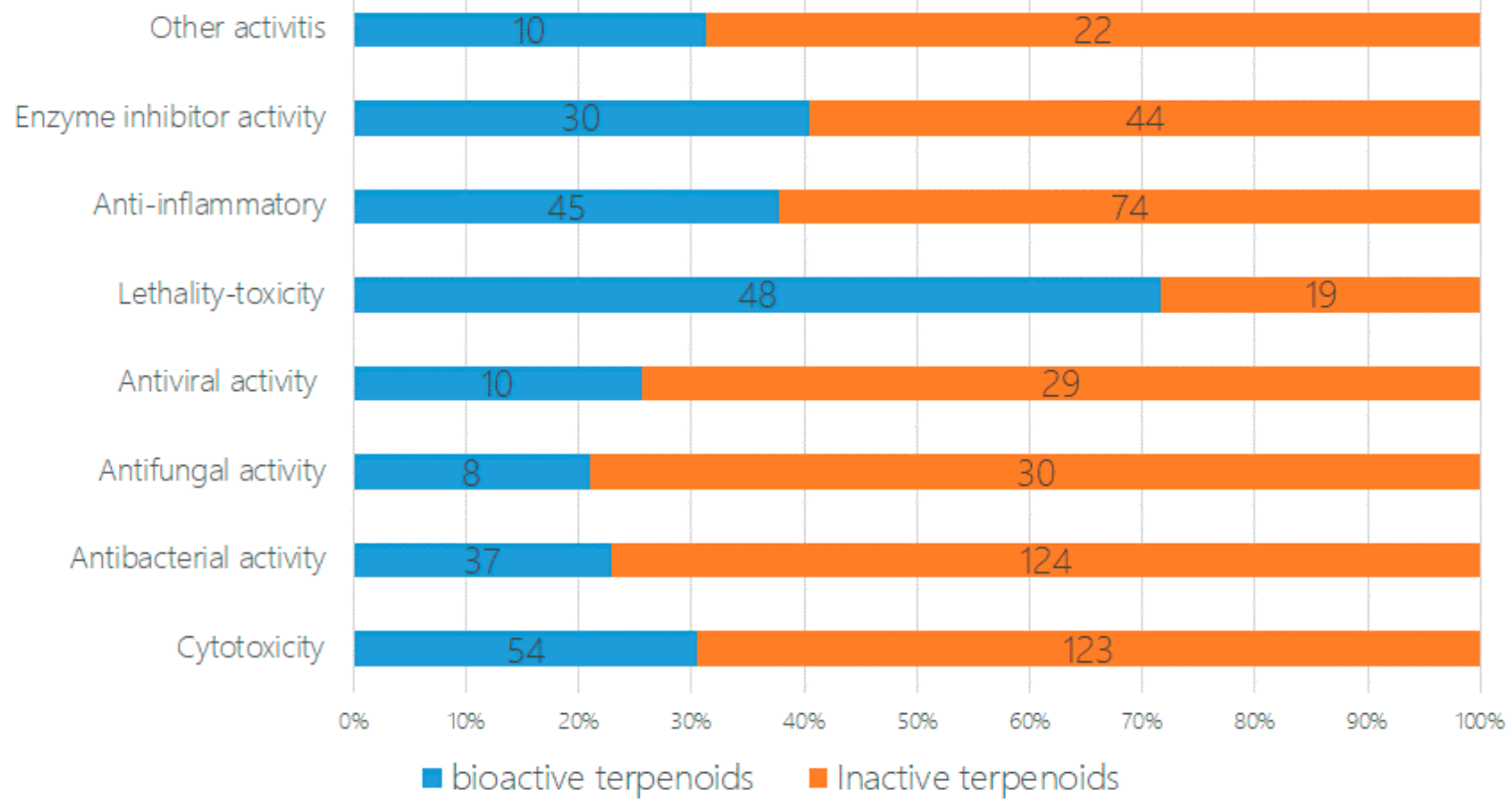

Figure 5. The number of bioactive terpenoids and inactive terpenoids from marine fungi evaluated by eight classes of bioactivity modes. 


\section{Isolation, Structure, and Bioactivities of Terpenoids from Marine Fungi}

\subsection{Monoterpenes}

While monoterpenes were rarely isolated from fungi in the past 15 years, there has been a significant increase in the number of new metabolites reported from marine fungi (only one before 2014 vs. 11 from 2015 to 2019) (1-11, Figure 6) [7,8].

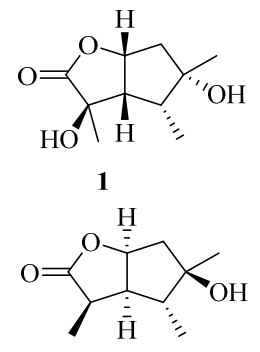

2

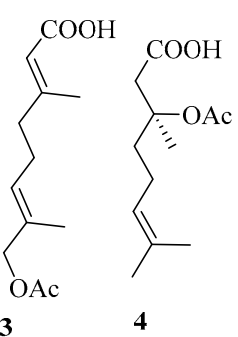

4

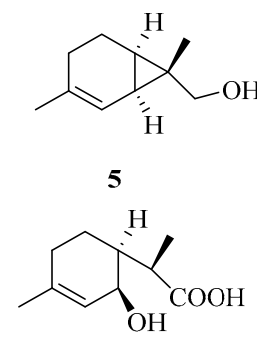

6

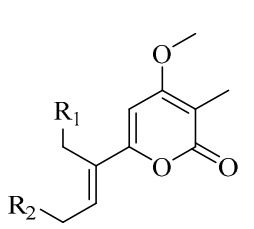

$7 \mathrm{R}_{1}=\mathrm{OH}, \mathrm{R}_{2}=\mathrm{H}$

$8 \mathrm{R}_{1}=\mathrm{H}, \mathrm{R}_{2}=\mathrm{OH}$

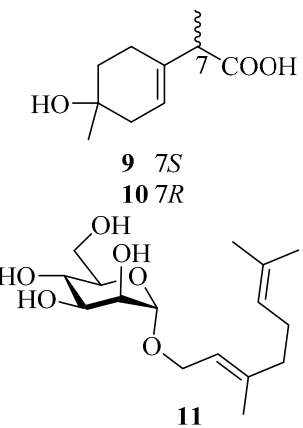

11

Figure 6. Chemical structures of monoterpenes (1-11).

From the deep-sea-sediment-derived fungus Aspergillus versicolor SD-330, two new butyrolactone-type monoterpenoids, pestalotiolactones $C$ and D (1 and 2), along with a known analog, were isolated, among which the absolute configuration of the known pestalotiolactone A was determined for the first time [10]. Another deep-sea fungus, Penicillium sp. (YPGA11), produced two new monoterpenoids, penicipenes A and B (3 and 4) [11]. The marine sediment-derived fungus Eutypella scoparia FS46 yielded two new natural monoterpenes, eutypellol B (5), a rare 7-methyl oxidized 2-carene derivative, and 2-(2-hydroxy-4-methylcyclohex-3-enyl) propanoic acid (6, synthesized before), and the analog 2,9-epoxy-p-menth-6-en-9-ol [12]. Two new monoterpenoid $\alpha$-pyrones, nectriapyrones $\mathrm{C}$ and $\mathrm{D}$ (7 and 8), and the known $\alpha$-pyrone (nectriapyrone), were obtained from the fungus Nectria sp. HLS206 associated with the marine sponge Gelliodes carnosa [13]. The chemical investigation of a fermentation culture of the marine brown alga-endophytic strain (cf44-2) of Trichoderma asperellum led to the isolation of two new natural monoterpenes, (7S) and (7R)-1-hydroxy-3-p-menthen-9-oic acids (9 and 10) [14]. Moreover, using geraniol as a substrate, the biotransformation-culture broth of the marine mudflat-derived fungus Thielavia hyalocarpa yielded a new monoterpene glycoside, 1-O-( $\alpha$-D-mannopyranosyl) geraniol (11) [15]. Unfortunately, most of these monoterpenes lack bioactivities, except for $\mathbf{1}$ and 2, which show weak antibacterial effects (Aeromonas hydrophilia, Vibrio anguillarum for 1, MIC = 16 and $32 \mu \mathrm{g} / \mathrm{mL}$; Vibrio harveyi, Edwardsiella tarda for 2, MIC = 32 and $32 \mu \mathrm{g} / \mathrm{mL})$.

\subsection{Sesquiterpenes}

Sesquiterpenes are the largest group and an excellent source of terpenoids. A total of 45 research papers in 2015-2019 describe 188 new sesquiterpenes (12-199, Figures 7-15) from approximately 19 genera of marine fungi, showing the significant increase in the rate of sesquiterpenes being reported based on the fact that about 208 sesquiterpenes (111 in 2011-2014 and $\mathbf{9 7}$ before 2010) were reported from marine fungi by the end of 2014 [7,8].

The majority of the fungi yielding these new sesquiterpenes were mainly isolated from marine algae (44, 23\%); mangrove plants $(43,23 \%)$; deep-sea sediments $(38,20 \%)$; marine animals, including sponges, coral, and the crinoid $(26,14 \%)$; and other marine sediments $(23,12 \%)$. In terms of fungal genera, the four genera of Trichoderma (28,15\%), Aspergillus (27,14\%), Eutypella (27, 14\%), and Penicillium $(20,11 \%)$ are the major objects of focus for researchers in this field, while other groups of fungi, including Chondrostereum, Graphostroma, Diaporthe, Rhinocladiella, Paraconiothyrium, Talaromyces, Stachybotrys, Tinctoporellus, Pseudallescheria, Cochliobolus, Trichothecium, Leptosphaerulina, and Coriolopsis, are other 
significant sources of marine sesquiterpenes. Regarding biological activities, approximately $30 \%$ of the new sesquiterpenes ( 84 active in 281 tests of sesquiterpenes) have notable abilities, primarily cytotoxicity (30\%), anti-inflammatory activity $(24 \%)$, lethal toxicity $(20 \%)$, antibacterial activity $(15 \%)$, and enzyme inhibitor activities $(8 \%)$.<smiles></smiles>

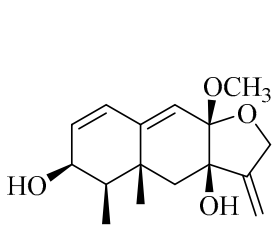

16<smiles>CC1(c2ccc(C(=O)O)cc2O)CCC(=O)O1</smiles>

$19(+)$

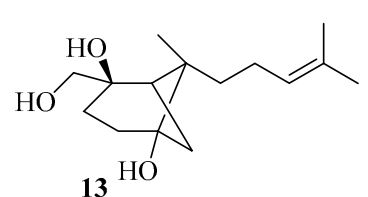<smiles>C=CC(=O)OCCC(C)(CCC=C(C)C)C(=O)O</smiles><smiles>CC1=CCC(C)=C(CO)CC1</smiles><smiles>C=C(COC12C=C3C=CC(O)C(C)C3(C(F)(F)F)CC1(O)C(=C)CO2)C1(O)CC(=O)C=C2C=CC(O)C(C)C2(C)C1C</smiles><smiles>C=C(CO)C1(O)CC2(C)C(=CC1=O)C=CC(=O)C2C</smiles><smiles>C=C1COC2(O)C=C3C=CC(=O)C(C)C3(C)CC12O</smiles>

18

B form<smiles>O=C1CCC(O)(c2ccc(C(=O)O)cc2O)O1</smiles><smiles>CC(C)[C@@H]1CC[C@@](C)(c2ccc(C(=O)O)cc2O)O1</smiles>

21<smiles>CC(C)[C@@H]1CC[C@@H](c2ccc(C(=O)O)cc2O)O1</smiles><smiles>CC1CCCC(C)(c2ccc(C(=O)O)cc2O)OC1</smiles><smiles>COc1cc(C(=O)O)ccc1[C@]1(C)CCCC(C)CO1</smiles><smiles>C=C(CCCC(C)CO)c1ccc(C(=O)O)cc1O</smiles><smiles>C/C(=C/CCC(C)CO)c1ccc(C(=O)O)cc1O</smiles><smiles>C/C(=C\CCC(C)CO)c1ccc(C(=O)O)cc1O</smiles><smiles>COC(=O)C(C)CC/C=C(/C)c1ccc(C)c(O)c1O</smiles>

25

27<smiles>CC1(CO)CCCC(C)(c2ccc(C(=O)O)cc2O)O1</smiles>

29<smiles>[R]OC(=O)c1ccc(C(C)(C)CCCC(C)(C)C)c(O)c1</smiles>

$30 \mathrm{R}_{1}=\mathrm{CH}_{3}, \mathrm{R}_{2}=\mathrm{OH}, \mathrm{R}_{3}=\mathrm{OH}(7 R)$

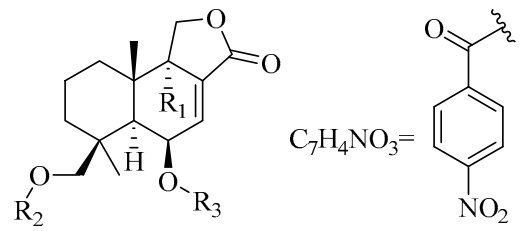<smiles>CC(O)[C@H](O)/C=C/C=C/C(=O)OC1C=C2COC(=O)C2C2(C)CCCC(C)(C)[C@H]12</smiles>
$31 \mathrm{R}_{1}=\mathrm{H}, \mathrm{R}_{2}=\mathrm{OCH}_{3}, \mathrm{R}_{3}=\mathrm{OH}(7 R)$

$32 \mathrm{R}_{1}=\mathrm{H}, \mathrm{R}_{2}=\mathrm{C}_{7} \mathrm{H}_{4} \mathrm{NO}_{3}, \mathrm{R}_{3}=\mathrm{H}$

$33 \mathrm{R}_{1}=\mathrm{OH}, \mathrm{R}_{2}=\mathrm{CH}_{3} \mathrm{CO}, \mathrm{R}_{3}=\mathrm{C}_{7} \mathrm{H}_{4} \mathrm{NO}_{3}$ $34 \mathrm{R}_{1}=\mathrm{H}, \mathrm{R}_{2}=\mathrm{CH}_{3} \mathrm{CO}, \mathrm{R}_{3}=\mathrm{C}_{7} \mathrm{H}_{4} \mathrm{NO}_{3}$<smiles>CC(O)[C@H](O)/C=C/C=C/C(=O)OC1C=C2COC(=O)C2C2(C)CCCC(C)(C)[C@H]12</smiles>

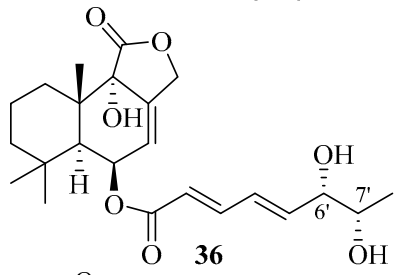<smiles>C[C@H](O)[C@H](O)/C=C/C=C/C(=O)O[C@H]1C=C2COC(=O)[C@@H]2[C@@]2(C)CCCC(C)(C)[C@H]12</smiles>

Figure 7. Chemical structures of sesquiterpenes (12-38 from Aspergillus sp.). 

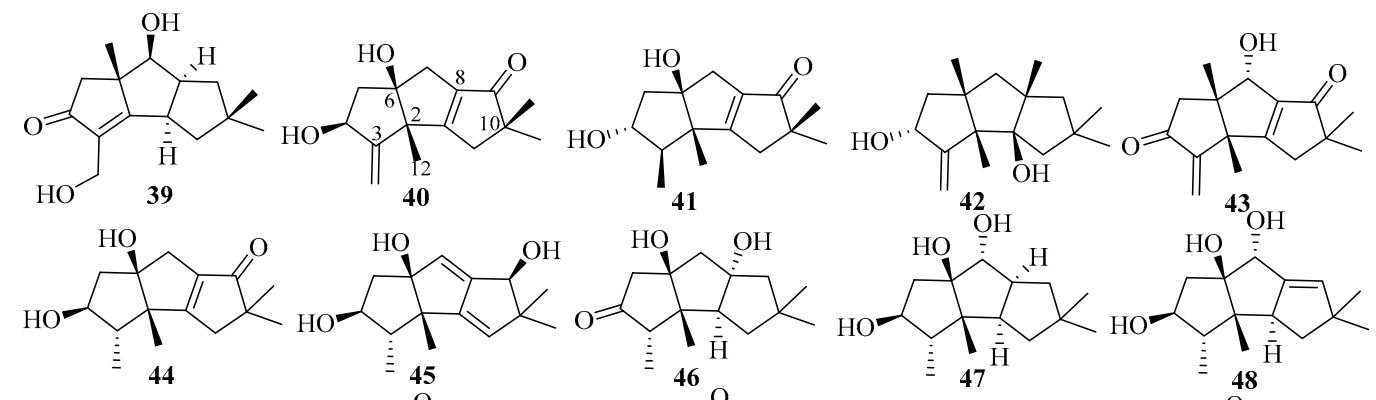

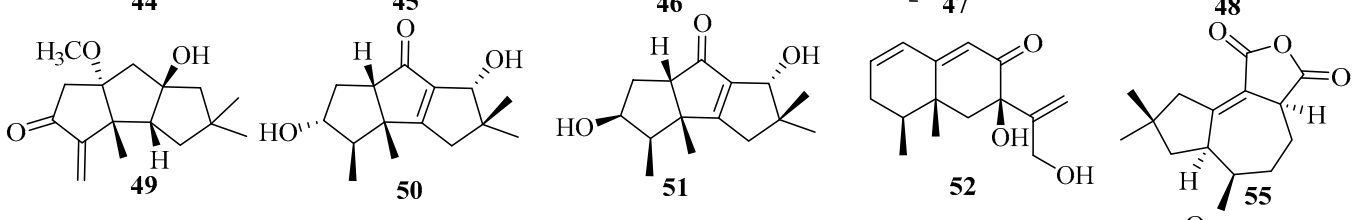

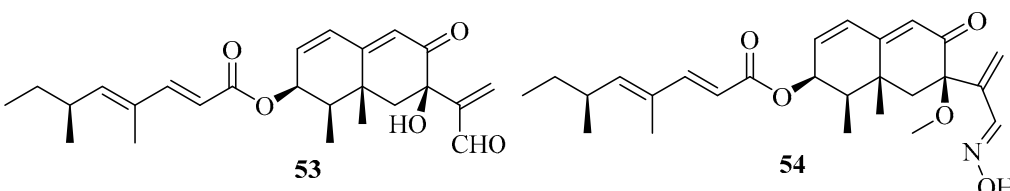
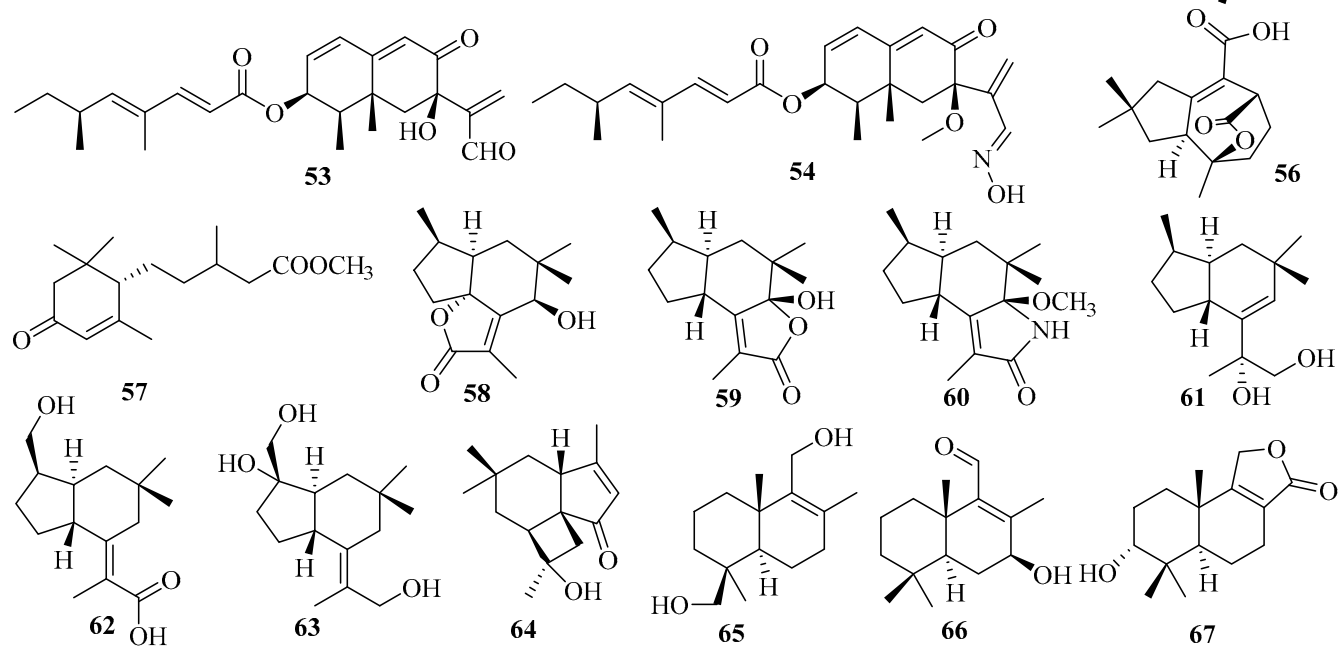

Figure 8. Chemical structures of sesquiterpenes (39-51 from Chondrostereum sp., 52-54 from Cochliobolus sp., 55-56 from Coriolopsis sp., and 57-67 from Diaporthe sp.).<smiles>CC1=CC(C)CCC1(C)CCO</smiles><smiles>CC(C)C1(C(C)C)CC(C)(C)C(=O)CC1=O</smiles><smiles>CC(C)=C1CC2(C)C(=O)CCC(=O)C2(C)C1C</smiles>

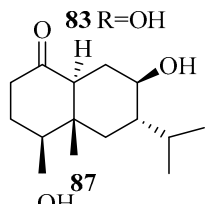<smiles>C=C(C)[C@H]1C[C@@]2(C)[C@H](C)CC[C@@H](O)[C@]2(O)C[C@H]1O</smiles><smiles>CC1C(=O)O[C@]2(C)CC3C(=O)CCC(C)[C@@]3(C)CC12C</smiles><smiles>CC(C)C1CC(=O)C2CC(=O)CCC2(C)C1(C)C</smiles><smiles>CC(C)=C1CC2CC(=O)CC(C)C2(C)C(C)CCC1O</smiles><smiles>CC(C)C(C)C1C[C@H](O)C[C@H]2C(=O)CCC(C)C12C</smiles><smiles>CC(C)C1CC(=O)C2C(=O)CCC(C)C2(C)C1</smiles><smiles>CC1CCC(=O)C2CC3(CC12C)C(C)CCC(C)C3(C)O</smiles><smiles>CC(C)C1(C)CC(=O)CC2(C)C(C)CCC(=O)C12</smiles>

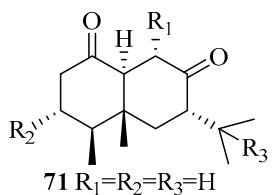
$71 \mathrm{R}_{1}=\mathrm{R}_{2}=\mathrm{R}_{3}=\mathrm{H}$ $72 \mathrm{R}_{1}=\mathrm{R}_{2}=\mathrm{H}, \mathrm{R}_{3}=\mathrm{OH}$ $73 \mathrm{R}_{1}=\mathrm{R}_{3}=\mathrm{H}, \mathrm{R}_{2}=\mathrm{OH}$ $74 \mathrm{R}_{1}=\mathrm{OH}, \mathrm{R}_{2}=\mathrm{R}_{3}=\mathrm{H}$<smiles>CC(C)=C1CC2[C@H](O)CCC(C)C2(C)CC1=O</smiles><smiles>CC(C)C(C)C1CC(=O)CC2C(O)CCC(C)C21C</smiles><smiles>CC(C)=C1CC(=O)CC2(C)C(C)CCC(O)C12</smiles>

$\mathrm{OH}$<smiles>CC1CCC(C)C2(C#N)C1=CC(=O)C2C(C)C</smiles>

89<smiles>CC(C)[C@H]1CC(=O)C[C@H]2C(=O)CC[C@H](C)[C@]21C</smiles>

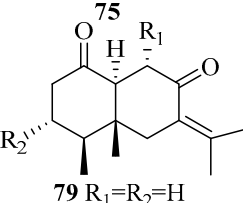

$\mathbf{8 0 ~} \mathrm{R}_{1}=\mathrm{OH}, \mathrm{R}_{2}=\mathrm{H}$ $81 \mathrm{R}_{1}=\mathrm{H}, \mathrm{R}_{2}=\mathrm{OH}$

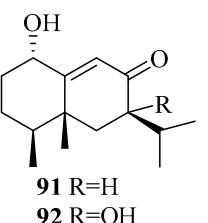

Figure 9. Chemical structures of sesquiterpenes (68-94 from Eutypella sp.). 


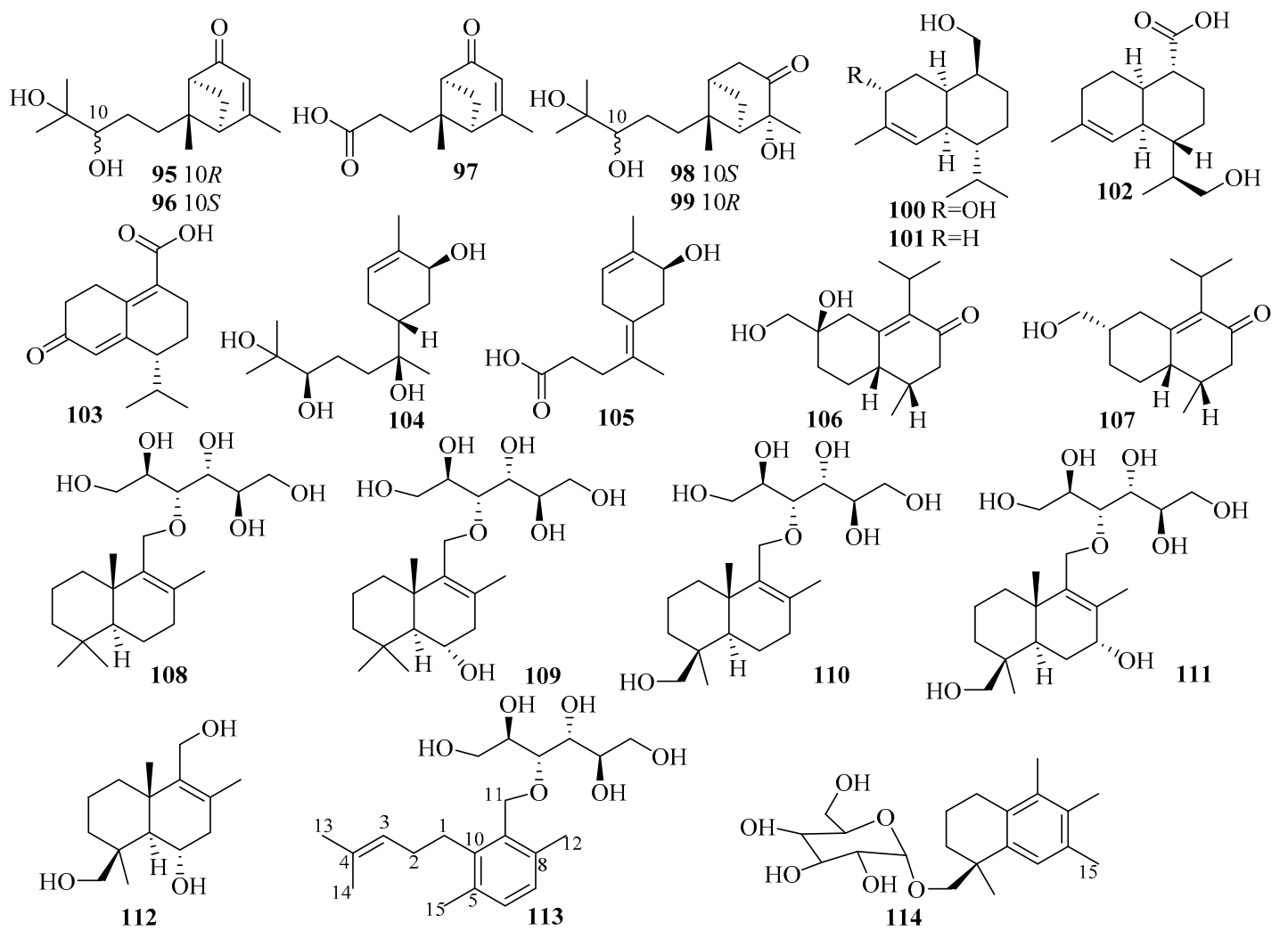

Figure 10. Chemical structures of sesquiterpenes (95-105 from Graphostroma sp., 106-107 from Leptosphaerulina sp., and 108-114 from Paraconiothyrium sp.).<smiles>CC1=CC(=O)CC(C)C12CCC([C@H](CO)C(C)(O)CO)C2(C)C</smiles><smiles>CC1=CC(=O)CC(C)C12CCC(C(C)(O)CO)CC2C</smiles><smiles>CC1=CCC[C@H]2CCCC3(CO)OC12[In]3</smiles><smiles>CC1=CC(=O)C[C@H]2CC[C@H](C(C)CO)C[C@]12C</smiles><smiles></smiles><smiles>CC1CC(O)[C@H](O)[C@]2(C)CCC([C@](C)(O)CO)CC12</smiles>

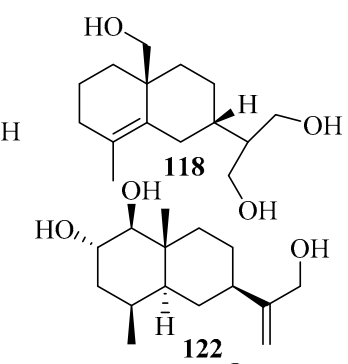<smiles>CC(C)=C1CCC2(C)CCC(O)(C(=O)O)CCC12CCC(C)(CO)[C@H]1CCC(C(=O)O)=CCC1(C)C</smiles>

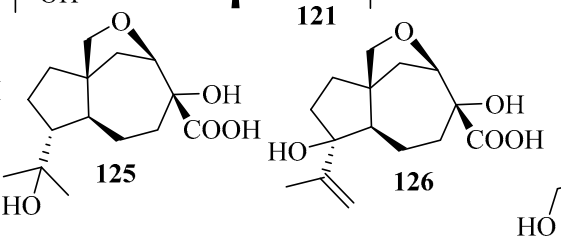

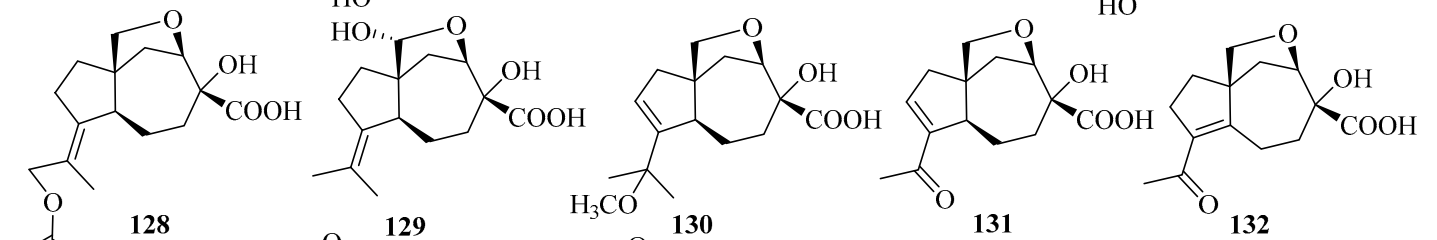<smiles>CC(C)=O</smiles>

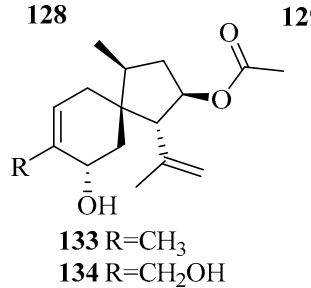

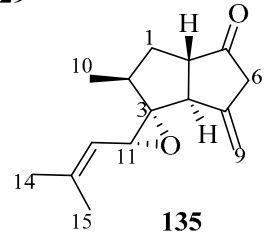

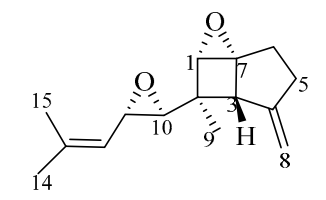

136

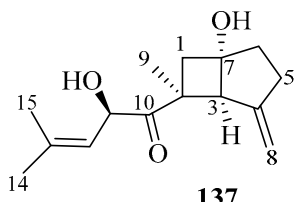

137

Figure 11. Chemical structures of sesquiterpenes (115-134 from Penicillium sp., 135-137 from Pseudallescheria sp.). 


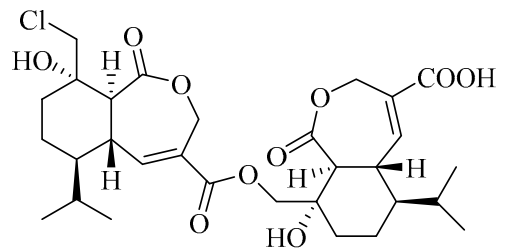

138<smiles>C=C1CC[C@H](C(C)(C)O)[C@]2(C)C=C(C(=O)O)C[C@H](O)[C@H]12</smiles>

143<smiles>[R]OC(=O)C(=C[C@@H]1[C@@H](C(C)C)CC[C@](O)(CCl)[C@@H]1C(=O)O)CO</smiles>

$139 \mathrm{R}=\mathrm{H}$

$140 \mathrm{R}=\mathrm{CH}_{3}$

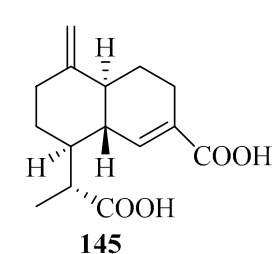<smiles>CC(=O)OCC(=C[C@H]1C=C(CO)CC[C@H]1C(C)C)C(=O)O</smiles>

141

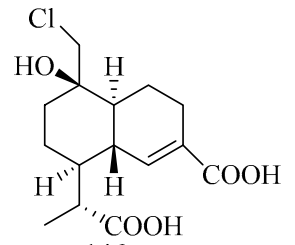

146<smiles>CC(C)[C@H]1CC[C@@H](CO)[C@H]2OCC(C(=O)O)=C[C@@H]21</smiles>

142<smiles>CC1CCC2=C(C1=O)C(C)CCC2C(C)(O)CO</smiles>

147<smiles>C[C@](O)(CO)CCC[C@@](C)(O)c1ccc(C(=O)O)cc1O</smiles><smiles>CC1(c2ccc(C(=O)O)cc2O)CCC(=O)O1</smiles>

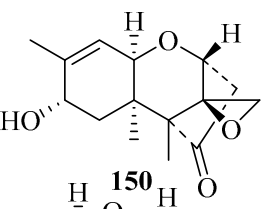<smiles>CO[C@H]1C[C@@H](O)[C@@]2(C)[C@@H]3CCC(C)=C[C@H]3O[C@]12CO</smiles><smiles>CC1=CC[C@H]([C@@]2(C)CCC[C@]2(O)CO[C@H]2O[C@H](CO)[C@@H](O)[C@H](O)[C@H]2O)CC1</smiles>

151

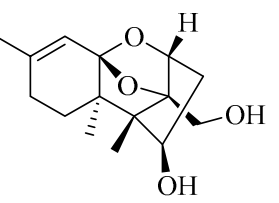

153

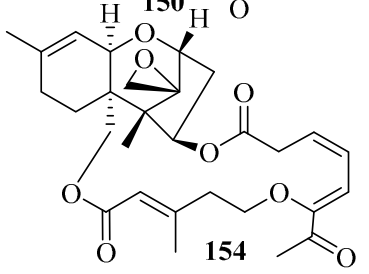

Figure 12. Chemical structures of sesquiterpenes (138-147 from Rhinocladiella sp., 148-149 from Scopulariopsis sp., and 150-154 from Stachybotrys sp.).<smiles>CC1(C)[C@H](O)[C@H](O)C[C@]2(C)CC=C(C(=O)O)C[C@@]12C</smiles>

155<smiles>[R]C1C[C@@H]2C(C)(C)CCC(OC(=O)[C@@H](NC(C)=O)C(C)C)[C@]2(C)C2=C1C(=O)OC2</smiles>

$$
156 \mathrm{R}=\mathrm{Cl}
$$

$$
157 \mathrm{R}=\mathrm{OH}
$$

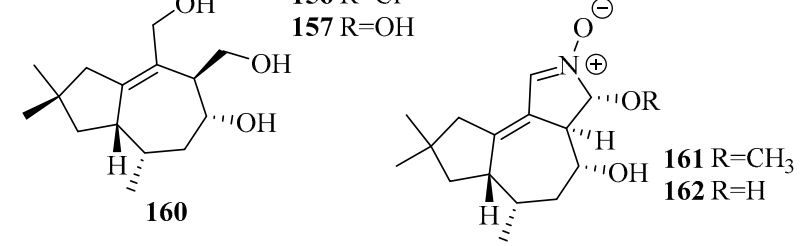<smiles>CC(=O)N[C@H](C(=O)O[C@H]1CCC(C)(C(F)(F)F)[C@H]2C[C@H](O)C3=C(COC3=O)[C@]12C)C(C)C</smiles><smiles>[CH][C@@]12C3=C(C(=O)OC3)[C@@H](OC(=O)C(NC(C)=O)C(C)C)C[C@@H]1C(C)(C)CC[C@@H]2O</smiles>

Figure 13. Chemical structures of sesquiterpenes (155-159 from Talaromyces sp. and 160-162 from Tinctoporellus sp.). 


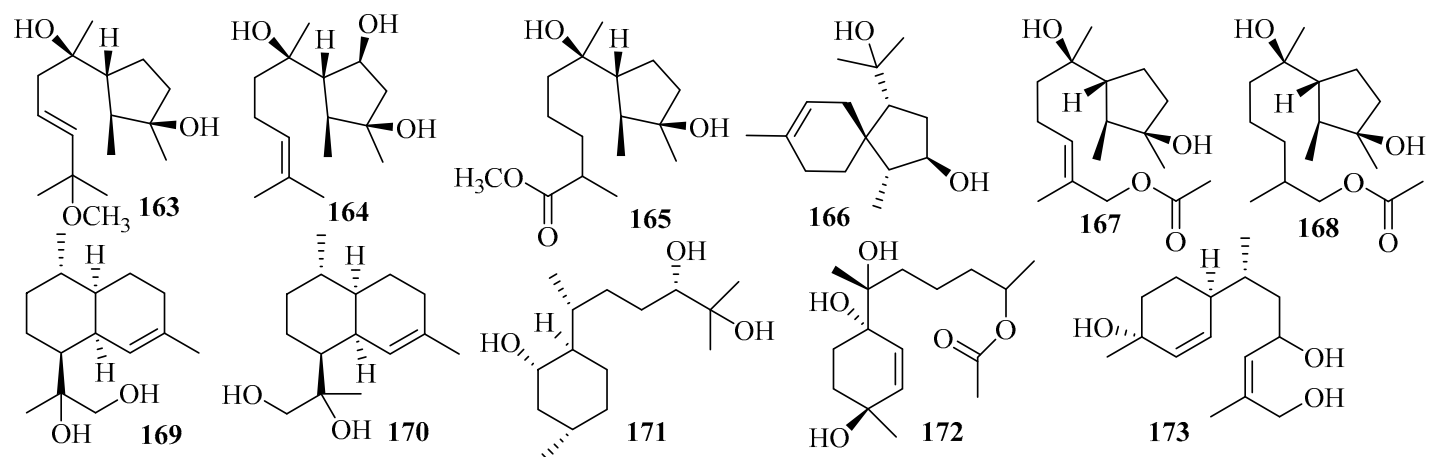<smiles>CC(=O)OC(C)CCC[C@H](C)c1ccc(C)cc1</smiles>

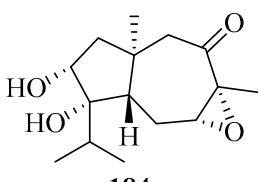

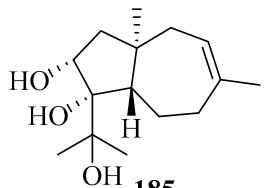

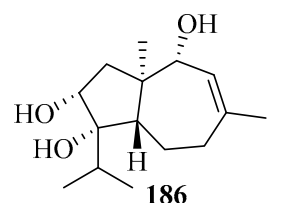

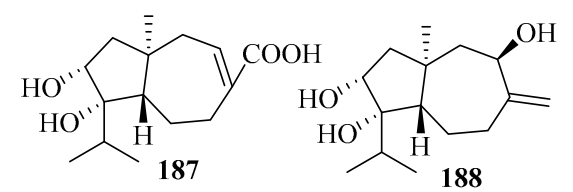<smiles>C=C1CCC(C(C)C)C2(C=CC(=O)O)C=C(C)CC12</smiles><smiles>CC(=O)OC/C(C)=C/CCCC1(O)CCCC1(C)O</smiles><smiles>CC1C(C)C(O)(CC=CC(C)(C)O)CCC1(C)O</smiles>

Figure 14. Chemical structures of sesquiterpenes (163-189 from Trichoderma sp. and 190-191 from Trichothecium sp.).<smiles>CC1(C)CCC(=O)C23CC(O)(O)CC2(O)C13</smiles>

192

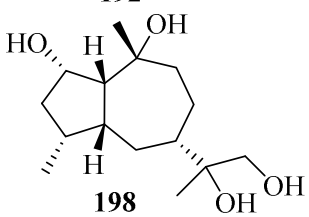<smiles>CC1(C)CCC(O)C(O)C12CC=C(CO)CC2</smiles>

193

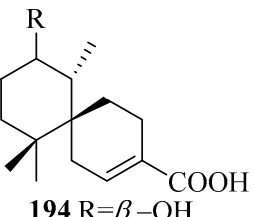

$194 \mathrm{R}=\beta-\mathrm{OH}$ $195 \mathrm{R}=\alpha-\mathrm{OH}$<smiles>CC1=C(O)C(=O)CC(C)(C)C12CC=C(C(=O)O)CC2</smiles>

196<smiles>CC1([18O])CCC(=O)C(C)(O)C12CCC(O)C(=O)C2(O)CO</smiles><smiles>CC(O)(CO)C1CC[C@](C)(O)[C@]2(C)CC[C@H](O)[C@]2(C)C1</smiles>

Figure 15. Chemical structures of sesquiterpenes (192-199 from an unidentified fungus).

\subsubsection{Aspergillus sp.}

The production of two new $\beta$-bergamotane sesquiterpenoids that are likely important intermediates in the biosynthesis of fumagillin and its derivatives, $E-\beta$-trans-5,8,11-trihydroxybergamot-9-ene (12) and $\beta$-trans-2 $\beta, 5,15$-trihydroxy-bergamot-10-ene (13), were obtained from the marine-derived fungus Aspergillus fumigatus YK-7 isolated from sea mud of the intertidal zone [16]. Compound 12 exhibited weak activities against the $\mathrm{U} 937$ cell line with $\mathrm{IC}_{50}$ values of $84.9 \mu \mathrm{M}[16]$.

An investigation of the extracts from the deep-sea-sediment fungus Aspergillus terreus YPGA10, collected in the Yap Trench at a depth of $4159 \mathrm{~m}$, furnished two new farnesol derivatives, sesquiterpenes 
aspterric A (14) and aspterric B (15), which are considered to be intermediates in the derivation of aspterric acid [17].

Chemical examination of the deep-sea-sediment-derived Aspergillus sp. SCSIOW2, treated with a combination of $1 \mathrm{mM}$ suberohydroxamic acid (SBHA), a competitive histone deacetylase (HDAC) inhibitor, and $1 \mathrm{mM}$ 5-azacytidine (5-AZA), a DNA methyltransferase (DNMT) inhibitor, led to the isolation of three novel eremophilane-type sesquiterpenes, dihydrobipolaroxin B-D (16-18). However, 16 and 17 might be artificial products since they could be obtained from the spontaneous intracellular acetalization reaction of dihydrobipolaroxin in water. Moreover, $\mathbf{1 8}$ was found to be a mixture of two equilibrium structures in a solution formed through the same acetalization reaction [18]. All of these molecules exerted moderate nitric oxide (NO)-inhibitory activities that were stimulated by lipopolysaccharides (LPSs) and interferon (IFN)- $\gamma$ in a dose-dependent manner without any cytotoxic effects [18].

A pair of new norbisabolane enantiomers, named (+)-1-hydroxyboivinianic acid (19) and (-)-1-hydroxyboivinianic acid (20), were obtained from fermenting Aspergillus versicolor SYSU-SKS025 purified from the branches of the mangrove plant Excoecaria agallocha [19]. In bioactivity assays, 19 and 20 showed greater $\alpha$-glucosidase inhibitory activity with $\mathrm{IC}_{50}$ values of 120.3 and $113.3 \mu \mathrm{M}$, respectively, compared to the $\mathrm{IC}_{50}=350 \mu \mathrm{M}$ of acarbose as the positive control (p.c.) [19].

An endophytic fungus Aspergillus sp. xy02 associated with the Thai mangrove Xylocarpus moluccensis yielded seven new phenolic bisabolane sesquiterpenoids: (7R,10S)-7,10-epoxysydonic acid (21), (7S,10S)-7,10-epoxysydonic acid (22), (7R,11S)-7,12-epoxysydonic acid (23), (7S,11S)-7,12epoxysydonic acid (24), 7-deoxy-7,14-didehydro-12-hydroxysydonic acid (25), (Z)-7-deoxy-7,8-didehydro-12-hydroxysydonic acid (26), and (E)-7deoxy-7,8-didehydro-12-hydroxy-sydonic acid (27) [20]. Biologically, compounds 22-23, 25, and 27 displayed mild antibacterial activity against Staphylococcus aureus ATCC 25923, with $\mathrm{IC}_{50}$ values ranging from 31.5 to $41.9 \mu \mathrm{M}$ [20].

The extraction of the seawater-associated fungus Aspergillus sydowii SW9 resulted in the isolation and identification of a novel aromatic bisabolene-type sesquiterpenoid, methyl (R,E)-6-(2,3-dihydroxy-4-methylpenyl)-2-methylhept-5-enoate (28) [21]. The bioassay results for 28 demonstrated selective inhibition against Escherichia coli, S. aureus, S. epidermidis, and S. pneumoniae, with MIC values ranging from 2.0 to $16 \mu \mathrm{g} / \mathrm{mL}$ (chloramphenicol as the p.c. with MIC values ranging from 1.0 to $2.0 \mu \mathrm{g} / \mathrm{mL}$ ) [21].

Studies of the deep-sea-sediment-derived fungus Aspergillus versicolor SD-330 from the South China Sea afforded three undescribed sesquiterpenes, including one aromatic bisabolene-type, 12-hydroxysydowic acid (29) [22], and two bisabolane-type, ent-aspergoterpenin C (30) and 7-O-methyl-hydroxy-sydonic acid (31) [10]. Notably, compound 29 exhibited selective inhibitory activities against four zoonotic pathogenic bacteria, Aeromonas hydrophilia, E. coli, Edwardsiella tarda, and Vibrio harveyi, with MIC values ranging from 4.0 to $8.0 \mu \mathrm{g} / \mathrm{mL}$ [22]. At the same time, 30 and 31 exerted selective inhibition against E. coli, E. tarda, V. parahaemolyticus, and V. harveyi, with MIC values ranging from 2.0 to $8.0 \mu \mathrm{g} / \mathrm{mL}$, and the p.c. chloramphenicol had MIC values ranging from 1.0 to $4.0 \mu \mathrm{g} / \mathrm{mL}[10]$.

Three relatively rare nitrobenzoyl sesquiterpenoids in nature, including two new compounds insulicolide B (32) and insulicolide C (34), and one novel natural product, 14-O-acetylinsulicolide A (33), were isolated from Aspergillus ochraceus Jcma1F17, which is related to the marine alga Coelarthrum sp. [23]. Among them, 14-O-acetylinsulicolide A (33) displayed potent inhibitory activities against three renal human tumor cell lines (HTCLs) (ACHN, OS-RC-2, and 786-O), with IC $_{50}$ values of 4.1, 5.3, and $2.3 \mu \mathrm{M}\left(\mathrm{IC}_{50}=3.4,7.0\right.$, and $4.9 \mu \mathrm{M}$ for the p.c. sorafenib), respectively [23]. Further studies indicated that compound 33 arrested the cell cycle in the G0/G1 phase at a concentration of $1 \mu \mathrm{M}$ and induced late apoptosis at a concentration of $2 \mu \mathrm{M}$ after treatment of 786-O cells for $72 \mathrm{~h}$ [23].

Asperienes A-D (35-38), two pairs of C-6/C-7 epimeric drimane sesquiterpene esters, were successfully isolated for the first time from the marine sediment fungus Aspergillus flavus CF13-11. All displayed significant cytotoxic activities against HeLa, MCF-7, MGC-803, and A549 cell lines, 
with the $\mathrm{IC}_{50}$ values ranging from 1.4 to $8.3 \mu \mathrm{M}$ (with cisplatin as p.c.) [24]. Interestingly, due to the configuration at carbon C- $6^{\prime}$, compounds 35 and $\mathbf{3 8}$ had lower toxicity than $\mathbf{3 6}$ and $\mathbf{3 7}$ (with different $\mathrm{IC}_{50}$ values of $78,83,6.2$, and $4.9 \mu \mathrm{M}$, respectively) regarding normal GES-1 cells, indicating greater potential as future antitumor agents [24].

\subsubsection{Chondrostereum sp.}

The fermentation of fungus Chondrostereum sp., separated from the soft coral Sarcophyton tortuosum, led to the isolation of three new triquinane-type sesquiterpenoids: chondrosterins K-M (39-41) [25]. Chondrosterin $\mathrm{K}(39)$ is a rare hirsutane sesquiterpenoid in which a methyl group has migrated from C-2 to C-6 with a double bond between C-2 and C-3 [25]. Biological assays revealed that compounds 39-41 exhibited significant cytotoxicity against seven HTCLs (CNE1, CNE2, HONE1, SUNE1, A549, GLC82, and HL7702), with IC 50 values ranging from 12.03 to $58.83 \mu \mathrm{M}$ in vitro, with hirsutanol A used as a positive control [25].

Chondroterpenes A-H (42-49), possessing a 5,5,5-tricyclic hirsutane-type sesquiterpene scaffold, were isolated from the marine fungus Chondrostereum sp. NTOU4196, which originated from the marine red alga, Pterocladiella capillacea [26]. Biologically, compounds 42, 43, and 49 exhibited significant inhibitory effect on LPS-induced NO production in BV-2 microglial cells at a concentration of $20 \mu \mathrm{M}$ [26]. However 49 displayed potent cytotoxic effects on BV-2 cells at a concentration of $20 \mu \mathrm{M}$, which implied that cell death predominantly caused decreasing NO production [26].

The soft coral-derived (Sarcophyton tortuosum) fungus Chondrostereum sp. produced two unreported hirsutane-type sesquiterpenoids, chondrosterins $\mathrm{N}$ and $\mathrm{O}$ (50 and 51) [27]. Compounds 50 and 51 were apparently inactive $\left(\mathrm{IC}_{50}\right.$ values $\left.>100 \mu \mathrm{M}\right)$ for seven HTCLs [27].

\subsubsection{Cochliobolus sp.}

Secondary metabolites from the marine alga-related fungus Cochliobolus lunatus SCSIO41401 contained three new eremophilane sesquiterpenes, dendryphiellins $\mathrm{H}-\mathrm{J}$ (52-54), among which dendryphiellin J (54) is a rare naturally occurring aldoxime analog [28]. In bioassays, compound 53 exerted cytotoxicity against five HTCLs (ACHN, 786-O, OS-RC-2, HepG2, and SGC7901), with IC 50 values of 1.4-4.3 $\mu \mathrm{M}$, and antibacterial activities for three bacterial species, $S$. aureus subsp. aureus Rosenbach, Erysipelothrix rhusiopathiae, and Pasteurella multocida subsp. multocida (MIC ranging from 1.5 to $13 \mu \mathrm{g} / \mathrm{mL}$ ), respectively [28]. Compound 54 showed cytotoxicity against HepG2 cells $\left(\mathrm{IC}_{50}=5.9 \mu \mathrm{M}\right)$ and $\mathrm{ACHN}$ cells $\left(\mathrm{IC}_{50}=3.1 \mu \mathrm{M}\right)$ by inducing apoptosis in a dose and time-dependent manner [28].

\subsubsection{Coriolopsis sp.}

Two new tremulane sesquiterpenes, coriolopsin A (55) and coriolopsin B (56), were obtained from the EtOAc fraction of the mangrove Ceriops tagal endophytic fungus Coriolopsis sp. J5 [29]. None of these showed obvious cytotoxic or antibacterial activities in bioassays, in which three HTCLs and six strains of bacteria were tested [29].

\subsubsection{Diaporthe sp.}

Further work on the mangrove plant Rhizophora stylosa endophytic fungus Diaporthe sp. SCSIO 41011 led to the isolation of one novel sesquiterpenoid, 1-methoxypestabacillin B (57) [30].

The chemical investigation of Diaporthe sp., an endophytic fungus associated with the leaves of Rhizophora stylosa collected in Hainan Province, yielded ten new sesquiterpenoids, including six brasilane-type, diaporols J-O (58-63); one 3,6-cycloprecapnellane compound, diaporol P (64); and three drimane ones, diaporols Q-S (65-67) [31]. Among them, compound 66 showed moderate cytotoxicity against the SW480 cell lines with an $\mathrm{IC}_{50}$ value of $8.72 \mu \mathrm{M}$ [31]. 


\subsubsection{Eutypella sp.}

Eutypellol A (68), the first norsesquiterpenoid of the sequicarene family found in nature, was obtained in the marine sediment-derived fungus Eutypella scoparia FS46, which was collected in the South China Sea at a depth of $292 \mathrm{~m}$ [12].

The chemical epigenetic manipulation of Eutypella sp. MCCC 3A00281, a deep-sea-sedimentassociated fungus obtained from the South Atlantic Ocean at a depth of $5610 \mathrm{~m}$, resulted in a significant change in the metabolite profile, including the isolation of an array of 26 eremophilane-type sesquiterpenoids, eutyperemophilanes A-Z (69-94), when treated with SBHA and a histone deacetylase inhibitor (HDI) [32]. Remarkably, most of analogs featured a trans fusion of rings A and B, which is uncommon for the eremophilane family in nature [32]. In terms of biological evaluation, compounds 77 and 78 significantly inhibited LPS-activated NO production in RAW264.7 macrophage cells with $\mathrm{IC}_{50}$ values of 8.6 and $13 \mu \mathrm{M}$, respectively [32].

\subsubsection{Graphostroma sp.}

Graphostroma sp. MCCC 3A00421, a deep-sea-derived fungus obtained from the hydrothermal sulfide deposits of the Atlantic Ocean, produced two structurally corrected sesquiterpenes, (10R)-xylariterpenoid B (95) and (10S)-xylariterpenoid A (96); and nine new sesquiterpenes, xylariterpenoid E-G (97-99), khusinol B-E (100-103), and graphostromabisabol A-B (104-105) [33]. Among them, xylariterpenoid E (97) and graphostromabisabol B (105) were the first examples of trinor-bergamotane and trinor-bisabolane found in nature [33]. Interestingly, compound $\mathbf{1 0 0}$ was shown to be a potent anti-inflammatory and weak antiallergic agent, exerting an anti-inflammatory effect with an $\mathrm{IC}_{50}$ value of $17 \mu \mathrm{M}$, which is more potent than that of the p.c. aminoguanidine $\left(\mathrm{IC}_{50}=23 \mu \mathrm{M}\right)$, and antiallergic activity with an $\mathrm{IC}_{50}$ value of $150 \mu \mathrm{M}$, while the $\mathrm{IC}_{50}$ of the p.c. loratadine was $92 \mu \mathrm{M}[33]$.

\subsubsection{Leptosphaerulina sp.}

An investigation of extracts from the crinoid-derived fungus Leptosphaerulina chartarum sp. 3608 afforded two new sesquiterpenes, leptoterpenes A (106) and B (107) [34].

\subsubsection{Paraconiothyrium sp.}

Seven new drimane-type sesquiterpenoids, sporulositols A-D (108-111), 6-hydro-xydiaporol (112), seco-sporulositol (113), and sporuloside (114), were later found in the sea mud-derived fungus Paraconiothyrium sporulosum YK-03 collected from the intertidal zone of Bohai Bay in Liaoning Province [35]. Structurally, compounds 108-111 and $\mathbf{1 1 3}$ represent the first five examples of a unique class of drimanic mannitol derivatives, while compounds $\mathbf{1 1 3}$ and $\mathbf{1 1 4}$ might belong to two new series of natural drimanes possessing an aromatic ring with a rare 4,5-secodrimanic skeleton and an unusual $\mathrm{CH}_{3}-15$ rearranged drimanic $\alpha$-D-glucopyranside, respectively [35]. Compounds 108-114 did not show any detectable cytotoxicity against the two tested cell lines A549 and MCF-7 [35].

\subsubsection{Penicillium sp.}

Penicillium thomii KMM 4667, isolated from the rhizome surface of Zostera marina (Sea of Japan), was the source of five unknown eudesmane-type sesquiterpenes, thomimarines A-E (115-119) [36,37]. Compounds 115-116 and 118-119, at $10.0 \mu \mathrm{M}$, induced a significant downregulation of NO production in LPS-stimulated murine macrophages (RAW 264.7) by $24.9 \%, 43.4 \%, 20.9 \%$, and $22.5 \%$, respectively $[36,37]$.

Three previously undescribed eudesmane-type sesquiterpenoids (penicieudesmols E-G (120-122)) were extracted from the mangrove plant Ceriops tagal endophytic fungus Penicillium sp. J-54 [38]. The bioactivity results showed that compound $\mathbf{1 2 1}$ has $\alpha$-glucosidase inhibitory activity with an $\mathrm{IC}_{50}$ value of $2.27 \mathrm{mM}$ (using acarbose as the p.c., with an $\mathrm{IC}_{50}$ value of $1.67 \mathrm{mM}$ ) [38]. 
Systematic isolation of the deep-sea-sediment-derived $(-1420 \mathrm{~m})$ fungus Penicillium griseofulvum from the Indian Ocean was also conducted, which resulted in the extraction of four new carotane sesquiterpenoids, penigrisacids A-D (123-126) [39]. Biologically, compound 126 exhibited weak cytotoxicity against ECA-109 tumor cells $\left(\mathrm{IC}_{50}=28.7 \mu \mathrm{M}\right)$ [39].

Studies of the marine-subaqueous-soil-derived fungus Penicillium piltunense KMM 4668, collected from Piltun Bay, Sea of Okhotsk, afforded six undescribed carotane sesquiterpenoids, piltunines A-F (127-132), among which piltunine A (127) was reported for the first time to be a natural product. Piltunine C (129) was established as a 13-hydroxy derivative of aspterric acid, and compounds 131-132 included 9-en-11-one and 6-en-11-one enone chromophoresin molecular structures [40]. The biological assay results showed that compound $\mathbf{1 3 1}$ induced a significant downregulation of reactive oxygen species (ROS) production (with LPS as a p.c.) at a concentration of $10 \mu \mathrm{M}$ [40].

A chemical investigation was applied to the marine sponge-derived fungus Penicillium adametzioides AS-53, leading to the isolation of two unreported acorane sesquiterpenes, adametacorenols A (133) and B (134) [41]. As shown by cytotoxicity assay, compound 134 exerted selective activity against the NCI-H446 cell line $\left(\mathrm{IC}_{50}=5.0 \mu \mathrm{M}\right)[41]$.

\subsubsection{Pseudallescheria sp.}

Pseudapene A (135), with a unique 2-methyl-5-methylene-3-(2-methyl)-dicyclo(3, 3, 0)-octane carbon skeleton, and pseudapenes B-C (136-137), possessing an unprecedented 2-methyl-4methylene-2-(2-methylpent-2-ene)-dicyclo(3,2,0)-heptane chemical scaffold, were isolated from the marine-derived fungus Pseudallescheria apiosperma F52-1 [42].

\subsubsection{Rhinocladiella sp.}

The mangrove-derived fungus Rhinocladiella similis from the fresh leaves of Acrostichum aureum (Pteridaceae) was the source of ten new sesquiterpenoid derivatives, rhinomilisins A-J (138-147), corresponding to one dimeric sesquiterpenoid, four new heptelidic acid derivatives, and five new cadalene-type derivatives [43]. The cytotoxicities of all these isolated compounds were evaluated against the mouse lymphoma cell line L5178Y; compounds 138 and $\mathbf{1 4 4}$ exhibited moderate activity with $\mathrm{IC}_{50}$ values of 5.0 and $8.7 \mu \mathrm{M}$, respectively [43].

\subsubsection{Scopulariopsis sp.}

Two new phenolic bisabolane-type sesquiterpenes, 11,12-dihydroxysydonic acid (148) and 1-hydroxyboivinianic acid (149), were later found in solid rice cultures of the marine-derived fungus Scopulariopsis sp., which was obtained from the fresh crushed inner tissues of the Red Sea hard coral Stylophora sp. near the coastline of the Ain El-Sokhna area, Red Sea, Egypt [44].

\subsubsection{Stachybotrys sp.}

A new trichothecene-type sesquiterpenoid, stachybotrichodermone A (150), was obtained from the cultures of the sponge-derived fungus Stachybotrys sp. HH1 ZDDS1F1-2 [45]. A bioassay-guided investigation of the fermentation of the sponge (Niphates recondite)-associated fungus Stachybotrys chartarum WGC-25C-6, collected from the inner coral reef in Beibuwan Bay, resulted in the isolation and identification of four trichothecene-based sesquiterpenes, chartarenes A-D (151-154) [46]. Notably, trichothecene (with a sugar linkage like 151) was found in nature for the first time [46]. Compounds 151-154 exerted potent or selective inhibition against a panel of HTCLs, including HCT-116, HepG2, BGC-823, NCI-H1650, and A2780 [46]. Specifically, at a concentration of less than $10 \mu \mathrm{M}$, compounds 151-154 showed inhibition against HCT-116 with $\mathrm{IC}_{50}$ values ranging from 0.74 to $5.58 \mu \mathrm{M}$, while 151, 153, and 154 exerted inhibitory effects against HepG2 $\left(\mathrm{IC}_{50}=0.90-3.95 \mu \mathrm{M}\right)$ and $\mathrm{A} 2780$ $\left(\mathrm{IC}_{50}=0.69-2.38 \mu \mathrm{M}\right)$ [46]. Moreover, 151 and 154 exhibited inhibitory activities against BGC-823 with $\mathrm{IC}_{50}$ values of 2.87 and $0.68 \mu \mathrm{M}$, respectively, while 153 and 154 inhibited NCI-H1650 $\left(\mathrm{IC}_{50}=2.58\right.$ and $1.23 \mu \mathrm{M}$, respectively) [46]. Additionally, these compounds presented potent inhibition against 
the tumor growth-related tyrosine multiple kinase targets FGFR3, IGF1R, PDGFRb, and TRKB at a concentration of $<10.4 \mu \mathrm{M}$, except for 151, which showed weak activity, with $\mathrm{IC}_{50}>25 \mu \mathrm{M}$ [46].

\subsubsection{Talaromyces sp.}

An investigation of the extracts from a marine mud-related fungus Talaromyces purpurogenus PP-414 collected on a coastal beach furnished the first thujopsene-type sesquiterpenoid, 9,10-diolhinokiic acid (155), possessing a 9,10-diol moiety [47]. Compound 155 exhibited moderate antiproliferative activities against two HTCLs (A549 and HL-60), with $\mathrm{IC}_{50}$ values of 12.6 and $35.7 \mu \mathrm{M}$, respectively [47].

The extraction of Talaromyces minioluteus (Penicillium minioluteum) PILE 14-5, a marine sponge-derived fungus (collected in Pilae Bay, Phi Phi Island, Thailand), led to the production of four new sesquiterpene lactones (156-159), namely, minioluteumides A-D, which are sesquiterpene lactones conjugated with $\mathrm{N}$-acetyl-L-valine that rarely occur in nature [48]. The result of the cytotoxic activity assay of the HepG2 cancer cell lines revealed that compounds 156 and 159 exerted cytotoxicity, with $\mathrm{IC}_{50}$ values of 50.6 and $57.0 \mu \mathrm{M}$, respectively [48].

\subsubsection{Tinctoporellus sp.}

Three new tremulene terpenes, $\mathbf{1 6 0}-\mathbf{1 6 2}$, two of which bear structurally unprecedented 2-hydroxy or 2-methoxy-3,4-dihydro-2 $\mathrm{H}$-pyrrole $\mathrm{N}$-oxide moieties, were obtained from the RBBR degradation medium as the products of the metabolism of Tinctoporellus sp. CBMAI 1061, which was isolated from a specimen of the sponge Dragmacidon reticulatum [49].

\subsubsection{Trichoderma sp.}

Secondary metabolites from Trichoderma harzianum X-5, an endophytic fungus associated with the marine brown alga Laminaria japonica from the Chang Islands, included three cyclonerane sesquiterpenes, 11-methoxy-9-cycloneren-3,7-diol (163), 10-cycloneren-3,5,7-triol (164), and methyl-3,7-dihydroxy-15-cycloneranate (165) in addition to one acorane sesquiterpene, 8-acoren-3,11-diol (166) [50]. In the biological evaluation, they all exhibited growth inhibition of four phytoplankton species (Chattonella marina, Heterosigma akashiwo, Karlodinium veneficum, and Prorocentrum donghaiense), among which 163 was most active against $C$. marina and $K$. veneficum with $\mathrm{IC}_{50}$ values of 0.66 and $2.2 \mu \mathrm{g} / \mathrm{mL}$, respectively [50].

Two undescribed cyclonerane sesquiterpenoid derivatives, (10E)-12-acetoxy10-cycloneren-3,7-diol (167) and 12-acetoxycycloneran-3,7-diol (168), were isolated from the cultures of the marine sediment-derived fungus Trichoderma harzianum P1-4 collected in the Bohai Sea [51].

Further work on an endophytic fungal strain from the marine red alga Gracilaria verrucose collected from the Yangma Island, Trichoderma asperellum A-YMD-9-2, led to the production of two new sesquiterpenoids, 4-cadinen-11,12-diol (169) and 4-cadinen-11,13-diol (170) [52]. During the bioactivity assay, compounds 169-170 showed potent inhibition of four marine phytoplankton species related to red tides: Chattonella marina, Heterosigma akashiwo, Karlodinium veneficum, and Prorocentrum donghaiense, with $\mathrm{IC}_{50}$ values ranging from 1.1 to $8.9 \mu \mathrm{g} / \mathrm{mL}$ and weak inhibition against marine pathogenic bacteria, including four different strains of Vibrio and a strain of Pseudoalteromonas citrea, at $40 \mu \mathrm{g} / \mathrm{disk}$ [52].

Research on secondary metabolites of the strain Trichoderma asperellum cf44-2, which is related to the marine brown alga Sargassum sp. collected from the Zhoushan Islands, led to a new bisabolane sesquiterpene, bisabolan-1,10,11-triol (171), and a novel norbisabolane sesquiterpene, 12-nor-11-aceto-xybisabolen-3,6,7-triol (172) [14]. The evaluation of compounds 171-172 for the inhibition of four marine phytoplankton species and four marine-derived pathogenic bacteria (the same test strain used for compounds 169-170) revealed that they all resulted in growth inhibition of the four phytoplankton species tested and weak antibacterial activities were observed against the four tested bacteria, with inhibitory zone diameters of $6.3-7.5 \mathrm{~mm}$ at $20 \mu \mathrm{g} /$ disk [14].

From the culture of Trichoderma asperellum Y6-2, originating from the surface of the marine red alga Chondrus ocellatus, eight new bisabolane derivatives, trichobisabolins A-H (173-180), were 
obtained [53]. All displayed inhibition against four phytoplankton species (H. akashiwo, P. donghaiense, C. marina, and $K$. veneficum), among which 180 , with $\mathrm{IC}_{50}$ values ranging from 1.9 to $3.8 \mu \mathrm{g} / \mathrm{mL}$, was more active than the others [53]. In addition, $\mathbf{1 7 6}$ and $\mathbf{1 8 0}$ showed weak lethality to the marine zooplankton Artemia salina, with $\mathrm{IC}_{50}$ values of 48 and $62 \mu \mathrm{g} / \mathrm{mL}$, respectively [53].

Further research on the marine red alga-associated fungus Trichoderma virens Y13-3 yielded two types of sesquiterpenes: eight new carotene sesquiterpenes, trichocarotins A-H (181-188), and a new cadinene sesquiterpene, trichocadinin A (189) [54]. Compounds 183-185 and $\mathbf{1 8 8}$ showed potent inhibition against the four phytoplankton species (H. akashiwo, P. donghaiense, C. marina, and $K$. veneficum $),\left(\mathrm{IC}_{50}=0.24-12 \mu \mathrm{g} / \mathrm{mL}\right)$, especially against $C$. marina, with $\mathrm{IC}_{50}$ values ranging from 0.24 to $1.2 \mu \mathrm{g} / \mathrm{mL}$, which indicates that they might be promising agents to control harmful algal bloom [54].

\subsubsection{Trichothecium sp.}

A culture of the marine-derived fungus Trichothecium roseum from marine driftwood, collected from the intertidal zone of Lingshan Island, was the source of two cyclonerodiol sesquiterpenes: cyclonerodiol C-D (190-191) [55]. The biological evaluation showed that 191 produces moderate antifungal activity against Valsa mali, with a MIC value of $64 \mu \mathrm{g} / \mathrm{mL}$; meanwhile, 190 exhibited weak bioactivity against $V$. mali and rhellozoctonia cerealis [55].

\subsubsection{Unidentified Fungus}

Six new chamigrane sesquiterpenes, merulinols A-F (192-197), were isolated from the culture of the endophytic fungus XG8D belonging to the family Meruliaceae and associated with the Thai mangrove Xylocarpus granatum [56]. Among them, merulinol A (192) was a nor-chamigrane with a novel tricyclic ring system, whereas compounds 193-197 were 6/6 spirobicyclic charmigrane sesquiterpenes [56]. Compounds 194 and 195 exhibited selective cytotoxicity toward gastric KATO-3 cells, with $\mathrm{IC}_{50}$ values of 35.0 and $25.3 \mu \mathrm{M}$, respectively [56].

Two new sesquiterpenoids, $2 \alpha$-hydroxyxylaranol B (198) and 4 $\beta$-hydroxyxylaranol B (199), were obtained from the fermentation of the endophytic fungus J3 isolated from the leaf of the mangrove plant Ceriops tagal collected from the mangrove reserve of Dong Zhai Gang [57].

\subsection{Diterpenes}

Diterpenes are a significant class of terpenoids with diverse structures and notable bioactivities. The current research (25 articles from 2015 to 2019) reported 75 undescribed diterpenes (200-274, Figures 16-19) in total from diverse marine fungi compared to 77 diterpenes (42 in 2011-2014, with 35 before 2010) described in 36 papers up to 2014 [7,8], which indicates that the number of diterpenes isolated from marine fungi continues to increase.

The newly reported diterpenes were obtained from fungi associated with diverse marine habitats; the number of fungi from marine animals $(28,37 \%)$ was the highest, followed by those from deep-sea sediments $(17,23 \%)$, and then seawater $(12,16 \%)$, algae $(10,13 \%)$, other marine sediments $(6,8 \%)$, and mangrove plants $(2,3 \%)$. These marine fungi can be divided into nine groups of genera, in which five main genera each account for more than $10 \%$ : Trichoderma (27\%), Aspergillus $(17 \%)$, Penicillium $(15 \%)$, Acremonium (13\%), Botryotinia (12\%); some groups occur in relatively small amounts; namely, Curvularia, Talaromyces, Epicoccum, and one unidentified fungus. The results of the biological evaluations conducted for new diterpenes show that $38 \%$ of them ( 40 active in 106 tested diterpenes) offer diverse inhibitory activities, most of which displayed lethal toxicity $(35 \%)$, cytotoxicity $(20 \%)$, and antibacterial $(17.5 \%)$ and anti-inflammatory (15\%) activities. 


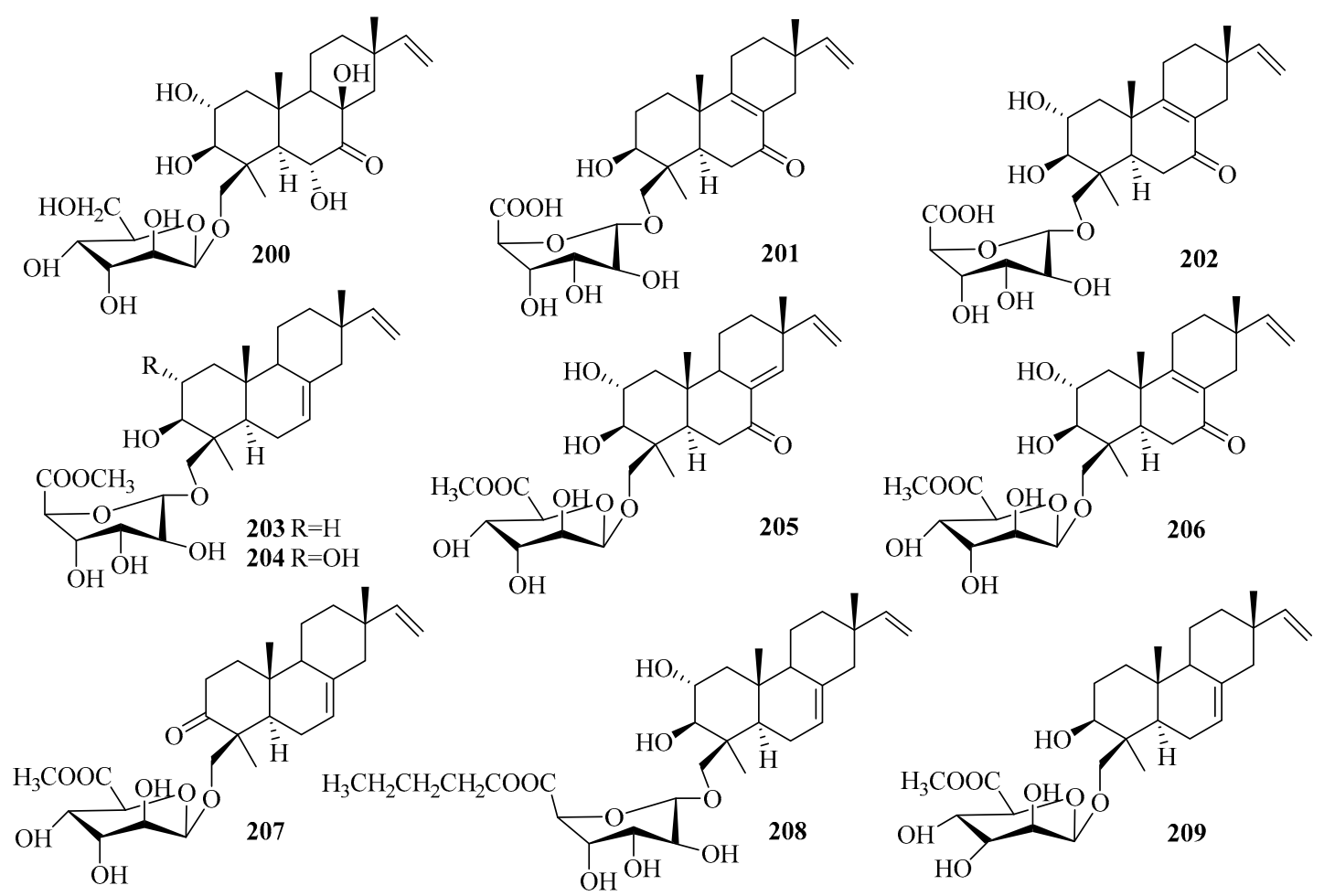

Figure 16. Chemical structures of diterpenes (200-209 from Acremonium sp.).

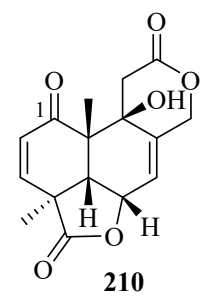

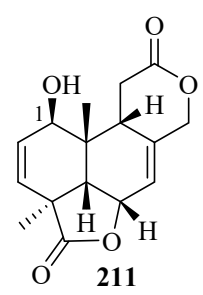

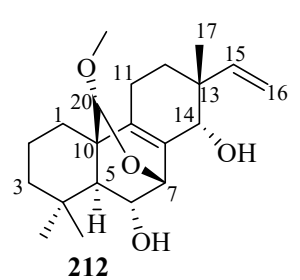

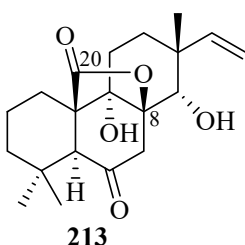

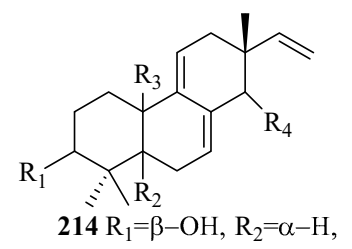

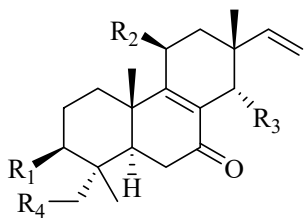

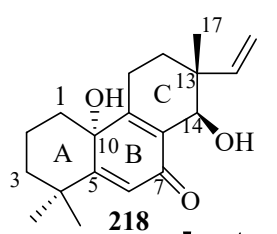<smiles>C=CC1(C)CCC2=C(C(=O)C=C3C(C)CCCC32)[C@@H]1O</smiles>
$\mathrm{R}_{3}=\beta-\mathrm{CH}_{3}, \mathrm{R}_{4}=\alpha-\mathrm{OH}$

$216 \mathrm{R}_{1}=\mathrm{OH}, \mathrm{R}_{2}=\mathrm{H}$ $\mathrm{R}_{3}=\mathrm{OAc}, \mathrm{R}_{4}=\mathrm{H}$ $217 \mathrm{R}_{1}=\mathrm{OH}, \mathrm{R}_{2}=\mathrm{OH}$ $\mathrm{R}_{3}=\mathrm{H}, \mathrm{R}_{4}=\mathrm{H}$

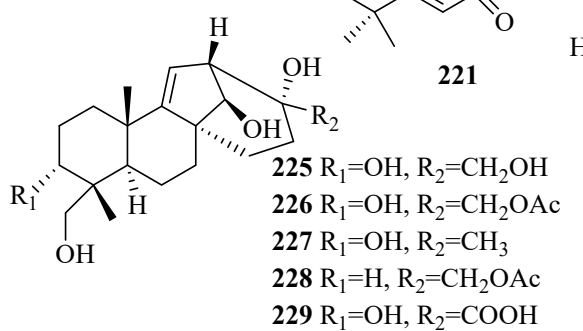<smiles></smiles>

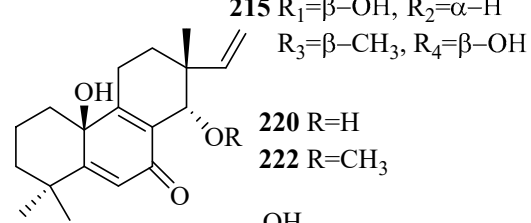

Figure 17. Chemical structures of diterpenes (210-222 from Aspergillus sp. and 223-231 from Botryotinia sp.). 

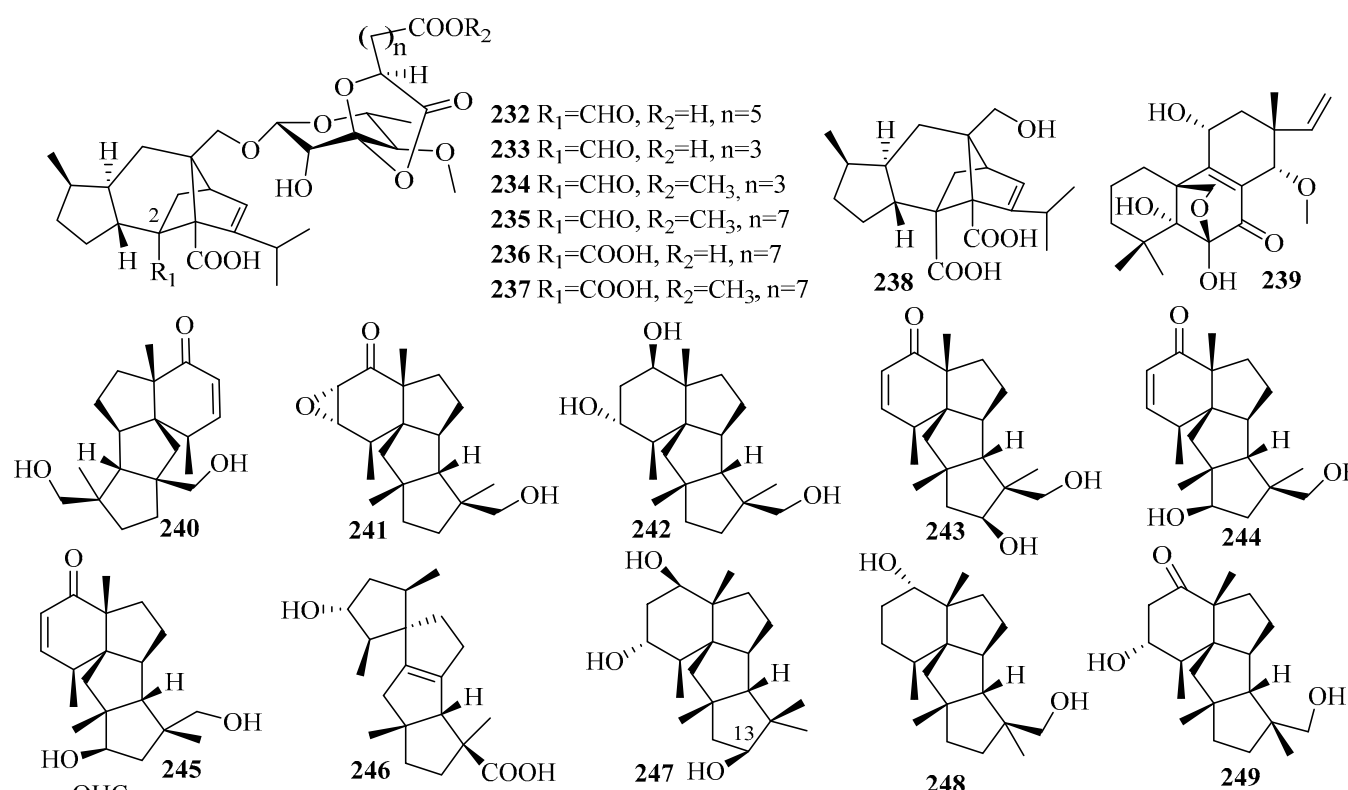

$\mathrm{HO}$
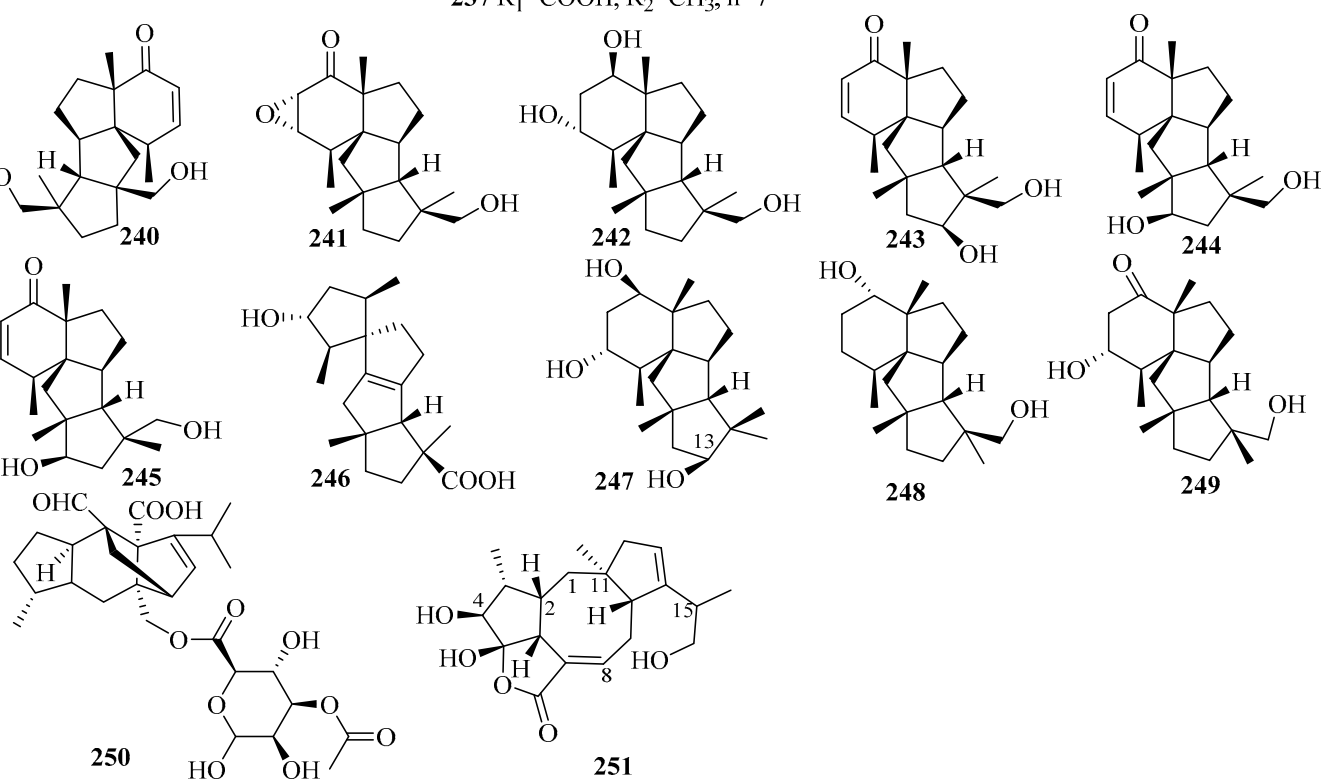

Figure 18. Chemical structures of diterpenes (232-238 from Curvularia sp., 239 from Epicoccum sp., 240-250 from Penicillium sp., and 251 from Talaromyces sp.).

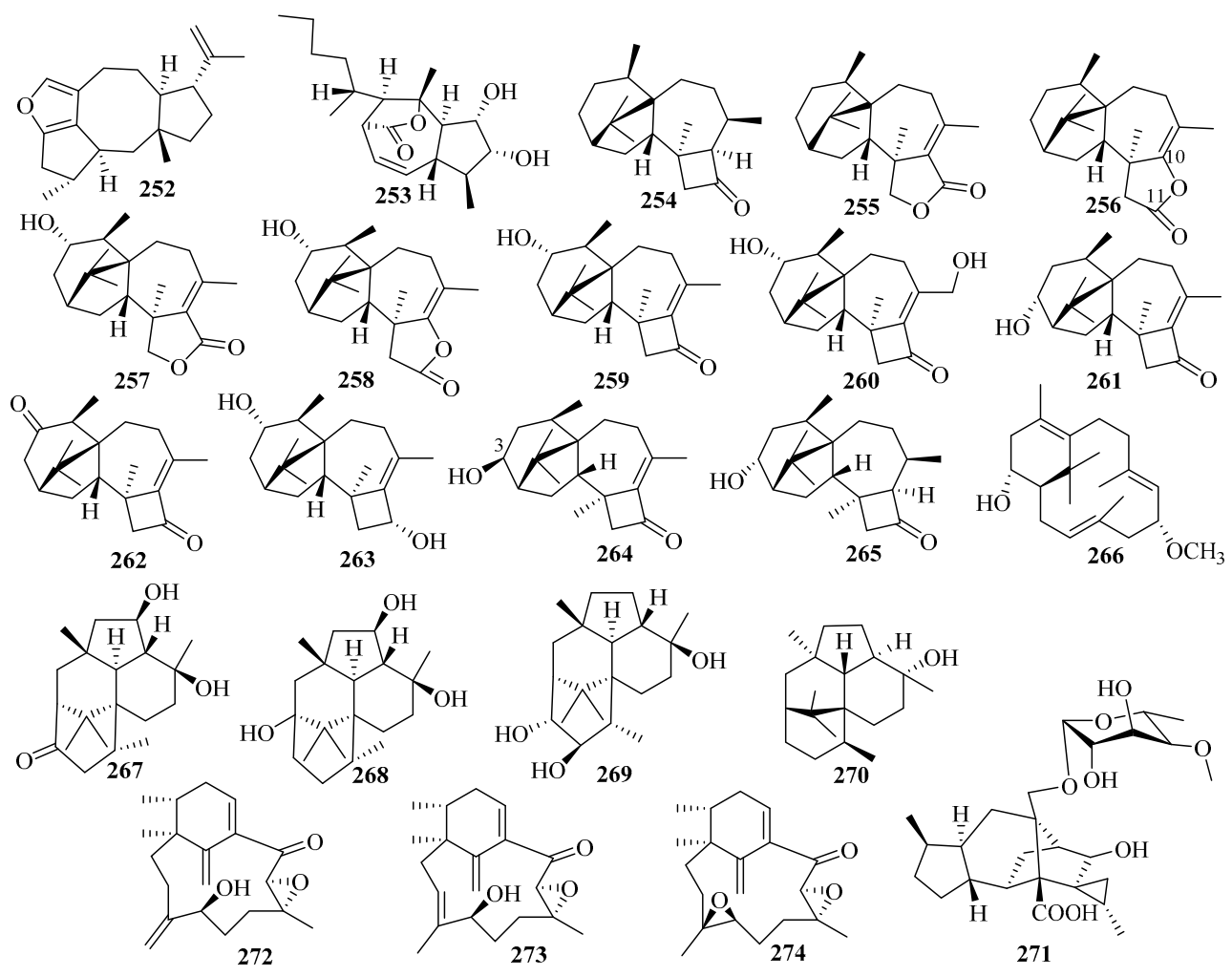

Figure 19. Chemical structures of sesquiterpenes (252-271 from Trichoderma sp. and 272-274 from an unidentified fungus). 


\subsubsection{Acremonium sp.}

Ten undescribed diterpene glycosides, virescenosides $Z_{9}-Z_{18}$ (200-209), were identified as secondary metabolites of the marine-derived fungus Acremonium striatisporum KMM 4401 associated with the holothurian Eupentacta fraudatrix on a wort agar medium treated with potassium bromide [58]. Structurally, compound 200 is an altroside featuring a new 7-oxo-isopimara-15-en- $2 \alpha, 3 \beta, 6 \alpha, 8 \beta$-tetraol aglycon. 203-207 were determined to be monosides coupled with unique methyl esters of altruronic acid as their sugar moieties [58]. The carbohydrate chain of virescenoside Z18 (209) was identified as the methyl ester of mannuronic acid [58]. The bioactivity assay revealed that compounds 200, 201, 203, and 204 induced a significant downregulation of ROS production in macrophages stimulated with LPS at a concentration of $10 \mu \mathrm{M}$, especially for virescenoside $\mathrm{Z}_{10}$ (201), thereby decreasing the ROS content in the macrophages by 45\% [58]. Furthermore, compounds 201 and 204 displayed moderate downregulation of NO production in LPS-stimulated macrophages at a concentration of $1 \mu \mathrm{M}$ [58].

\subsubsection{Aspergillus sp.}

The team of $\mathrm{Li}$ et al. conducted a further investigation on the deep-sea-sediment-derived fungus Aspergillus wentii SD-310, collected in the South China Sea at a depth of $2038 \mathrm{~m}$, which led to the isolation of 13 new diterpenoids, including two tetranorlabdane diterpenoids, asperolides D-E (210-211) [59], six isopimarane-type diterpenoids, wentinoids A-F (212-217) [60], four new, uncommon 20-nor-isopimarane diterpenoid epimers, aspewentins I-L (218-221), and a new methylated derivative, aspewentin M (222) [61]. Among them, wentinoid A-B (212-213) belonged to a rarely-described class of tetracyclic isopimaranes-specifically wentinoid A (212), which contains an unusual 20-acetal moiety and 7,20-oxabridged functionality, whereas wentinoid B (213) possesses a novel 8,20-lactone-bridged scaffold [60]. Moreover, compounds 218-222 are rare examples of 20-nor-isopimarane analogs coupled with a cyclohexa-2,5-dien-1-one moiety at ring B [61]. The results of the biological assay revealed that compound 211 exerts cytotoxic activities against HeLa, MCF-7, and NCI-H446 cell lines, with $\mathrm{IC}_{50}$ values of $10.0,11.0$, and $16.0 \mu \mathrm{M}$, respectively, and moderate activity against the aquatic bacteria Edwardsiella tarda, with a MIC value of $16 \mu \mathrm{g} / \mathrm{mL}$ [59]. However, compound 210 did not display this activity, possibly due to the keto substitution at C-1 [59]. Thus, compound 212 might prove useful as an antifungal agent for its selective inhibition of four plant pathogenic fungi, including Phytophthora parasitica, Fusarium oxysporum f. sp. lycopersici, Fusarium graminearum, and Botryosphaeria dothidea, with MIC values of 8.0,4.0, 1.0, and $4.0 \mu \mathrm{g} / \mathrm{mL}$, respectively, compared to the p.c., amphotericin B (MIC $=2.0$, $1.0,1.0$, and $2.0 \mu \mathrm{g} / \mathrm{mL}$, respectively) [60]. Furthermore, compound 218 showed activity against $E$. coli $(\mathrm{MIC}=32 \mu \mathrm{g} / \mathrm{mL})$, while compounds 218 and 219 possessed potent inhibitory activities toward three marine bacteria (E. tarda, V. harveyi, and V. parahaemolyticus), each with a MIC value of $8.0 \mu \mathrm{g} / \mathrm{mL}$ [61]. Compound 222 exhibited activity against F. graminearum with a MIC value of $4.0 \mu \mathrm{g} / \mathrm{mL}$ (the same MIC as for the p.c. amphotericin B) [61]. Moreover, compounds 218-219 were more active against pathogenic bacteria than 220-222, suggesting that compounds with an $R$ absolute configuration at $C-10$ are more active than those with $S$ configuration [61]. Compared to 218-221, compound 222 offered better inhibition of F. graminearum with methoxylation at C-14 [61].

\subsubsection{Botryotinia sp.}

Further work was done by Niu et al. on the fermentation broth of the Botryotinia fuckeliana MCCC obtained from the deep seawater in the western Pacific Ocean at a depth of $5572 \mathrm{~m}[62,63]$. This led to the isolation of a new pimarane diterpenoid, botryopimarene A (223), featuring a $\Delta^{9(11)}$ double bond, a rare moiety in the pimarane family [62], and eight unprecedented diterpenoids: botryotins A-H (224-231), representing three novel carbon skeletons with 6/6/5/5 (224),6/6/5/6 (225-229), and 6/6/6/5 (230 and 231) tetracyclic scaffolds [63]. Compounds 224-231 proved inactive against six HTCLs (HL-60, BEL-7402, BIU-87, PANC-1, HeLa-S3, and ECA109) ( IC $\left._{50}>20 \mu \mathrm{M}\right)$. However, 224 exhibited moderate antiallergic activity in RBL-2H3 cells $\left(\mathrm{IC}_{50}=0.2 \mathrm{mM}\right)$ with the loratadine as p.c. $\left(\mathrm{IC}_{50}=0.1 \mathrm{mM}\right)[62,63]$. 


\subsubsection{Curvularia sp.}

Secondary metabolites from the marine fungus Curvularia hawaiiensis TA2615 (related to the zoanthid Palythoa haddoni collected from the Weizhou coral reefs in the South China Sea) contained a new sordaricin tetracyclic diterpene named sordaricin $B(238)$ and six new sordarin tetracyclic diterpene glycosides, moriniafungins B-G (232-237) - the first instances of sordarins from marine-derived fungi each bearing a sordarose with a rare spiro 1,3-dioxolan-4-one ring [64]. Among them, compound 235 displayed strong antifungal activity against Candida albicans ATCC10231, with a MIC value of $2.9 \mu \mathrm{M}$ [64]. The differences in antifungal activity among these compounds indicate that the glycosyl moiety, the length of the aliphatic acid side chain, and C-2 carboxylic acid might have impacts on antifungal activity [64].

\subsubsection{Epicoccum sp.}

One unreported isopimarane diterpene (239) was sourced from the Apostichopus japonicusassociated fungus Epicoccum sp. HS-1 [65]. In the bioassay, 239, with $\mathrm{IC}_{50}$ values of $4.6 \mu \mathrm{M}$, exhibited greater effective inhibition against $\alpha$-glucosidase than the p.c. resveratrol, with $\mathrm{IC}_{50}=31.2 \mu \mathrm{M}$ [65].

\subsubsection{Penicillium sp.}

A further study on the deep-sea-derived fungus Penicillium commune MCCC 3A00940 yielded three new cyclopiane diterpenes exhibiting a rare rigid 6/5/5/5 fused tetracyclic ring framework, conidiogenone J-K (240-241) and conidiogenol B (242), among which conidiogenone J (240) is notably the first naturally occurring cyclopiane diterpene enantiomer [66]. However, all these compounds were devoid of bioactivity when tested for antiallergic effects in immunoglobulin E (IgE)-mediated rat basophilic leukemia RBL2H3 cells [66].

An investigation of the extracts from Penicillium sp. TJ403-2, a sea sediment-derived fungus, yielded three new rare diterpenes identified as $13 \beta$-hydroxy conidiogenone $C$ (243), 12 $\beta$-hydroxy conidiogenone $C$ (244), and $12 \beta$-hydroxy conidiogenone D (245) [67]. Regarding anti-inflammatory activity against LPS-induced NO production in RAW 264.7 cells, 243 displayed notable inhibitory potency, with an $\mathrm{IC}_{50}$ value of $2.19 \mu \mathrm{M}$-three-fold lower than the p.c. indomethacin $\left(\mathrm{IC}_{50}=8.76 \mu \mathrm{M}\right)$ [67]. Moreover, further experiments showed that $\mathbf{2 4 3}$ could significantly inhibit the production of cell cytokines (IL-1 $\beta$, IL-13, TNF- $\alpha$, GM-CSF, MIP- $1 \beta$, and MCP-1), suppress inducible nitric oxide synthesis (iNOS) and cyclooxygenase-2 (COX-2) protein expression in a dose-dependent manner, and abolish the nuclear translocation of NF- $k$ B p65 in LPS-activated RAW264.7 cells [67]. From these data, it is apparent that 243 is a promising starting point for the development of new anti-inflammatory agents due to its inhibition of the NF-kB-activated pathway [67].

The deep-sea-sediment fungus Penicillium granulatum MCCC 3A00475, occurring in the Prydz Bay of Antarctica at a depth of $2284 \mathrm{~m}$, produced a rare novel spiro-tetracyclic diterpene, spirograterpene A (246), reported to be the second example of a diterpene featuring a 5/5/5/5 spirocyclic carbon skeleton [68]. Biologically, compound 246 showed modest antiallergic activity against IgE-mediated rat mast RBL-2H3 cells with $18 \%$ inhibition, compared to $35 \%$ inhibition for the p.c. loratadine at the same concentration of $20 \mu \mathrm{g} / \mathrm{mL}$ [68].

The EtOAc extract of Penicillium sp. YPGA11, a deep-sea-sediment fungus collected in the West Pacific Ocean at a depth of $4500 \mathrm{~m}$, resulted in the isolation of three new cyclopiane diterpenes, conidiogenols C-D (247-248) and conidiogenone L (249) [69]. Structurally, compound 247 is the second example of cyclopianes bearing a hydroxyl group at C-13, while 248 is the third example of conidiogenols (coupled with a distinct $\alpha$-oriented 1-hydroxy group) [69]. After the bioassay study demonstrated the inhibitory effects against five esophageal HTCLs (EC109, KYSE70, EC9706, KYSE30, and KYSE450), compounds $\mathbf{2 4 7}$ and $\mathbf{2 4 9}$ displayed weak inhibitory effects with inhibition rates less than $36 \%$ at an initial concentration of $50 \mu \mathrm{M}$ [69]. Compound 248 exerted moderate antiproliferative effects, with $\mathrm{IC}_{50}$ values ranging from 36.80 to $54.7 \mu \mathrm{M}$ (cisplatin as the p.c.) [69]. 
A new glycosyl ester identified as xylarinonericin E (250) was later found in the fermentation broth of the fungus Penicillium sp. H1 from the sediments of the Beibu Gulf [70]. Compound 250 showed moderate antifungal activity against Fusarium oxysporum f. sp. cubense, with an MIC value of $32.0 \mu \mathrm{M}[70]$.

\subsubsection{Talaromyces sp.}

Characterized as a new diterpenoid bearing a novel tetracyclic fusicoccane framework with an unexpected hydroxyl at C-4, roussoellol C (251) was obtained from the laboratory cultures of Talaromyces purpurogenus PP-414 originating from a mud sample collected on a coastal beach [47]. Additionally, compound 251 exhibited moderate antiproliferative activities against four HTCLs (SW480, HL-60, A549, and MCF-7), with $\mathrm{IC}_{50}$ values ranging from 6.5 to $25.8 \mu \mathrm{M}$ [47]. Furthermore, 251 showed significant selectivity toward MCF-7 cells, with an $\mathrm{IC}_{50}$ value of $6.5 \mu \mathrm{M}$ but an $\mathrm{IC}_{50}$ value of $10.9 \mu \mathrm{M}$ against HL-60, contrary to the expectation that cytotoxic natural products will display greater activities against HL-60 cells due to their high sensitivity in the assay [47]. Thus, the selectivity of 251 against MCF-7 makes it a promising lead compound for further study [47].

\subsubsection{Trichoderma sp.}

The ongoing studies of Liang, X. R. et al. on the fungus Trichoderma citrinoviride cf-27 associated with the fresh tissue of the marine brown alga Dictyopteris prolifera afforded the first Trichoderma-derived and furan-bearing fusicoccane diterpene trichocitrin (252) [71], and a novel norditerpene, citrinovirin (253), with an unprecedented skeleton [72]. The bioactivity results showed that 252 can exert antibacterial activity against $E$. coli with an inhibitory diameter of $8.0 \mathrm{~mm}$ at $20 \mu \mathrm{g} / \mathrm{disc}$ and possesses anti-microalgal capability against Prorocentrum donghaiense with $54.1 \%$ growth inhibition at $80 \mu \mathrm{g} / \mathrm{mL}$ [71]. Compound 253 inhibited the growth of $S$. aureus with an MIC value of $12.4 \mu \mathrm{g} / \mathrm{mL}$, displayed toxicity against the marine zooplankton Artemia salina with an $\mathrm{LC}_{50}$ value of $65.6 \mu \mathrm{g} / \mathrm{mL}$, and additionally achieved 14.1-37.2\% inhibition of three marine phytoplankton species (C. marina, H. akashiwo, and P. donghaiense) at $100 \mu \mathrm{g} / \mathrm{mL}$ but promoted the growth of one marine phytoplankton Scrippsiella trochoidea [72].

The fermentation culture of the endophytic fungus Trichoderma sp. Xy24 from the mangrove plant Xylocarpus granatum, collected in the Sanya district, was the source of two new harziane diterpenoids, $(9 R, 10 R)$-dihydro-harzianone (254) and harzianelactone (255) [73]. Among them, 254 was the reductive product of harzianone, and 255 was the Baeyer-Villiger monooxygenase-catalyzed oxidation product of harzianone [73]. In terms of in vitro biological evaluation, compound 254 exerted selective cytotoxicity on the HeLa and MCF-7 cell lines with $\mathrm{IC}_{50}$ values of 30.1 and $30.7 \mu \mathrm{M}$, respectively, whereas 255 was inactive at $10 \mathrm{mM}$ [73].

The cultivation of Trichoderma longibrachiatum A-WH-20-2, an endophyte from the marine red alga Laurencia okamurai, yielded one new harziane lactone with an ester linkage between C-10 and C-11, deoxytrichodermaerin (256), which was possibly an oxidation product of harzianone [74]. Deoxytrichodermaerin (256) and the other two isolates (harzianol A and harzianone) were assayed for their inhibition of four marine phytoplankton species (C. marina, H. akashiwo, K. veneficum, and P. donghaiense) with $\mathrm{IC}_{50}$ values ranging from 0.53 to $2.7 \mu \mathrm{g} / \mathrm{mL}$ [74]. The toxicity of 256 against the marine zooplankton A. salina was also evaluated $\left(\mathrm{LC}_{50}=19 \mu \mathrm{g} / \mathrm{mL}\right)$ and revealed that the lactone unit in deoxytrichodermaerin may contribute slightly to these activities [74].

The chemical investigation was applied to the soft coral-derived fungus Trichoderma harzianum XS20090075 in the South China Sea, resulting in the production of seven secondary metabolites, including two new harziane diterpene lactones possessing a 6/5/7/5-fused carbocyclic core containing a lactone ring system, harzianelactones A and B (257 and 258), and five new harziane diterpenes, harzianones A-D (259-262) and harziane (263) [75]. Specifically, 257 and 258 represent a unique type of harziane diterpene lactone that originated from harziane diterpenes though Baeyer-Villiger monooxygenase-catalyzed oxidation [75]. In the bioactivity study, the above compounds (except for 262) showed obvious phytotoxicity against the seedling growth of amaranth and lettuce at a 
concentration of $200 \mathrm{ppm}$ [75]. Among them, compounds 257, 259, 260, and 261 were more effective for the complete inhibition of seed germination against amaranth at $200 \mu \mathrm{g} / \mathrm{mL}$ and were still effective at lower concentrations $(50 \mu \mathrm{g} / \mathrm{mL})$ compared to the p.c. glyphosate [75]. However, none was found to inhibit the root growth of lettuce at $200 \mathrm{ppm}$ [75]. In short, the tested compounds seemed to cause weaker inhibition to lettuce than to amaranth and had stronger toxicity on root growth than hypocotyl [75]. Notably, this was the first report of the phytotoxicity of harziane diterpenes from Trichoderma spp. [75].

The search for antagonistic metabolites from Trichoderma asperellum A-YMD-9-2, an endophytic fungal from the marine red alga Gracilaria verrucose, led to the isolation of one new harziane diterpenoid, 3S-hydroxyharzianone (264), which may be an intermediate in the biosynthesis of harziandione from harzianone [52]. Compound $\mathbf{2 6 4}$ could strongly inhibit a wide spectrum of red tide-related phytoplankton species (C. marina, H. akashiwo, K. veneficum, and P. donghaiense) with $\mathrm{IC}_{50}$ values ranging from 3.1 to $7.7 \mu \mathrm{g} / \mathrm{mL}$ [52]. A structure-activity relationship analysis revealed that the hydroxy group at C-3 of $\mathbf{2 6 4}$ greatly contributes to its inhibitory ability. During the antibacterial assay, $\mathbf{2 6 4}$ exhibited weak inhibition against five marine-derived pathogenic bacteria (four different strains of Vibrio and a P. citrea), at $40 \mu \mathrm{g} / \mathrm{disc}$ [52].

As a result of the continuing endeavor to research secondary metabolites from brown alga, the Laminaria japonica-derived strain Trichoderma harzianum X5, two new structurally related diterpenes, 3R-hydroxy-9R,10R-dihydroharzianone (265) and 11R-methoxy-5,9,13-proharzitrien-3-ol (266), were isolated and identified [50]. They were all evaluated for their ability to inhibit four marine phytoplankton species, as with the above strains tested for $\mathbf{2 6 4}$, and exhibited growth inhibition of these tested species $\left(\mathrm{IC}_{50}=1.2-70 \mu \mathrm{g} / \mathrm{mL}\right)$ [50]. Notably, compound 266 exhibited potent inhibition of $H$. akashiwo and P. donghaiense with $\mathrm{IC}_{50}$ values in the low $\mu \mathrm{g} / \mathrm{mL}$ range [50].

Trichodermanins C-E (267-269), three undescribed diterpenes with a rare fused 6-5-6-6 ring system, were isolated from the fungus Trichoderma harzianum OUPS-111D-4 from a piece of a marine sponge Halichondria okadai [76]. Significantly, this was the first determination of the absolute configurations of 267-269 [76]. In a primary screen for antitumor activity, 267 exerted strong inhibition against the cell lines P388, HL-60, and L1210, with $\mathrm{IC}_{50}$ values ranging from 6.8 to $7.9 \mu \mathrm{M}$, in which the p.c. 5-fluorouracil exhibited $\mathrm{IC}_{50}$ values ranging from 4.5 to $6.1 \mu \mathrm{M}$ [76].

An investigation of the extracts from the fungus Trichoderma asperellum d1-34 that occurs on marine brown alga afforded one unknown diterpene antipode, (+)-wickerol A (270) [77]. The bioactivity assay showed that compound $\mathbf{2 7 0}$ could inhibit $E$. coli and $S$. aureus with the same inhibitory diameters of $8.0 \mathrm{~mm}$ at $30 \mu \mathrm{g} / \mathrm{disc}$, and lethal activity was displayed against $A$. salina with an $\mathrm{LC}_{50}$ value of $12.0 \mu \mathrm{g} / \mathrm{mL}$ [77].

A new sordarin derivative, trichosordarin A (271), bearing a unique norditerpene aglycone, was discovered from the extracts of a marine sediment-derived fungal strain collected in the Bohai Sea, Trichoderma harzianum R5 [78]. It was assayed to be toxic to the marine zooplankton A. salina with an $\mathrm{LC}_{50}$ value of $233 \mu \mathrm{M}$, but was weak in inhibiting two marine phytoplankton species (Amphidinium carterae and Phaeocysti globosa), with inhibition rates of $20.6 \%$ and $8.1 \%$, respectively, at $100 \mu \mathrm{g} / \mathrm{mL}$ [78].

\subsubsection{Unidentified Fungus}

An unidentified marine fungus associated with the marine brown alga Ishige okamurae (Tateishi, Kanagawa Prefecture) furnished three novel diterpenes, phomactins N-P (272-274) [79].

\subsection{Sesterterpenes}

Sesterterpenoids are a small group of terpenoids with bioactivities in marine fungi. The number of newly isolated sesterterpenoids from marine fungi notably increased in the last five years ( $29 \mathrm{vs} .10$ in 2011-2014, with 16 before 2010) (275-303 in Figure 20) [7,8]. Aspergillus (25 compounds) is the main source of sesterterpenes from marine fungi, especially ophiobolins ( 23 compounds), and has always 
displayed cytotoxicity, anti-inflammatory activity, and enzyme inhibitory activity (e.g., against protein tyrosine phosphatase B).

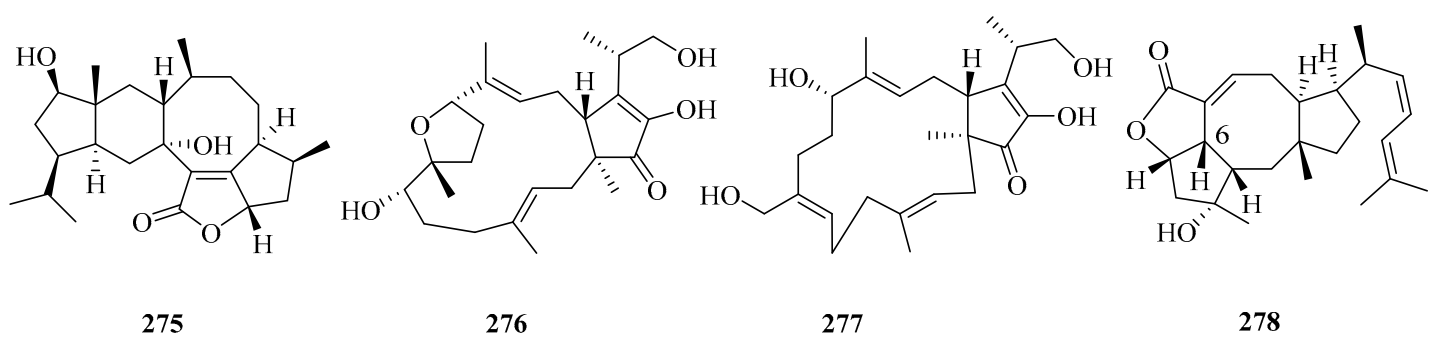

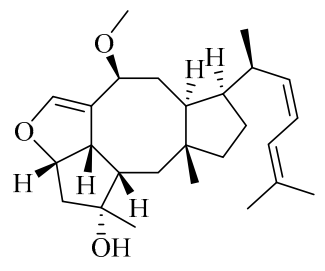

279

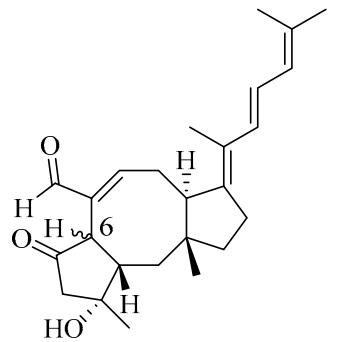

$2856 R$ $2876 S$<smiles>CC(C)=C/C=C\[C@H](C)[C@H]1CC[C@]2(C)CC3=C(C(=O)C[C@H]3C)/C(C=O)=C\C[C@H]12</smiles>

281

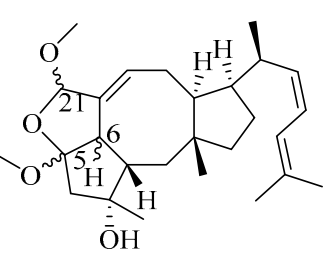

$\begin{array}{ll}\mathbf{2 8 0} & 5 R, 6 R, 21 R \\ \mathbf{2 8 2} & 5 R, 6 R, 21 S\end{array}$ $2835 S, 6 S, 21 R$

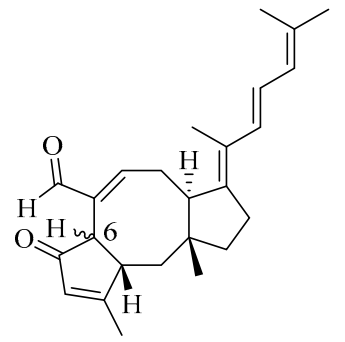

$2866 R$ $2886 S$

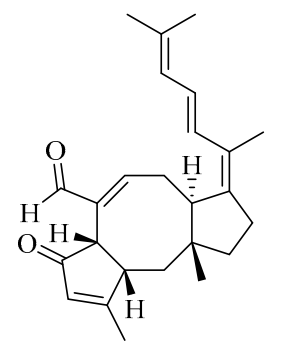

289

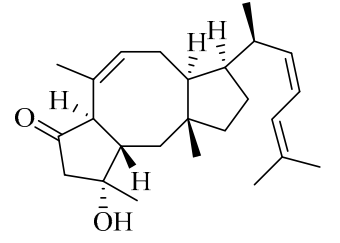

284

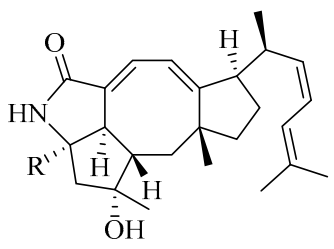

$290 \mathrm{R}=\mathrm{OCH}_{3}$ $291 \mathrm{R}=\mathrm{OH}$ $292 \mathrm{R}=\mathrm{H}$

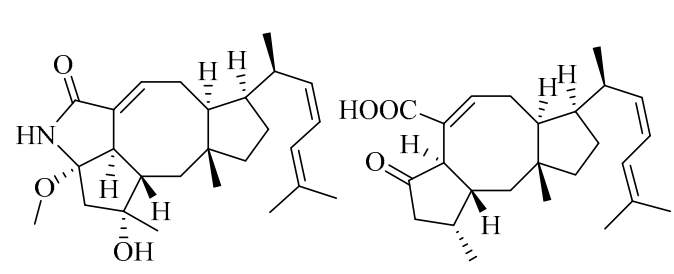

293

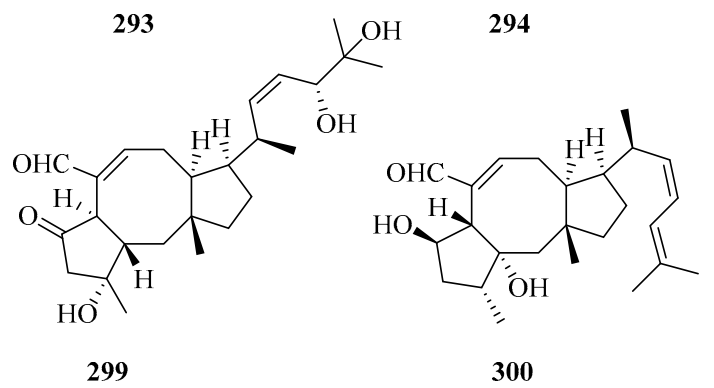

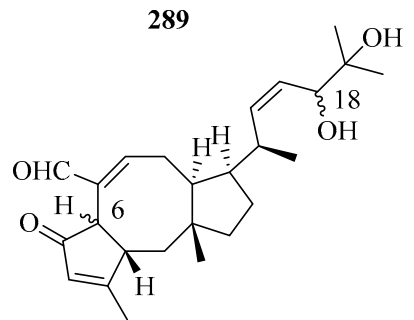

$2976 S, 18 R$

$2956 R, 18 S$

$2966 S, 18 S$

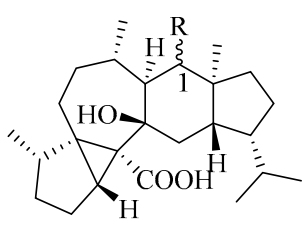

$301 \mathrm{R}=\mathrm{OAc}, 1 S$ $302 \mathrm{R}=\mathrm{OH}, 1 R$

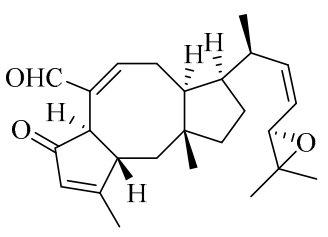

298<smiles>CC/C(C)=C\C[C@]1(C)C(=O)O[C@H](O)[C@H](C(C)C)[C@H]1C/C=C(/C(=O)O)C1=C(CCC(C)=O)[C@H](C)CC1</smiles>

303

Figure 20. Chemical structures of sesterterpenes (275-303).

An investigation of the EtOAc extract of the fermentation cultures of the algicolous fungus Alternaria alternata k21-1, collected from the surface of the marine red alga Lomentaria hakodatensis, led to the discovery of sesteralterin (275), which was the first nitidasane sesterterpene naturally produced by fungi [80]. Sesteralterin displayed weak to moderate activity against three marine 
phytoplankton strains [80]. Two new oxidative terpestacin-type sesterterpenes, terpestacin B and 21-hydroxyterpestacin (276 and 277), and their biosynthetic precursor terpestacin, were isolated from the marine fungal strain Arthrinium sp. (5XNZ5-4) collected from the gut of a marine crab [81].

Marine sesterterpenes, especially ophiobolins, are mainly produced by Aspergillus. The ophiobolin family features a unique 5-8-5-tricarbocyclic skeleton whose biosynthesis involves five gene clusters responsible for $\mathrm{C} 15, \mathrm{C} 20, \mathrm{C} 25$, and $\mathrm{C} 30$ terpenoid biosynthesis [82]. Seven new ophiobolins, ophiobolins X-Z (278-280), 21-dehydroophiobolin U (281), 21-epi-ophiobolin Z and O (282 and 283), and 21-deoxyophiobolin $\mathrm{K}$ (284), along with 11 known analogs, were identified from the crude extracts of the liquid and solid cultures of the mangrove fungus Aspergillus ustus 094102 [83]. As evaluated by bioassays, compounds 280, 282-284 and the known ophiobolins $\mathrm{K}, \mathrm{G}, \mathrm{O}$, and Q, 6-epi-ophiobolin $\mathrm{K}$, and 21,21-O-dihydro-6-epi-ophiobolin $\mathrm{G}$ displayed potential cytotoxic activity against six HTCLs (G3K, MCF-7, MD-MBA-231, MCF/Adr, A549, and HL-60), with $\mathrm{IC}_{50}$ values ranging from 0.6 to $9.5 \mu \mathrm{M}$ [83]. The structure-activity relationships (SAR) study suggested that the 2,5-dimethoxyl-2H,3H,5H-furan moiety or $\mathrm{H}-6 \beta$ and HO-3 are the pharmacophores responsible for the cytotoxicity against MCF-7 and MCF-7/Adr, while HO-3 and the $\alpha, \beta$-unsaturated aldehyde moiety are important for MD-MBA-231 cytotoxicity, and the 2,5-dimethoxyl $-2 \mathrm{H}, 3 \mathrm{H}, 5 \mathrm{H}$-furan moiety is required for cytotoxicity against $\mathrm{A} 549$ and HL-60 [83].

Chemical investigations of the secondary metabolites of the marine fungus Aspergillus flocculosus, collected from the seaweed Padina sp. in Vietnam, resulted in the identification of five new ophiobolin-type sesterterpenes with a fully unsaturated side chain, 14,15-dehydro-6-epi-ophiobolins $\mathrm{K}$ and G (285 and 286), 14,15-dehydro-ophiobolins K and G (287 and 288), and 14,15-dehydro-(Z)-14ophiobolin G (289), together with four known ophiobolins [84]. All isolated metabolites (compounds 285-289, 6-epi-ophiobolins $C$ and $N$, and ophiobolins $C$ and N) showed potent cytotoxicity against six HTCLs (HCT-15, NUGC-3, NCI-H23, ACHN, PC-3, and MDA-MB-231) $\left(\mathrm{GI}_{50}=0.14-2.01 \mu \mathrm{M}\right)$ [84].

The bioassay and HPLC-UV-guided investigation of the fermentation culture of the mangrove endophytic fungus Aspergillus sp. ZJ-68 led to the identification of 11 new ophiobolin-type sesterterpenoids, asperophiobolins A-K (290-300), together with 12 known analogs, among which asperophiobolins A-D (290-293) were the first examples of a $\gamma$-lactam ring between C-5 and C-21 in ophiobolins [85]. According to the bioactivity assays, compounds 297-299, ophiobolins O, U, and $\mathrm{U}^{\prime}$, and 21-deoxo-21-hydroxy-6-epi-ophiobolin G showed potential inhibitory activity of LPS-induced NO production in RAW 264.7 macrophage cells ( $\mathrm{IC}_{50}=9.6-25 \mu \mathrm{M}$ vs. $38 \mu \mathrm{M}$ for indomethacin), and compounds 291, 293, 294, and 298, ophiobolins G, P, and 21-deoxo-21-hydroxy-6-epi-ophiobolin $\mathrm{G}$ exhibited moderate inhibitory effects on the Mycobacterium tuberculosis (Mtb) protein tyrosine phosphatase B (MptpB) ( $\left(\mathrm{IC}_{50}=24-42 \mu \mathrm{M}\right.$, vs. $22 \mu \mathrm{M}$ for oleanolic acid), particularly 297 , which showed significant anti-MptpB activity $\left(\mathrm{IC}_{50}=19 \mu \mathrm{M}\right)$ [85].

Many new activities were reported for known ophiobolins. Most of ophiobolins show the significant inhibitory activity of tumor cell proliferation and are considered potential antitumor drugs [86]. MHO7 (6-epi-ophiobolin G) can suppress breast cancer cells by downregulating estrogen receptor alpha $(\mathrm{ER} \alpha)$, which acts as a novel estrogen receptor degrader [87]. Further research of MHO7 showed that it is appropriate for oral administration according to the target reproductive organs and influences the metabolic pathways via short-chain fatty acids by regulating the levels of the gut microbiome (Ruminococcaceae and Lachnospiraceae) [88]. Another study was also carried out on the antitumor drug candidate ophiobolin $\mathrm{O}$. The results showed that the compound could exert significant antitumor activity, with little in vivo and in vitro toxicity, by inducing G1 phase arrest in the human breast cancer MCF-7 cells related to the AKT/GSK3//cyclin D1 signaling pathway [89].

Two new unusual 5/3/7/6/5-pentacyclic sesterterpenes (aspterpenacids $A$ and B) (301 and 302) [90] and a new atypical 5/12/6-tricyclic sesterterpene acid (bipolarenic acid, 303) [91] were isolated from the two mangrove fungi (Aspergillus terreus $\mathrm{H} 010$ and Lophiostoma bipolare BCC25910) but were devoid of antibacterial activity or cytotoxicity. 


\subsection{Triterpenes}

Triterpenes (excluded from steroids) are very rare in marine fungi, and only 11 new compounds were discovered in recent years (including three new molecules, 304-306, in 2015-2019, as shown in Figure 21) [7,8].

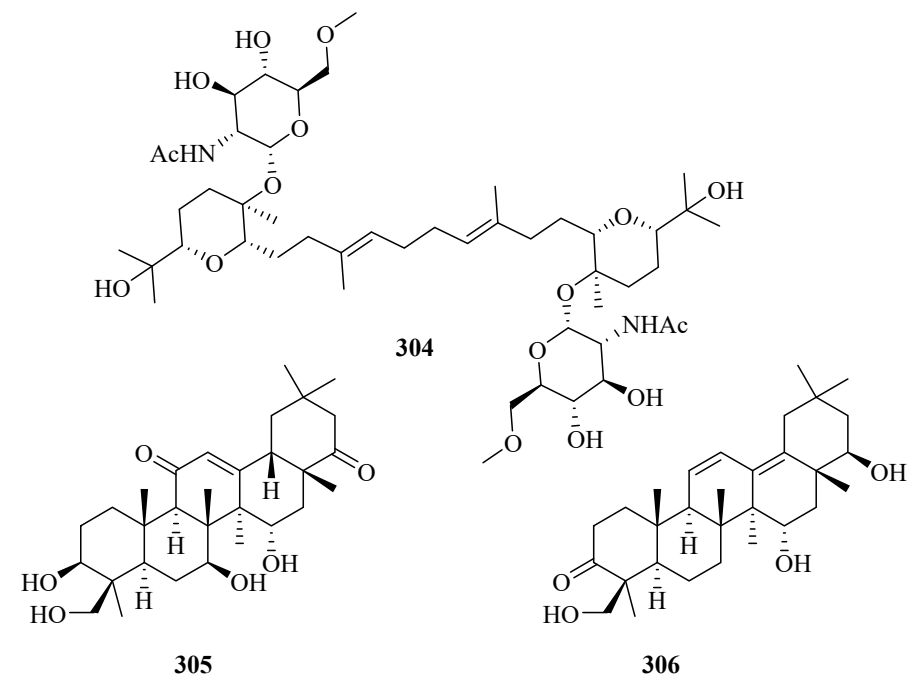

Figure 21. Chemical structures of triterpenes (304-306).

The novel triterpene glycoside, auxarthonoside (304), possessing a rare sugar moiety ( $N$-acetyl-6methoxy-glucosamine) in nature, was reported in the marine sponge-derived fungus Auxarthron reticulatum [92]. The Red Sea hard coral-derived fungus Scopulariopsis sp. yielded two new triterpenoids $(3 \beta, 7 \beta, 15 \alpha, 24$-tetrahydroxyolean-12-ene-11,22-dione and $15 \alpha, 22 \beta, 24$-trihydroxyolean11,13-diene-3-one) (305 and 306) and three known derivatives, $7 \beta, 15 \alpha, 24$-trihydroxyolean-12-ene3,11,22-trione, 15 $\alpha$,24-dihydroxyolean-12-ene-3,11,22-trione, and soyasapogenol B-none of which displayed significant cytotoxic, antibacterial, or antitubercular activities [93].

\subsection{Meroterpenes}

Fungal meroterpenoids can be classed into two major groups according to their biosynthetic origins as polyketide-terpenoids ( $>80 \%$ fungal meroterpenoids, including orsellinic acid, 5 -methylorsellinic acid (5-MOA), and 3,5-dimethylorsellinic acid (DMOA), and 6-methylsalycylic acid (6-MSA) as the polyketide part) and non-polyketide-terpenoids (including indole diterpenoids and shikimate-derived terpenoids, such as tricycloalternarenes). Interesting, these two groups of meroterpenes are found in marine fungi. Simple isopentenyl (C5)-substituted alkaloids, polyketides, peptides, and shikimates, and their derivates, were excluded from this review.

There are 165 novel meroterpenoids (307-471, Figures 22-27). Polyketide-terpenoids (the polyketide part is mainly derived from DMOA) and indole diterpenoids (27, 16.4\%) were largely discovered in marine fungi during the last five years. Penicillium (75, 45.5\%) and Aspergillus $(33,20.0 \%)$ were the principal sources of marine meroterpenoids, though they were also found in 10 other genera of marine fungi (Alternaria, Eupenicillium, Lophiostoma, Mucor, Myrothecium, Neosartorya, Pestalotiopsis, Pleosporales, Stachybotrys, and Talaromyces). These fungi were mainly isolated from living matter $(125,75.8 \%)$, such as marine animals $(66,40.0 \%)$ and aquatic plants $(59,35.8 \%)$, and to a lesser extent, living environments (35, 21.2\%, mainly marine sediments). The most important specific source of fungi was algae (31), followed by sponges (24), mangrove habitats (23), other marine sediments (18), deep-sea sediments (11), mollusks (12), and sea worms (11). According to the bioactivity assessment, $37 \%$ of the new meroterpenoids (98 actives in 265 test compounds) displayed various activities, such as 
enzyme inhibitor activity $(17 \%, 17)$, anti-inflammatory activity $(16 \%, 16)$, lethal toxicity activity $(16 \%, 16)$, antibacterial activity $(15 \%, 15)$, cytotoxicity $(13 \%, 13)$, and antiviral activity $(10 \%, 10)$.<smiles></smiles>

307<smiles>CO[C@H]1CCC2=C(C[C@H]3C(C(C)CCC[C@H](C)COC(C)=O)=CC[C@@]3(C)O2)C1=O</smiles>

311<smiles>CC(CCCC(C)C1=CC[C@]2(C)OC3=C(C[C@H]12)C(=O)CC[C@H]3O)C(=O)O</smiles>

315<smiles>[R]C1C[C@@H](O)C2=C(C[C@H](O)C(C)(C)O2)C1=O</smiles>

$309 \mathrm{R}=\mathrm{H}$ $310 \mathrm{R}=\mathrm{OH}$<smiles>COC(=O)CCC(C)C1=CC[C@]2(C)OC3=C(C[C@H]12)C(=O)CC[C@H]3O</smiles>

312<smiles>CC(CCC(=O)O)C1=CC[C@]2(C)OC3=C(C[C@H]12)C(=O)CC[C@H]3O</smiles>

316<smiles>CC(=O)COC(C)=O</smiles>

$313(2 E)$

314 (2Z)
317

Figure 22. Chemical structures of sesquiterpenes (307-317 from Alternaria sp.). 


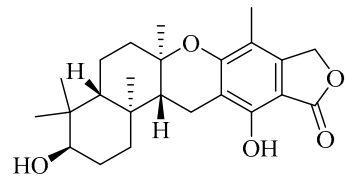

318

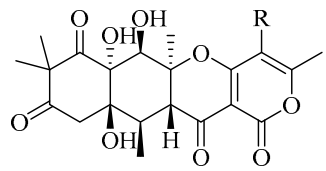

$321 \mathrm{R}=\mathrm{CH}_{3}$

$323 \mathrm{R}=\mathrm{H}$
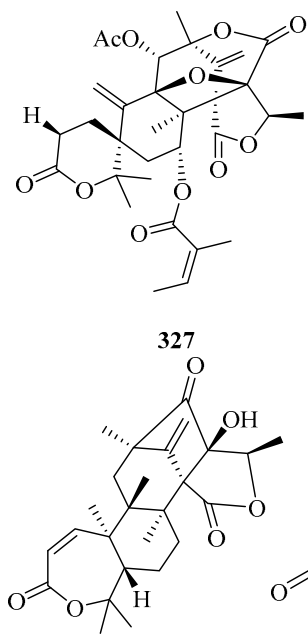

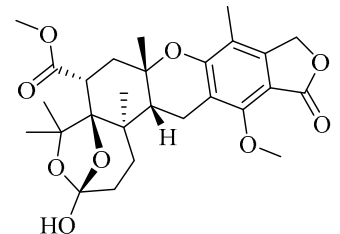

319

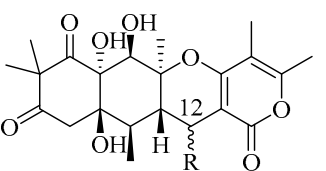

$322 \mathrm{R}=\mathrm{H}$

$324 \mathrm{R}=\mathrm{OH}, 12 \mathrm{R}$

$325 \mathrm{R}=\mathrm{OH}, 12 S$

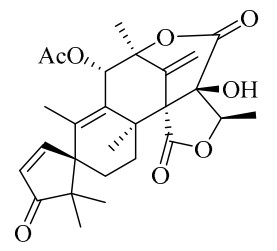

328
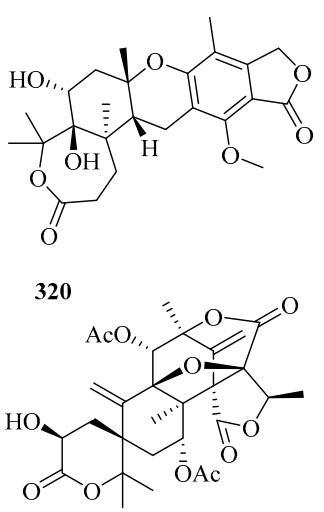

326

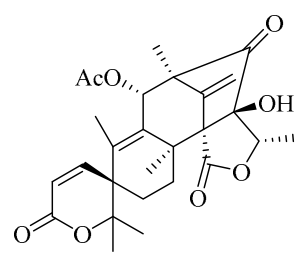

329
330

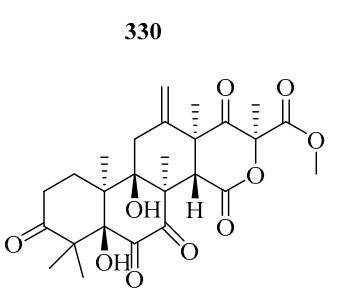

335<smiles>C[C@H](C/C=C/C(C)(C)O)C1=CC[C@H]2OC3=C(C[C@H]12)C(=O)[C@H](O)CC3</smiles>

340

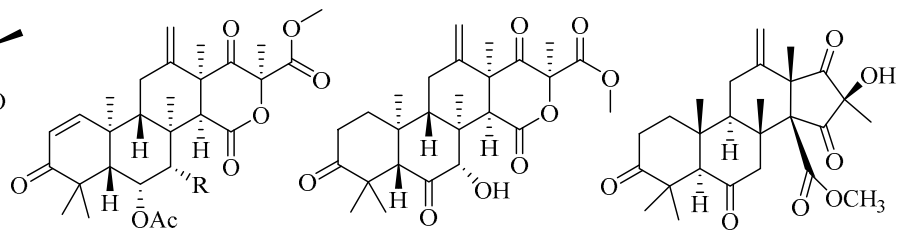

$331 \mathrm{R}=\mathrm{OH}$

$332 \mathrm{R}=\mathrm{H}$

333

$33 \quad 0 \quad 334$

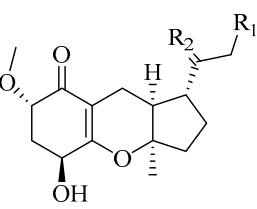

$336 \mathrm{R}_{1}=\mathrm{H}, \mathrm{R}_{2}=\mathrm{O}$ $337 \mathrm{R}_{1}=\mathrm{OH}, \mathrm{R}_{2}=\mathrm{CH}_{2}$

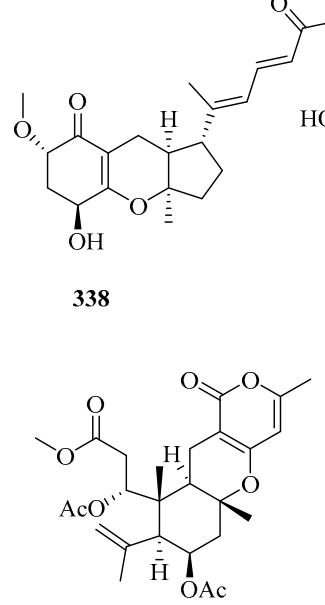

343<smiles>C=C(C)[C@H]1CC[C@]2(C)OC3=C(C[C@H]12)C(=O)[C@H](O)C[C@H]3O</smiles>

339

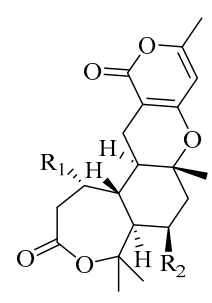

$344 \mathrm{R}_{1}=\mathrm{OH}, \mathrm{R}_{2}=\mathrm{H}$ $345 \mathrm{R}_{1}=\mathrm{OH}, \mathrm{R}_{2}=\mathrm{OAc}$

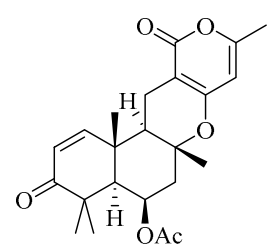

347<smiles>[R]O[R]([H])([H])OC</smiles>

348 $346 \mathrm{R}_{1}=\mathrm{R}_{2}=\mathrm{OAc}$

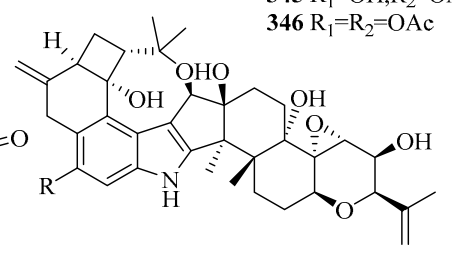

$349 \mathrm{R}=\mathrm{Cl}$

$350 \mathrm{R}=\mathrm{H}$

Figure 23. Chemical structures of meroterpenes (318-350 from Aspergillus sp.). 


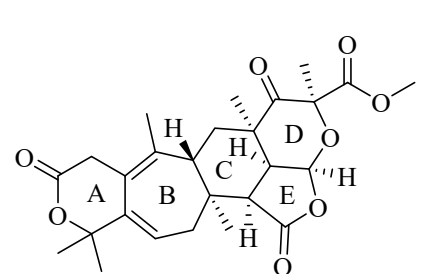

351<smiles>C[C@@H]1C2=CC(=O)OC(C)(C)C2=C[C@H](O)[C@@]2(C)[C@H]1C[C@@]1(C)C(=O)O[C@H]3O[C@H](C)OC3C(=O)[C@H]21</smiles>

$355 \mathrm{O}$

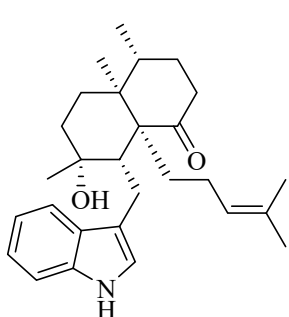

357

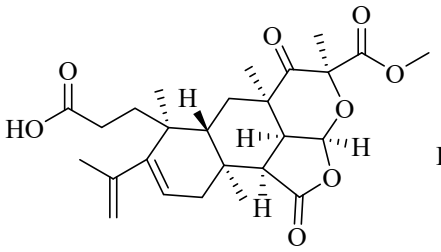

352

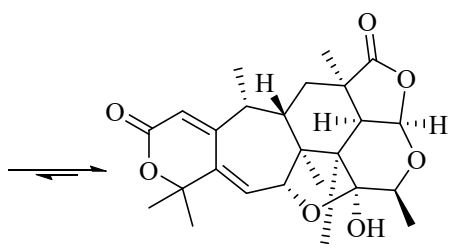

$\mathrm{O}_{\mathrm{O}}$

4-hydroxy-22-deoxyminiolutelide B

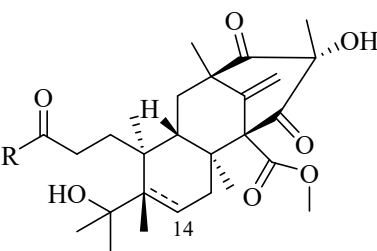

$353 \mathrm{R}=\mathrm{OCH}_{3}$

$354 \mathrm{R}=\mathrm{OH}, \Delta^{14}$

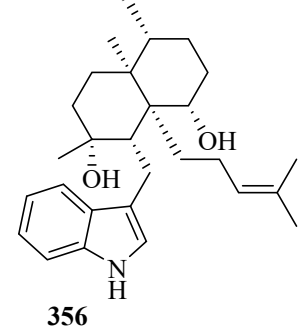

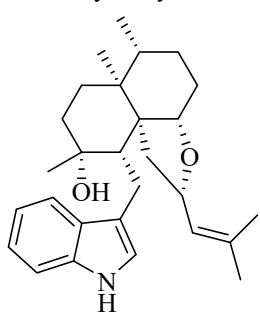

358

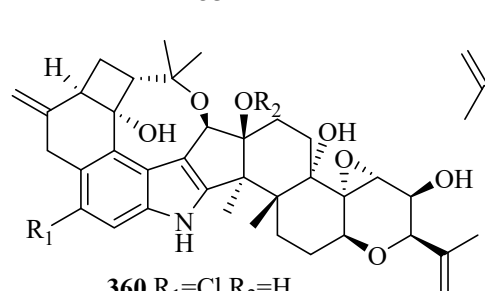

$360 \mathrm{R}_{1}=\mathrm{Cl}, \mathrm{R}_{2}=\mathrm{H}$

$361 \mathrm{R}_{1}=\mathrm{Cl}, \mathrm{R}_{2}=\mathrm{CH}_{3}$

$362 \mathrm{R}_{1}=\mathrm{H}, \mathrm{R}_{2}=\mathrm{CH}_{3}$

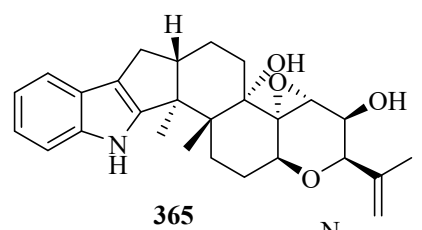

365

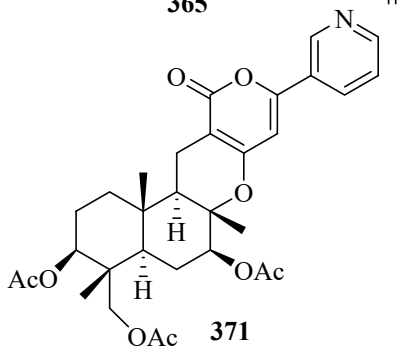

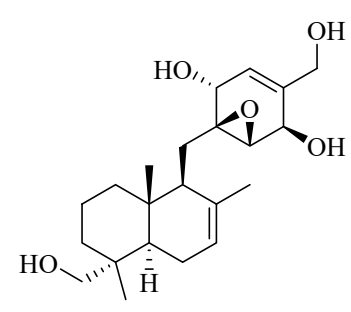

(2)

364

363<smiles>CC(=O)OC[C@@]1(C)C2=Cc3c(cc(-c4ccccc4)oc3=O)O[C@@](C)(COC(C)=O)[C@]2(C)CC[C@@H]1OC(C)=O</smiles>

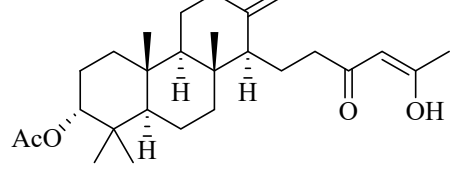

372

Figure 24. Chemical structures of meroterpenes (351-358 from Eupenicillium sp., 359 from Lophiostoma sp., 360-365 from Mucor sp., 366-369 from Myrothecium sp., and 370-372 from Neosartorya sp.). 


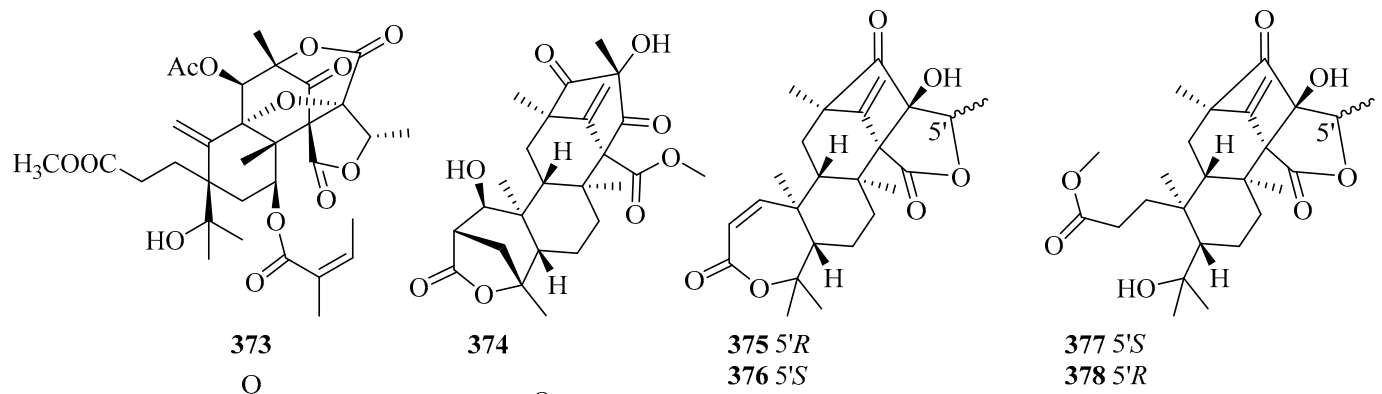

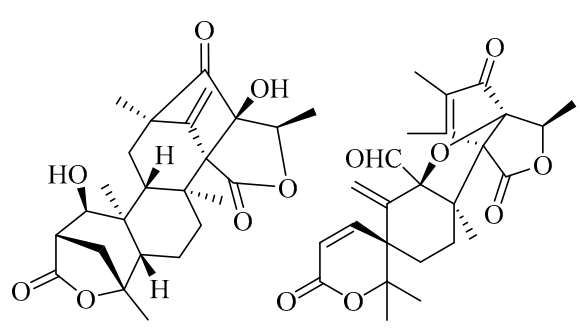

379

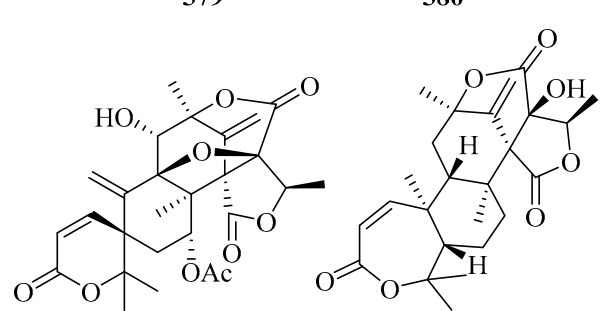

383

384

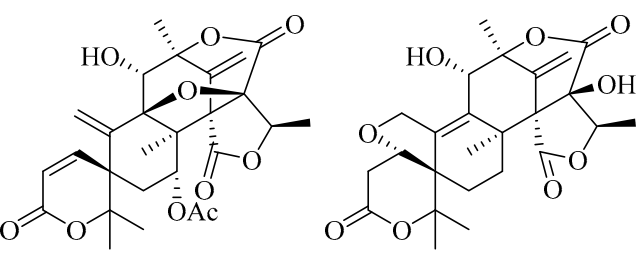

389

388

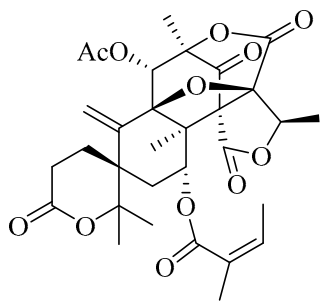

392

393

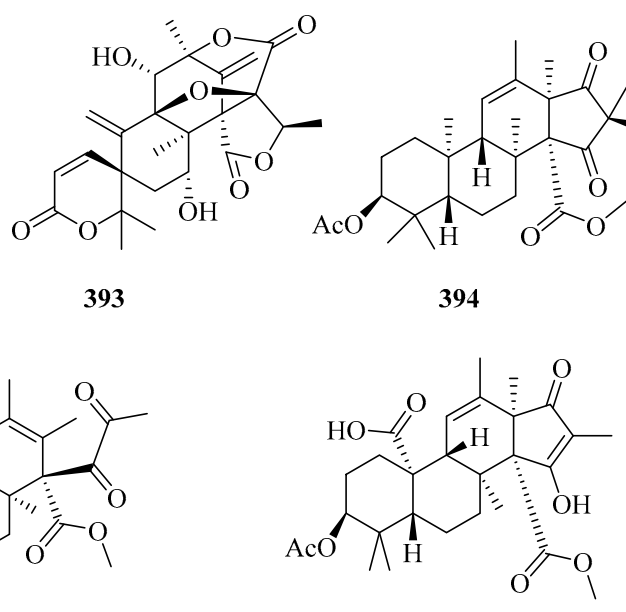

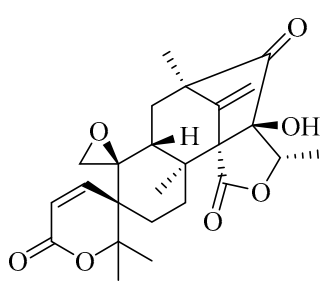

381

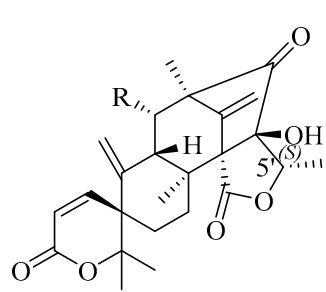

385

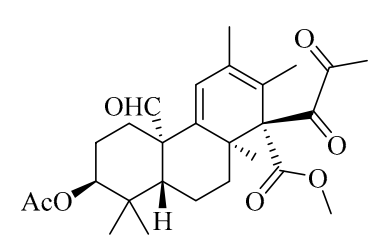

396
397

Figure 25. Cont.

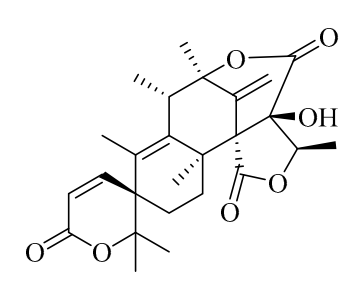

382

3865 ' $S$

$3875 ' R$

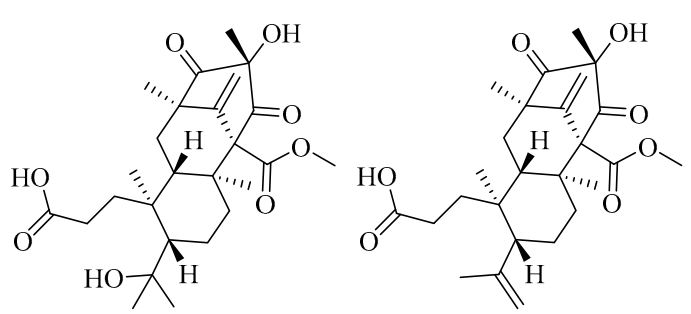

391

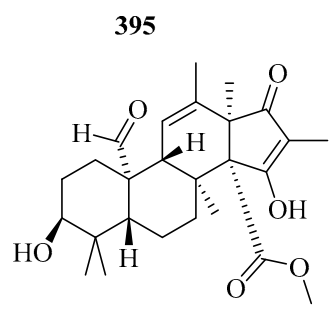

398 

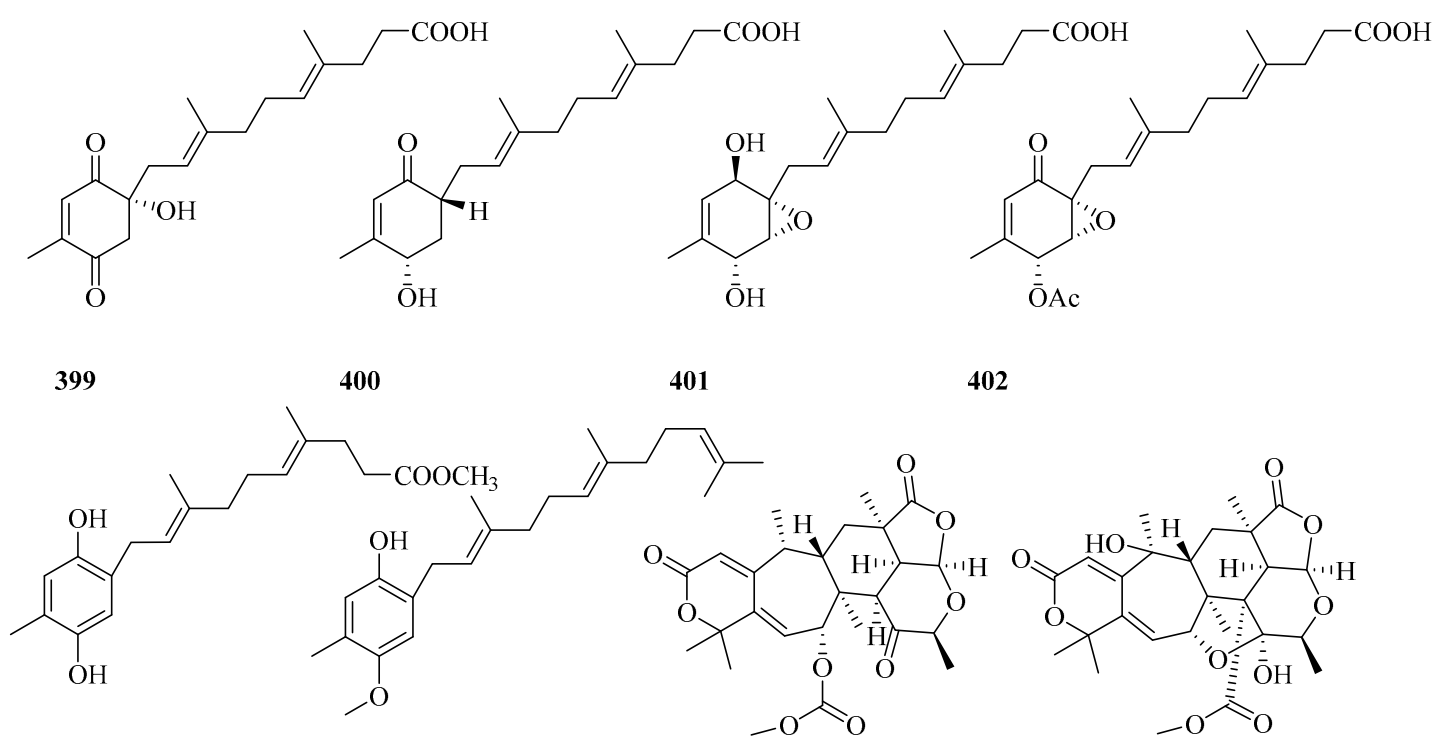

403

404

405

406

Figure 25. Chemical structures of meroterpenes (373-406 from Penicillium sp.).

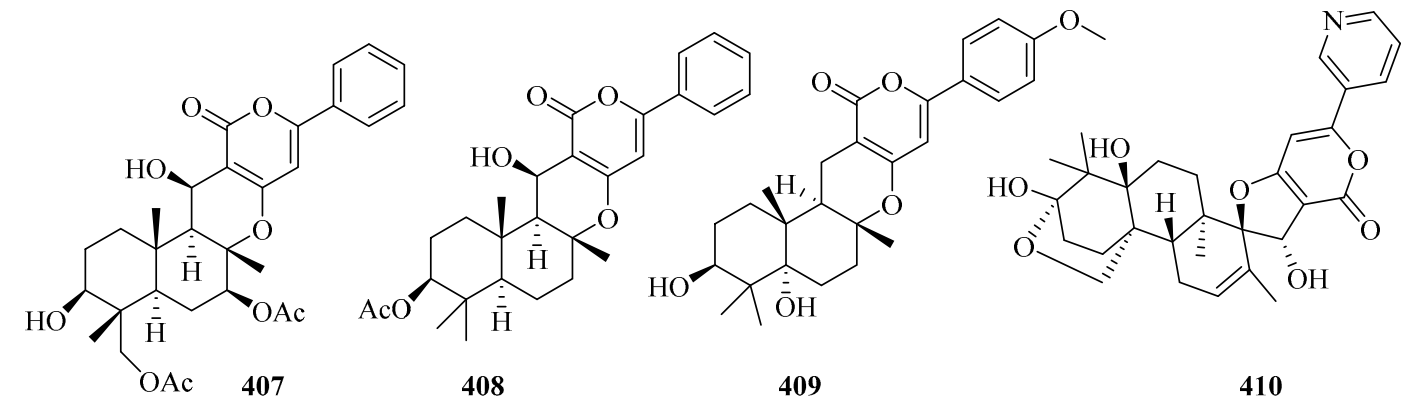

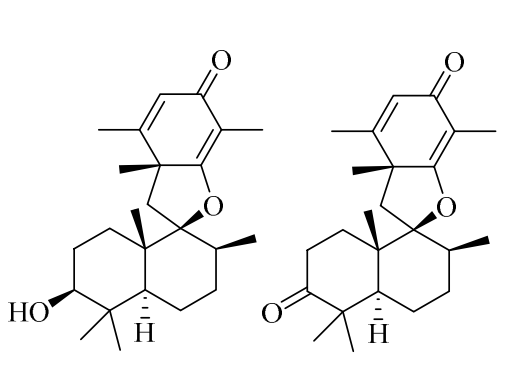<smiles>COC(=O)[C@H]1C(=O)C(C)=C2OC3(C(C)C(O)CC4C(C)(C)C(O)CCC43C)[C@@]2(C)C1C</smiles><smiles>CC1=C2OC3(C(C)CCC4C(C)(C)C(=O)CCC43C)C(C)C2(C)C(C(=O)O)C(=O)C1=O</smiles><smiles>C=C1CCC2C(C)(C)CCCC2(C)C1CC1(O)C(=O)C=C(C)C1=O</smiles>

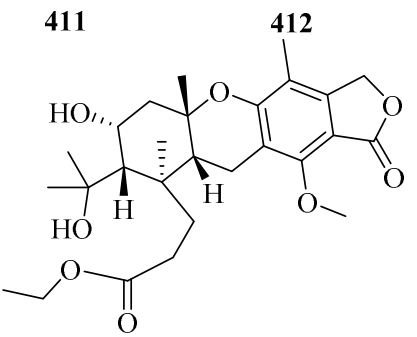

415

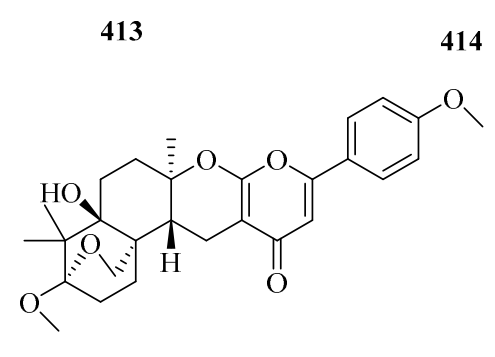

416

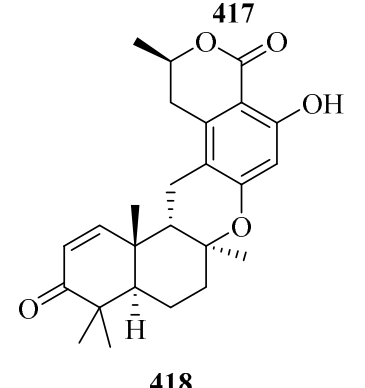

418

Figure 26. Cont. 

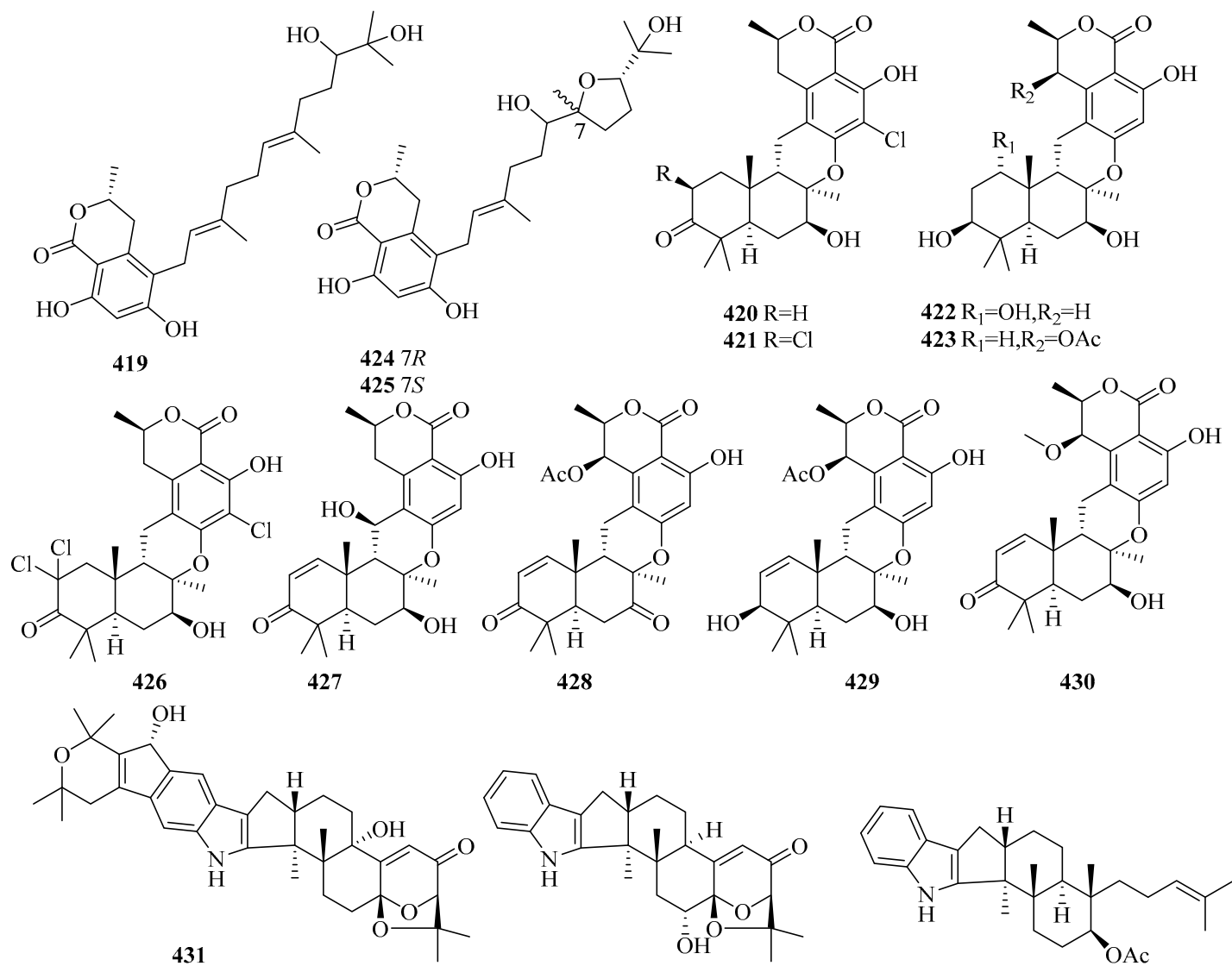
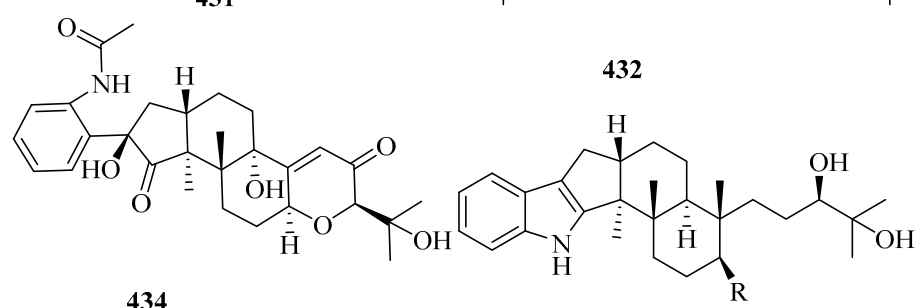

$435 \mathrm{R}=\mathrm{OH}$

$436 \mathrm{R}=\mathrm{OAc}$

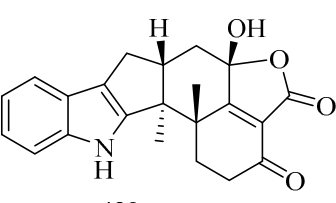

439

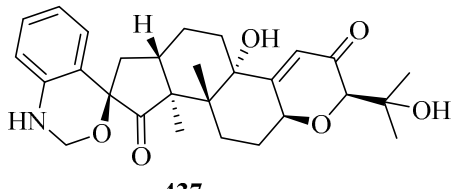

437

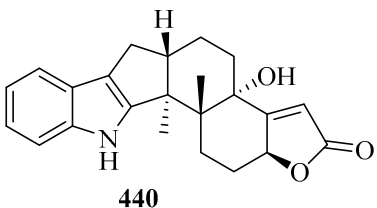

438

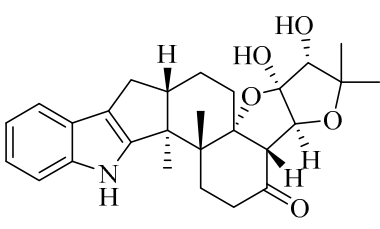

441<smiles>C[C@@]12c3[nH]c4ccccc4c3C[C@H]1CC[C@]1(O)C3=CC(=O)CO[C@@H]3CC[C@@]12C</smiles>

442

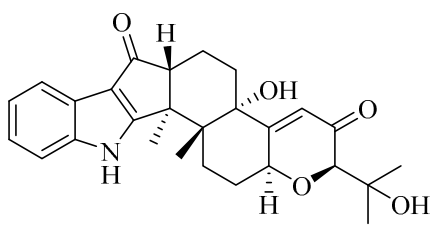

444

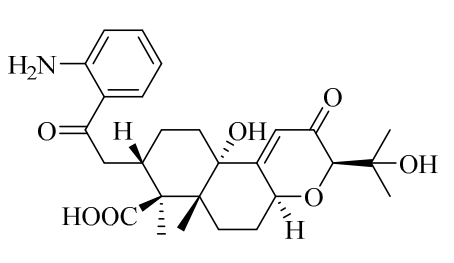

445
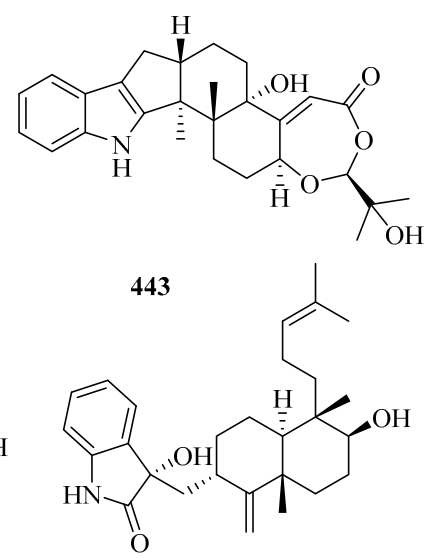

446

Figure 26. Chemical structures of meroterpenes (407-446 from Penicillium sp.). 


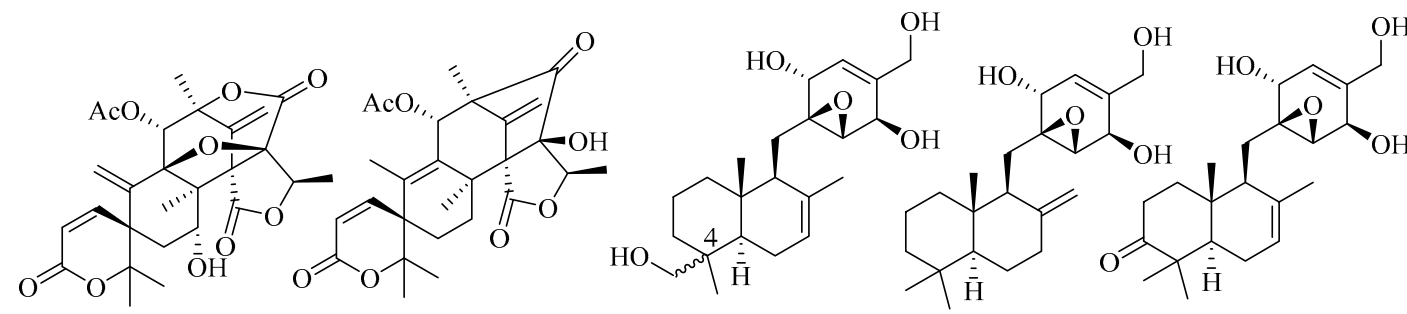

447

$448 \quad 4494 S$

451

452

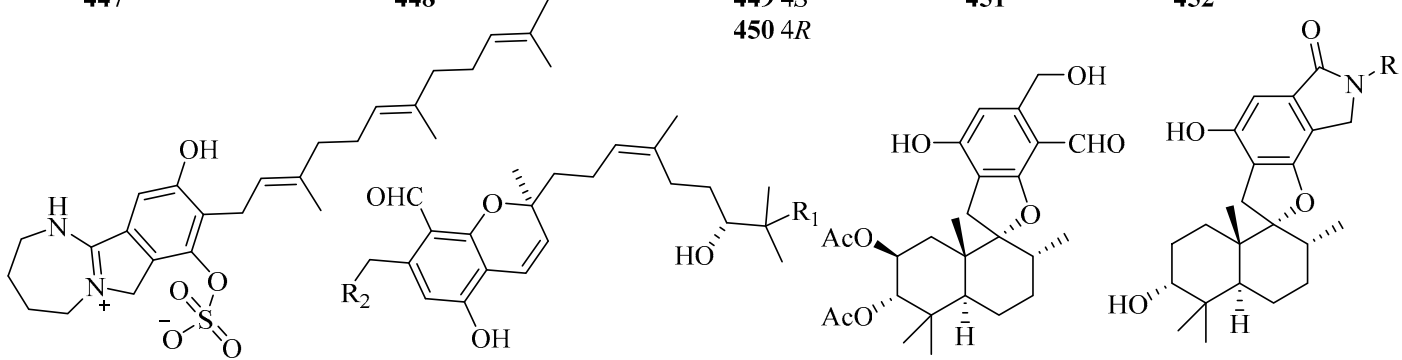

453

$454 \mathrm{R}_{1}=\mathrm{OCH}_{3}, \mathrm{R}_{2}=\mathrm{OAc}$

$455 \mathrm{R}_{1}=\mathrm{OH}, \mathrm{R}_{2}=\mathrm{OAc}$

$457 \quad 458 \mathrm{R}=\mathrm{CH}_{2} \mathrm{COOCH}_{3}$

$456 \mathrm{R}_{1}=\mathrm{OH}, \mathrm{R}_{2}=\mathrm{H}$

$459 \mathrm{R}=\mathrm{CH}_{2} \mathrm{CH}_{2} \mathrm{CH}_{2} \mathrm{COOCH}_{3}$

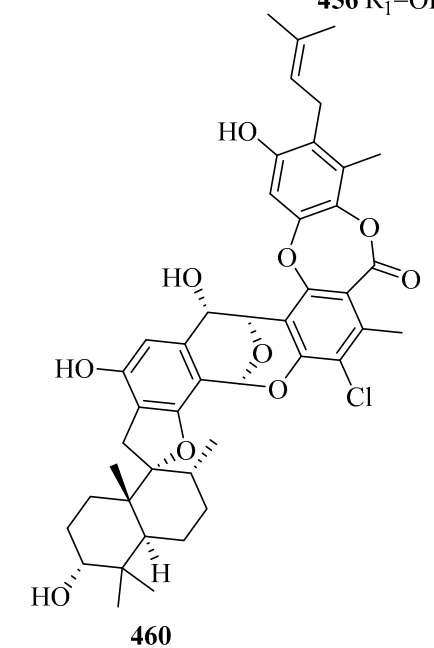

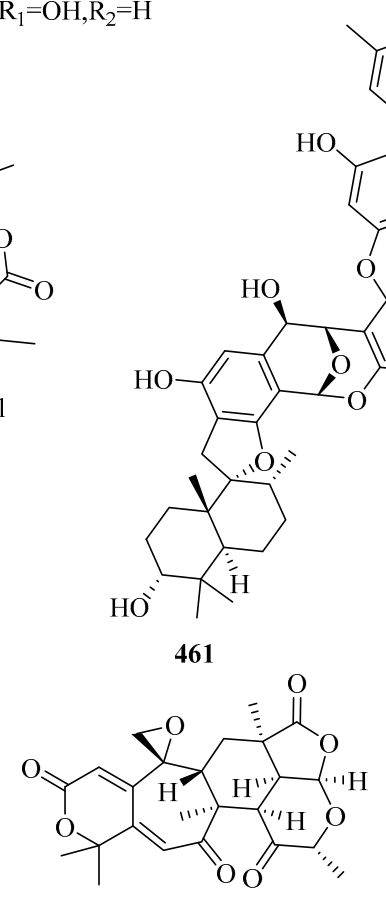

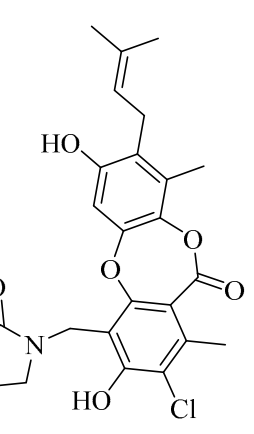

$\mathrm{Cl}$

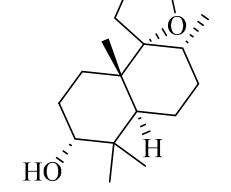

462

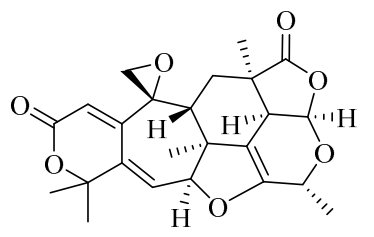

463

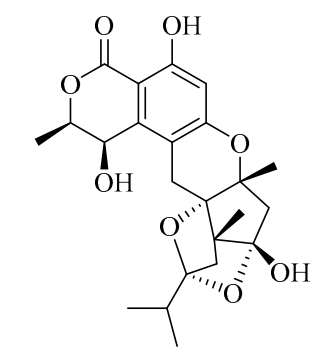

467
464

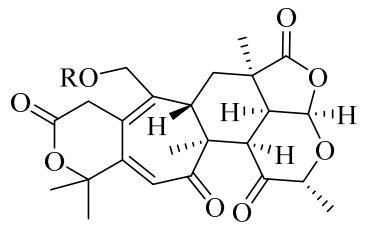

$465 \mathrm{R}=\mathrm{Ac}$

$466 \mathrm{R}=\mathrm{COCH}_{2} \mathrm{CH}\left(\mathrm{CH}_{3}\right)_{2}$

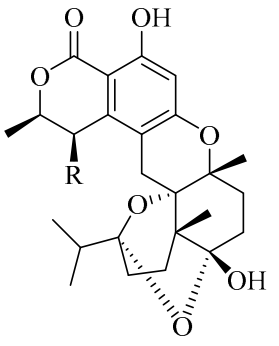

$468 \mathrm{R}=\mathrm{OH}$ $469 \mathrm{R}=\mathrm{H}$

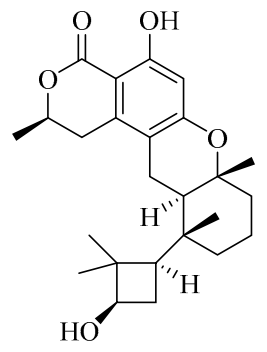

470

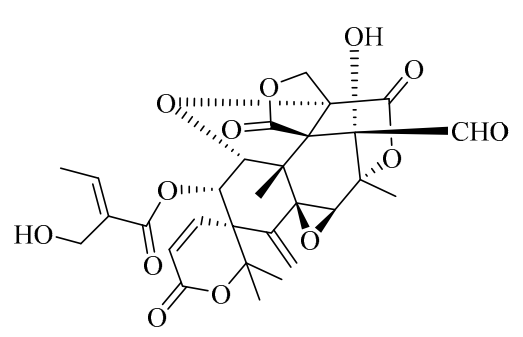

471

Figure 27. Chemical structures of meroterpenes (447-448 from Pestalotiopsis sp., 449-452 from Pleosporales sp., 453-462 from Stachybotrys sp., and 463-471 from Talaromyces sp.). 


\subsubsection{Alternaria sp.}

Eight new tricycloalternarene (TCA)-type meroterpenes, tricycloalterfurenes A-D (307-310) [80], 17-O-methyltricycloalternarene $\mathrm{D}$, and methyl nortricycloalternarate (311 and 312) [94]; (2E)-TCA 12a and (2Z)-TCA 12a (313 and 314) [95]; and four known congeners, TCAs F, D, 1b, and 11a, were isolated from the cultures of two marine red alga-epiphytic fungi Alternaria alternate (k21-1 and k23-3). These compounds showed weak or moderate inhibition of marine plankton species. Among them, compounds 307-310 possessed a rare tetrahydrofuran ring in TCAs [80]. Two new TCA acids (tricycloalternarenes $\mathrm{K}$ and L) (315 and 316) [96] and a new TCA ester (2H-(2E)-tricycloalternarene 12a, 317) [97] and six known derivatives were discovered from two fungal strains, Alternaria alternata ICD5-11, associated with marine isopod Ligia exotica, and Alternaria sp. W-1, derived from Laminaria japonica, respectively. In the bioassay experiments, compound 317 and TCA-3a exhibited weak cytotoxicity against SMMC-7721 cells in a dose-dependent manner $\left(\mathrm{IC}_{50}=49.7,45.8 \mu \mathrm{g} / \mathrm{mL}\right)$ [97]. Further studies revealed that the anticancer mechanism of TCA-3a is related to cell cycle arrest in the G1 phase, and that induction of apoptosis involved two pathways (mitochondrial and death receptor pathways) [97].

\subsubsection{Aspergillus sp.}

Three new austalide-type meroterpenoids, austalides S-U (318-320), were purified and identified from the sponge-derived fungus Aspergillus aureolatus HDN14-107, among which 318 possesses a 5/6/6/6/6-pentacyclic ring system with the trans configuration of C-11 [98]. Only compound 318 exhibited marked inhibitory effects of anti-influenza virus A (H1N1) activity with $\mathrm{IC}_{50}$ values of $90 \mu \mathrm{M}$ (ribavirin, $\mathrm{IC}_{50} 102 \mu \mathrm{M}$ ) but without cytotoxicity $\left(\mathrm{IC}_{50}>50 \mu \mathrm{M}\right)$ [98].

The marine algal-associated fungus Aspergillus sp. ZL0-1b14 yielded four new highly oxygenated putative triketide-sesquiterpenoid drimane-type meroterpenes, aspertetranones A-D (321-324), featuring an unusual skeleton rearrangement in the terpenoid part [99]. Using LPS-stimulated RAW264.7 as the anti-inflammatory cell model, compounds $\mathbf{3 2 1}$ and 324 inhibited the production of IL- 6 and IL- $1 \beta$ in a dose-dependent manner (43\%/42\% and $69 \% / 47 \%$ inhibition rates of IL-6/IL- $1 \beta$ at $40 \mu \mathrm{M}$, respectively), while compounds 322 and 323 only showed weak inhibitory effects [99]. A new enantiomer of compound 324, 12-epi-aspertetranone D (325), was isolated from marine sediment-derived Aspergillus flocculosus and showed $41 \%$ inhibition against the colony formation of 22Rv1 prostate cancer cells at $100 \mu \mathrm{M}$ but without cytotoxicity [100].

The chemical investigation of the mangrove endophytic fungus Aspergillus sp. 16-5c led to the isolation of ten DMOA-derived austin-type meroterpenoids, including the novel 2-hydroacetoxydehydroaustin (326) [101]. The stereochemistry configurations of known compounds, preaustinoid A2, isoaustinol, dehydroaustin, and dehydroaustinol, were first determined by XRD, and the latter three molecules displayed anti-acetylcholinesterase (anti-AchE) activity $\left(\mathrm{IC}_{50}=0.4 \sim 3 \mu \mathrm{M}\right)$ [101]. An unusual austinoid, 1,2-dehydro-terredehydroaustin (327), from the mangrove-derived fungus Aspergillus terreus H010, showed weak anti-inflammatory (NO) effects in RAW 246.7 cells $\left(\mathrm{IC}_{50}\right.$ $42.3 \mu \mathrm{M}$ vs. $30.7 \mu \mathrm{M}$ for indomethacin) [102]. The marine endophytic fungus of the brown alga, Aspergillus sp. ZYH026, was able to yield structurally diverse DMOA-derived meroterpenoids, including three new asperaustins A-C (328-330), and the stereostructures of the known austinoneol $\mathrm{A}$ and precalidodehydroaustin were ascertained [103]. Compound 328 possesses a special spiro[4.5]deca-3,6-dien-2-one unit with an unusual 5/6/6/6/5 pentacyclic skeleton; 329 and 330 feature a spiro-lactone core and a heptatomic lactone ring, respectively [103]. None of these compounds showed AChE inhibitory activity [103].

Terretonins, a group of polyoxygenated meroterpenoids mostly possessing the same unique tetracyclic scaffolds and primarily isolated from the Aspergillus genus, are derived from DMOA and farnesyl pyrophosphate (FPP) [104]. Three new terretonins with a reversed orientation at H-14, terretonins H and I (331 and 332) [105], along with terretonin D1 (333) [106] were obtained from the marine sediment-derived fungus Aspergillus ustus KMM 4664 and the marine fungus Aspergillus terreus EN-539 associated with the fresh gut of pacific oyster, respectively. Compounds 331 and 332 displayed 
weak inhibition of fertilized sea urchin eggs [105], and 333 was weakly anti-inflammatory (NO) in RAW264.7 cells [106]. In an alternative study, two new terretonin derivatives, aperterpenes $N$ (334) and $\mathrm{O}$ (335), and two known analogs were reported in the marine algal-derived fungus Aspergillus terreus EN-539, among which the stereostructures of the known terretonins A and G were first established by XRD [107]. Compound 334 exhibited inhibitory effects in influenza neuraminidase $\left(\mathrm{IC}_{50}=18.0 \mathrm{nM}\right.$ vs. $3.2 \mathrm{nM}$ for oseltamivir), and terretonin G displayed weak inhibition of Micrococcus luteus and Staphylococcus aureus growth (MIC $=8-32 \mu \mathrm{g} / \mathrm{mL}$ vs. $1.0 \mu \mathrm{g} / \mathrm{mL}$ for chloramphenicol) [107].

Five new TCA-type meroterpenoids, guignardones J-M (336-339) [108] and tricycloalternarene 14b (340) [109], along with eight known analogs, were isolated and identified from the mangrove endophytic fungus Aspergillus flavipes AIL8 and one symbiotic strain, Aspergillus sp. D, from the coastal plant Edgeworthia chrysantha Lindl. Only 340 possessed weak antimicrobial effects on three human pathogenic strains (Escherichia coli, Staphylococcus aureus, and Candida albicans) (MIC $\geq 15.63 \mu \mathrm{M}$ ) and moderate cytotoxic effects against A-549 cells $\left(\mathrm{IC}_{50}=8.89 \mu \mathrm{M}\right)$ [109].

Two previously undescribed pyrone meroterpenoids featuring an uncommon 5/6/6/6- tetracyclic skeleton with a tetrahydrofuran ring, asperversins $\mathrm{A}$ (341) and $\mathrm{B}$ (342), together with five new derivatives (asperversins C-G, 343-347) and a known asperdemin, were obtained from the marine sediment-derived fungus Aspergillus versicolor [110]. After assessing the inhibitory activity of acetylcholinesterase enzyme (AChE) and the cytotoxicity of all metabolites, only 347 displayed a moderate anti-AChE effect $\left(\mathrm{IC}_{50}=13.6 \mu \mathrm{M}\right.$ vs. $3.57 \mu \mathrm{M}$ for galanthamine) [110].

An unusual stress metabolite induced by $\mathrm{Co}$, aspergstressin (348), possessing a unique fused polycyclic structure, was isolated from the culture broth of the fungus Aspergillus sp. WU 243, collected from a crab dwelling in heavy metal-rich hydrothermal vents [111].

Two new indole diterpenoids, 19-hydroxypenitrem A (349) with Cl-substitution and 19-hydroxypenitrem E (350), were sourced from the cultures of the endophytic fungus Aspergillus nidulans EN-330 collected from marine red alga Polysiphonia scopulorum var. villum [112]. Compounds 349-350 exhibited potent brine shrimp cytotoxic activity $\left(\mathrm{LD}_{50}=3.2-4.6 \mu \mathrm{M}\right.$ vs. $10.7 \mu \mathrm{M}$ for colchicine) [112], and compound 349 showed moderate antimicrobial activity against four human-pathogens (Edwardsiella tarda and Vibrio anguillarum) and aqua-pathogens (Escherichia coli and Staphylococcus aureus) (MIC $=16-32 \mu \mathrm{g} / \mathrm{mL}$ ), while 350 had weak antibacterial activity against two bacteria (E. tarda and E. coli) [112]. The above SAR experiments suggest that Cl-substitution at C-6 enhanced the cytotoxicity of brine shrimp and antimicrobial activity, while 19-OH substitution diminished this activity [112].

\subsubsection{Eupenicillium sp.}

The LC-MS and ${ }^{1} \mathrm{H}$ NMR-based investigation of the fermentation culture of the marine sponge-associated fungus Eupenicillium sp. 6A-9 resulted in the discovery of ten meroterpenoids, including two rare 6(D)/5(E) ring-fused DMOA-related meroterpenoids, eupeniacetal A (351) and eupeniacetal B (352), and three new meroterpenoids, 1-methoxy-hydropreaustinoid A1 (353), hydroberkeleyone B (354), and 22-deoxy-10-oxominiolutelide B (355) [113]. Compound 355 and the known 22-deoxy-miniolutelide B exist as an equilibrium mixture [113]. All tested compounds (351-355) showed dramatic immune-suppressive activity towards TNF- $\alpha$ production in the LPS-induced THP-1 cell line ( $\mathrm{IC}_{50}=22.6-43.1 \mu \mathrm{M}$ vs. $0.23 \mu \mathrm{M}$ for pomalidomide) but were inactive against HTCLs and pathogenic bacteria [113].

The cytotoxicity-guided investigation of the fermented crude extract of Eupenicillium sp. HJ002, an endophytic fungus of mangrove, yielded three new indole diterpenes, penicilindoles $\mathrm{A}-\mathrm{C}$ (356-358) [114]. Compounds 356 and 357 were cytotoxic towards three HTCLs (A549, HeLa, and HepG2) $\left(\mathrm{IC}_{50}=1.5-47.2 \mu \mathrm{M}\right)$, among which 356 showed potential cytotoxicity against A549 and HepG2 $\left(\mathrm{IC}_{50}=5.5\right.$ and $1.5 \mu \mathrm{M}$, respectively) [114]. 


\subsubsection{Lophiostoma sp.}

One new merosesquiterpenoid, craterellin D (359), and a known analog craterellin A were isolated from a soft coral-derived fungus, Lophiostoma sp. ZJ-2008011, from which the absolute configuration of craterellin A was first determined [115]. In the bioassays of 359, craterellin A, and the acetonide and acetylation products of craterellin A, only craterellin A showed moderate antibacterial activity against Bacillus cereus, Escherichia coli, Staphylococcus aureus, and Micrococcus luteus (MIC = 3.12-6.25 $\mu \mathrm{M}$ ), indicating that the $\mathrm{OH}$ in the hydroquinone scaffold may decrease antibacterial activity [115].

\subsubsection{Mucor sp.}

The genome mining-aided chemical investigation of the mangrove fungus Mucor irregularis QEN-189 resulted in the isolation of 20 structurally diverse indole diterpenes, including six novel compounds, rhizovarins A-F (360-365) [116]. Compounds 360-362 were elucidated as an unusual 4,6,6,8,5,6,6,6,6-fused indole diterpene moiety scaffold, including the rarely observed acetal connected to hemiketal (360) or ketal (361 and 362) functionality [116]. Compounds 360 and 361, penitrems A, C, and $\mathrm{F}$; and 3b-hydroxy-4b-desoxypaxilline (a paxilline-type indole diterpene) showed activity against two HTCLs (A-549 and HL-60) ( $\left.\mathrm{IC}_{50}=2.6-11.5 \mu \mathrm{M}\right)$, while compound 364 exhibited activity only against $\mathrm{A}-549\left(\mathrm{IC}_{50}=9.2 \mu \mathrm{M}\right)$, implying that chlorine substitution might be required for the cytotoxicity of these target cells [116].

\subsubsection{Myrothecium sp.}

Studies of the fungus Myrothecium sp. OUCMDZ-2784 associated with the salt-resistant medicinal plant, Apocynum venetum (Apocynaceae) (the estuary of Yellow River, China), afforded four new meroterpenoids, myrothecisins A-D (366-369), which displayed a weak $\alpha$-glucosidase inhibitory effect $\left(\mathrm{IC}_{50}=0.50,0.66,0.058\right.$, and $0.20 \mathrm{mM}$ vs. $0.47 \mathrm{mM}$ for acarbose $)$ [117].

\subsubsection{Neosartorya sp.}

Bioactivity-guided isolation of the fermentation metabolites of the marine fungus Neosartorya pseudofischeri, which was separated from the inner tissue of the starfish Acanthaster planci, yielded two new meroterpenes, 5-olefin phenylpyropene A (370) and 13-dehydroxylpyripyropene A (371), together with four known analogs, phenylpyropene $A$ and $C$, pyripyropene $A$, and 7-deacetylpyripyropene A [118]. The six isolated compounds showed obvious cytotoxicity towards the insect cell line Sf 9 (the fatality rate was $85.2-95.0 \%$ after $48 \mathrm{~h}$ of compound treatment at $50 \mathrm{mg} / \mathrm{L}$ ) [118]. From the crude secondary metabolite extract of the algicolous fungus Neosartorya takakii KUFC 7898 collected from marine algal Amphiroa sp. (Samaesarn Island, Thailand), a new triketide-type meroditerpene, sartorenol (372), was obtained, though 372 lacked antibacterial activity and quorum-sensing inhibition [119].

\subsubsection{Penicillium sp.}

In the antibiotic screening experiments, a new metabolite-austinone (373) and six known austin derivatives were discovered from the fungi Penicillium sp. Y-5-2 collected from the sediment of a hydrothermal vent (Kueishantao, Taiwan, China) [120].

Based on the fungal genome cluster analysis, a sponge-associated fungus strain, Penicillium brasilianum WZXY-m122-9, was selected to search for diverse and novel meroterpenoids because of the highly similar aus' clusters. Twelve new DMOA-related meroterpenoids, brasilianoids A-F (374-379) [121] and G-L (380-385) [122], and 12 known analogs, were disclosed. Notably, brasilianoids $A$ (374) and F (378), possessing an unprecedented motif with a $\gamma$-lactone in ring A; brasilianoids B-C (376-376), bearing a 7/6/6/5/5-pentacyclic skeleton [121]; brasilianoid G (380), characterized by a rare 6/6/5/5/5 pentacyclic scaffold; and brasilianoid $\mathrm{K}(\mathbf{3 8 4})$, featuring an uncommon $7 / 6 / 6 / 6 / 5$ pentacyclic system [122] were first reported in nature. Compound 374 significantly promoted the expression of filaggrin and caspase-14 in HaCaT cells in a dose-dependent manner 
without cytotoxicity, suggesting that it could be used to reduce UVB-induced cell damage, while compounds $\mathbf{3 7 5}$ and $\mathbf{3 7 6}$ showed moderate anti-inflammatory activity (NO) in RAW 264.7 cells $\left(\mathrm{IC}_{50}=37.69 / 33.76 \mu \mathrm{M}\right)$ [121]. Compounds 376-378 displayed very weak antiviral (HBV) activity [121]. After testing for multiple activities (including cytotoxicity and antibacterial activity), the compounds brasilianoid L (385), austinol, and dehydroaustin (three different scaffolds) were all found to significantly inhibit bacteria-infected host cells by preventing the polymerization of actin in RAW264.7 [122].

A pair of new epimeric austin-type pentacyclic lactones, preaustinoids $\mathrm{E}(386)$ and $\mathrm{F}(387)$, were reported in the marine sediment-derived fungus, Penicillium sp. FCH061 (Chuja-do, Korea), but were devoid of cytotoxicity and antimicrobial or enzyme inhibitory activity [123]. The ${ }^{1} \mathrm{H}$ NMR facilitated the isolation of marine fungal Penicillium sp. SF-5497 (sea sand, Gijang-gun, Busan, Korea), which led to the obtaining four new DMOA-derived meroterpenoids, furanoaustinol and 7-acetoxydehydroaustinol (388 and 389) [124], and the preaustinoids A6 and A7 (390 and 391) [125] together with 11 known derivatives. Furanoaustinol (388) possesses an extra tetrahydrofuran ring that forms an uncommon hexacyclic austin skeleton [124]. Compounds 388 and 390 and berkeleyone $C$ showed weak or moderate dose-dependent anti-PTP1B activity $\left(\mathrm{IC}_{50}=77.2,17.6,58.4 \mu \mathrm{M}\right.$, respectively) $[124,125]$, and 389 weakly inhibited the overproduction of NO in LPS-induced BV2 microglial cells with an $\mathrm{IC}_{50}$ value of $61.0 \mu \mathrm{M}$ [124]. Two new DMOA-type meroterpenoids, penicianstinoids A and B (392 and 393), together with seven known analogs were uncovered from the mangrove endophytic fungus Penicillium sp. TGM112, among which 392 possesses a rare carbonyl group at C-1'-C-2' in the austinoids [126]. Moreover, the stereostructures of furanoaustinol (388) and 1,2-dihydro-7-hydroxydehydroaustin were reported [126]. Compounds 392 and 393, austinol, and austin displayed toxicity against newly hatched larvae of Helicoverpa armigera Hubner $\left(\mathrm{IC}_{50}=50-200 \mu \mathrm{g} / \mathrm{mL}\right.$ vs. $25 \mu \mathrm{g} / \mathrm{mL}$ for azadirachtin), and compounds 392, 393, 7-hydroxydehydroaustin, and dehydroaustinol showed inhibition against Caenorhabditis elegans ( $\mathrm{EC}_{50}=9.4-38.2 \mu \mathrm{g} / \mathrm{mL}$ vs. $4.8 \mu \mathrm{g} / \mathrm{mL}$ for levamisole) [126].

From the deep-sea-derived fungus Penicillium allii-sativi (deep seawater, western Pacific), we isolated two new tetraketide-type merosesquiterpenes, andrastone A (394) and 16-epi-citreohybriddione A (395), and the already known citreohybriddione A (confirmed by XRD), among which 394 was a rare andrastin possessing an unusual cyclopentan-1,3-dione without the lactone moiety at C-23 [127]. Compound 394 displayed significant selective antiproliferative effects against HepG2 $\left(\mathrm{IC}_{50}=7.8 \mu \mathrm{M}\right)$ by direct caspase-8-mediated caspase- 3 activation and regulating the RXR $\alpha$ pathways to induce apoptosis [127]. An analysis of the chemical pharmaceutical ingredient of fungal Penicillium simplicissimum MA-332, collected from the rhizospheric soil of the marine mangrove plant Bruguiera sexangula var. rhynchopetala, resulted in a new DMOA-type meroterpenoid, simpterpenoid (396), which is characterized by a highly functionalized cyclohexadiene motif bearing gem-propane-1,2-dione and methylformate groups [128]. Compound 396 showed significant influenza neuraminidase inhibitory activity at a nanomolar scale ( $\mathrm{IC}_{50}=8.1 \mathrm{nM}$ vs. $3.2 \mathrm{nM}$ for oseltamivir ) and weak or absent antimicrobial activities (MIC $\geq 64 \mu \mathrm{g} / \mathrm{mL}$ ) [128].

Citreohybridonol was re-isolated from the sponge-derived fungus Penicillium atrovenetum and found by NMR to exist as a keto-enol equilibrium tautomer in the solvent [129]. Then, the structure was assigned with the Flack parameter 0.06(3) in X-ray crystallography [129]. Citreohybridonol, re-obtained from the sponge-derived fungus Toxicocladosporium sp. SF-5699, was able to inhibit the production of NO and PGE2 and the expression of iNOS, COX-2, and other pro-inflammatory cytokines, including IL-1 $\beta$ and TNF- $\alpha$, in the LPS-stimulated BV2 cells [130]. Further experiments demonstrated that citreohybridonol displayed anti-neuroinflammatory activity involved in regulating the TLR4/ MyD88-mediated NF- $\kappa$ B and p38/MAPK inflammatory pathways [130].

Two new DMOA-derived meroterpenoids (15-deacetylated citreohybridone $\mathrm{E}$ and 3-deacetylated andrastin A) (397 and 398) [11], featuring a rare 23-aldehyde or 23-carboxylic acid group, and four new farnesylcyclohexenones (peniginsengins B-E, 399-402) [131], possessing a highly oxygenated 1-methylcyclohexene (ambuic acid derivatives) unit linked with a farnesyl-derived carboxylic acid (C12) side chain rarely found in nature, and seven known analogs, were isolated from the deep-sea 
fungus Penicillium sp. YPGA11. Bioassays showed that 400-402 possessed moderate activity toward methicillin-sensitive Staphylococcus aureus (MIC $=8-32 \mu \mathrm{g} / \mathrm{mL}$ ), while 400 and 402 exhibited an effect against methicillin-resistant $S$. aureus with MIC values of 32 and $64 \mu \mathrm{g} / \mathrm{mL}$ [131]. In another study, six farnesyl meroterpenes, including two new meroterpenoids, chrysogenester (403) and 5-farnesyl-2-methyl-1-O-methylhydroquinone (404), were observed in the jellyfish-derived fungus Penicillium chrysogenum J08NF-4 [132]. Interestingly, 403 was able to suppress the in vitro inflammatory response by participating in the peroxidase proliferator-activated receptor (PPAR $-\gamma$ )/NF- $\kappa$ B signalling pathway [132].

The combined chemical analysis strategies of HPLC-HRMS-based hierarchical clustering analysis (HCA) and MS/MS molecular networking were used to isolate the metabolites of the marine fungus Penicillium ubiquetum MMS330 from the blue mussel Mytilus edulis (Loire estuary, France) through six different culture media following the OSMAC approach [133]. Two new meroterpenoids, 22-deoxyminiolutelide A (405) and 4-hydroxy-22-deoxyminiolutelide B (406), together with seven known analogs, were selectively overexpressed and obtained from a seawater CYA (Czapek yeast extract agar) medium and were devoid of cytotoxicity at $50 \mu \mathrm{M}$ (KB and MCF-7 cells) [133]. Additionally, 22-deoxy-10-oxominiolutelide B was found to easily transform into either compound 405 or 22-deoxyminiolutelide B [133]. Thus, the latter two compounds may be artefacts [133].

Phenylpyropenes E (407) and F (408) and seven known phenylpyropenes and pyripyropenes, were characterized from the marine-derived fungus Penicillium concentricum ZLQ-69 (seawater, Bohai Sea coast, China) [134]. In the bioassay of the three strains of HTCLs, only 407 and phenylpyropene C showed moderate cytotoxicity toward MGC-803 cells ( $\mathrm{IC}_{50}=19.1$ and $13.6 \mu \mathrm{M}$, respectively) [134].

The mangrove endophytic fungus Penicillium sp. SK5GW1L, collected from the leaves of Kandelia candel (Shankou, Guangxi, China), was found to produce five $\alpha$-pyrone meroterpenoids, including one new 3-epiarigsugacin E (409), of which only 409 weakly inhibited AchE, while arisugacin $B$, territrem $C$, and terreulactone $C$, all already known, showed potent anti-AchE activity $\left(\mathrm{IC}_{50}=0.03-3.03 \mu \mathrm{M}\right)[135]$.

A new meroterpenoid, 15-hydroxydecaturin A (410), and seven other analogs were obtained from the marine algae-derived fungus Penicillium oxalicum EN-290 (Codium fragile, Qingdao, China) [136]. Four new spiromeroterpenoids, chermesins A-D (411-414), characterized by a drimane-type sesquiterpene moiety with a rare cyclohexa-2,5-dienone unit, were obtained from the fungus Penicillium chermesinum EN-480, which was separated from the marine red alga Pterocladiella tenuis (Rongcheng, China). Compounds 411 and 412 weakly or moderately inhibited the pathogens Micrococcus luteus, Candida albicans, Escherichia coli, and Vibrio alginolyticus (MIC $=8-64 \mu \mathrm{g} / \mathrm{mL}$ ) [137].

A new austalide-type meroterpenoids, austalide $H$ acid ethyl ester (415) [138], was isolated from the marine algae-derived fungi Penicillium thomii Maire KMM 4645, and compound 415 showed inhibition of the enzyme endo-1,3- $\beta$-D-glucanase [138]. Another deep-sea-derived fungus, Penicillium chrysogenum (SCSIO 41001), produced a new merosesquiterpenoid, yaminterritrem C (416), bearing a novel naphtho[2,1-b]pyrano-[3,2e]pyran scaffold [139]. In the screen for renoprotective agents from the deep-sea-derived fungus Penicillium sp. F00120, a new meroterpene was discovered, penicilliumin B (417), which possesses an unusual drimane sesquiterpene methylcyclopentenedione motif possibly from sesquiterpene quinones [140]. Compound 417 showed promising potential renoprotective activity with low toxicity by inhibiting the kidney fibrogenic action of high glucose in rat glomerular mesangial cells (RMC) involved in the disruption of oxidative stress [140].

Chrodrimanins, a small subclass of meroterpenoids sharing a 6/6/6/6/6 pentacyclic ring scaffold, were derived from a drimane-type sesquiterpene and a C10 polyketide (shown as a 6,8-dihydroxy-3-methylisochroman-1-one or a 3,6,8-trihydroxy-3,4dihydronaphthalen-1-one moiety). Five chrodrimanin-type meroterpenes, including the new verruculide A (418) and the biosynthetic precursor verruculide B (419) with a linear sesquiterpene moiety, together with three known analogs, were isolated from Indonesian ascidian-derived Penicillium verruculosum TPU1311. Compound 418 and chrodrimanins $\mathrm{A}$ and $\mathrm{H}$ showed good anti-PTP1B activity $\left(\mathrm{IC}_{50}=8.4-14.9 \mu \mathrm{M}\right)$, while 419 weakly 
inhibited PTP1B [141]. In an alternate study, 11 new chrodrimanin-type meroterpenes, chrodrimanins $\mathrm{K}-\mathrm{N}(\mathbf{4 2 0}-\mathbf{4 2 3})$, the biosynthetic precursors verruculides B2 (424) and B3 (425) [142], chrodrimanins O-S (426-430) [143], and eight known analogs were obtained from the fungus Penicillium sp. SCS-KFD09 isolated from the marine worm Sipunculus nudus (Haikou Bay, China). Among them, chrodrimanins $\mathrm{K}$ (420) and L (421) correspond to two unusual chlorinated chrodrimanins. Chrodrimanin O (426) features special dichlorine functionality as an uncommon trichlorinated meroterpenoid, and the absolute configurations of chrodrimanins A and F were assigned by XRD [142,143]. Only compound 424 showed weak antibacterial activity against Staphylococcus aureus (MIC $=32 \mu \mathrm{g} / \mathrm{mL}$ vs. $4.0 \mu \mathrm{g} / \mathrm{mL}$ for gentamicin sulfate) [142]. Compounds 420, 423, and 3-hydroxypentacecilide A displayed significant antiviral (H1N1) activity ( $\mathrm{IC}_{50}=34-74 \mu \mathrm{M}$ vs. $103 \mu \mathrm{M}$ for ribavirin) [142], and compounds 426, 429, and 430 exhibited moderate anti-PTP1B activity $\left(\mathrm{IC}_{50}=62.5-71.6 \mu \mathrm{M}\right)$ [143].

Indole diterpenoids were the main group of non-polyketide-terpenoids from marine fungi. From the sea anemone-derived fungus Penicillium sp. AS-79 (Qingdao, China), 11 indole diterpenoids were isolated, including three new indole diterpenoids, 22-hydroxylshearinine F (431), 6-hydroxylpaspalinine (432), and 7-O-acetylemindole SB (433), while only 432 displayed weak activity against Vibrio parahaemolyticus (MIC $=64.0 \mu \mathrm{g} / \mathrm{mL}$ ) during the antimicrobial tests of 16 strains of pathogenic microbes [144]. A new indole diterpenoid, secopaxilline A (434), bearing a rare C-N bond cleavage moiety, was obtained from the marine aciduric fungus Penicillium camemberti OUCMDZ-1492 from mangrove soil [14]. Four indole diterpenoids, including the novel penijanthines C and D (435 and 436), were explored from the marine sediment-derived fungus Penicillium janthinellum (Bohai Sea, China), among which compounds 435 and $\mathbf{4 3 6}$ displayed potent anti-Vibrio activity (MIC 3.1-6.30 and $12.5 \mu \mathrm{M}$, respectively) against three pathogenic Vibrio spp. [145].

When searching for biologically active compounds from the marine fungus Penicillium sp. KFD28, which is associated with the bivalve mollusk, Meretrix lusoria (Haikou Bay, China), nine new diverse skeletons of indole terpenoids, penerpenes A-D (437-440) [146] and E-I (441-445) [147], and nine known indole terpenoids, including paxilline, emindole SB, and 7-hydroxypaxilline-13-ene, were isolated. Notably, compound 437 possesses a 1,4-dihydro-2Hbenzo[d][1,3] oxazine moiety in an unusual spiro indole diterpene; compound $\mathbf{4 3 8}$ has an uncommon heptacyclic scaffold containing pyridine in the indole diterpene; compounds $\mathbf{4 3 9}, \mathbf{4 4 0}$, and $\mathbf{4 4 2}$ are norindole diterpenoids with new carbon frameworks possibly derived from paxilline via the loss of 3-5 carbons; compound 441 bears a unique 6/5/5/6/6/5/5 heptacyclic ring system; and compound 443 contains an unusual 6/5/5/6/6/7 hexacyclic motif bearing a 1,3-dioxepane ring rarely found in nature [146,147]. Compounds 437 and 438 and emindole SB are considered to be new potent protein tyrosine phosphatase (PTP1B and TCPTP, $\left.\mathrm{IC}_{50}=0.7-5.0 \mu \mathrm{M}\right)$ inhibitors via PTP inhibition and molecular docking experiments [146]. Compounds 441, 442, 444, and 7-hydroxypaxilline-13-ene inhibited PTP1B ( $\left.\mathrm{IC}_{50}=13-27 \mu \mathrm{M}\right)$. Compound 441 also showed anti-PTP $\sigma$ activity $\left(\mathrm{IC}_{50}=38 \mu \mathrm{M}\right)$, while compound 444 and 7-hydroxypaxilline-13-ene inhibited TCPTP $\left(\mathrm{IC}_{50}=35\right.$ and $37 \mu \mathrm{M}$, respectively) [147]. Penicindopene A (446), possessing a 3-hydroxyl-2-indolone moiety rarely found in indole diterpenes, was isolated from the deep-sea fungus Penicillium sp. YPCMAC1 and displayed moderate cytotoxicity $\left(\mathrm{IC}_{50}=15.2 \mu \mathrm{M}\right.$ for A549, and $20.5 \mu \mathrm{M}$ for HeLa) [148].

\subsubsection{Pestalotiopsis sp.}

Two new DMOA-derived meroterpenoids, 7-hydroxydehydroaustin (447) and 11 $\beta$ acetoxyisoaustinone (448), from the seagrass-derived fungus Pestalotiopsis sp. PSU-ES 19 were inactive in their antimycobacterial, antimalarial, and cytotoxic activity [149].

\subsubsection{Pleosporales sp.}

The investigation of a marine algae-derived fungus Pleosporales sp. led to the isolation of four new merosesquiterpenoids (pleosporallins A-D, 449-452); 449-451 displayed moderate anti-inflammatory 
(IL-6 in RAW264.7) effects, and $\mathbf{4 5 2}$ moderately inhibited the agricultural pathogen Clavibacter michiganense subsp. sepedonicus (MIC $=9.48 \mu \mathrm{g} / \mathrm{mL}$ ) [150].

\subsubsection{Stachybotrys sp.}

A new sulfate meroterpenoid, stachybotrin G (453), featuring an atypical farnesylated[1,3]diazepino[2,1-a]isoindole moiety, was isolated from the sponge derived fungus, Stachybotrys chartarum (MXH-X73) and lacked bioactivity [151].

Using the OSMAC approach, the marine crinoid-derived fungus, Stachybotrys chartarum 952, was able to yield nine metrosesquiterpenes derived from orsellinic acid and farnesyl, including three new linear farnesyl meroterpenoids, stachybonoids A-C (454-456) and one new phenylspirodrimane, stachybonoid D (457), from a solid rice medium, and five phenylspirodrimanes, including two new stachybonoids, E and F (458-459), from a PDB liquid medium [152]. Compound 454 showed significant inhibition of the dengue virus, and compound 459, stachybotrysin C, and stachybotrylactone exhibited moderate-to-good anti-inflammatory activity ( $\mathrm{NO}$ in RAW264.7) $\left(\mathrm{IC}_{50}=17.9-52.5 \mu \mathrm{M}\right.$ vs. $37.5 \mu \mathrm{M}$ for indomethacin) [152].

Three structurally diverse phenylspirodrimane-based meroterpenoids with new scaffolds, chartarolides A-C (460-462), and the known persecutors, stachybotrylactam and mollicellin D, were isolated from the cytotoxic fraction of the sponge-derived fungus, Stachybotrys chartarum WGC-25C-6 [153]. Regarding their biogenic synthesis, stachybotrydial with mollicelin J are constituents of the dioxabicyclononane core in 460-461, and stachybotrylactam with mollicellin D combined

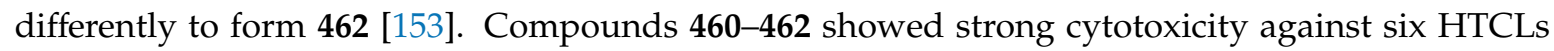
(HCT-116, HepG2, BGC-823, NCI-H1650, A2780, and MCF7) ( $\left.\mathrm{IC}_{50}=1.3-12.5 \mu \mathrm{M}\right)$ and exhibited selective significant inhibitory activity towards the human tumor-related protein kinases of FGFR3, IGF1R, PDGFRb, and $\operatorname{TrKB}\left(\mathrm{IC}_{50}=2.6-21.4 \mu \mathrm{M}\right)$ [153].

\subsubsection{Talaromyces sp.}

The analysis of chemically active components of the mangrove endophytic fungus Talaromyces amestolkiae YX1, cultured on a solid wheat substrate medium, resulted in the isolation of four new DMOA-derived meroterpenoids, the amestolkolides A-D (463-466), which bear a unique and fused polycyclic skeleton with a 6/7/6/5/6 system, along with three known ones, purpurogenolide $E$ and chrodrimanins A and B [154]. Amestolkolides B and A exert potent anti-inflammatory activity by suppressing NO production in LPS-induced RAW264.7 cells ( $\mathrm{IC}_{50}=1.6$ and $30 \mu \mathrm{M}$, respectively, vs. $26.3 \mu \mathrm{M}$ for indomethacin) [154].

Five new unusual polycyclic meroterpenoids, talaromyolides A-D (467-470), and talaromytin (471), were found in the marine fungus Talaromyces sp. CX11 [155]. Talaromyolide A (6/6/6/5/5/5 polycyclic skeleton) and talaromyolide D (containing one four-membered ring) are two novel carbon skeletons, and talaromyolides $B$ and $C$ are the first examples of 6/6/6/6/6/6 hexacyclic skeleton meroterpenoids with a seco-drimane sesquiterpene moiety and a C10 polyketide [155]. Talaromytin (471), a heptacyclic compound, is found to exist as two slowly interconverting conformers with different side-chain orientations [155]. Additionally, $\mathbf{4 7 0}$ showed potent antiviral (pig PRV) activity with an $\mathrm{IC}_{50}$ value of $3.35 \mu \mathrm{M}$ [155].

\section{Conclusions}

This review provides a comprehensive overview of the diverse chemical structures and bioactive properties of new terpenes that have been isolated from marine-derived fungi in the last five years. There has been a tremendous increase in the rate of new terpenoids being isolated from marine-derived fungi, representing a golden age of microbial-derived compound discovery in the field of marine natural products. Up to 471 new terpenes have been discovered from 133 marine fungal strains belonging to 34 genera. Among them, sesquiterpenes $(188,40 \%)$, meroterpenes $(165,35 \%)$, and diterpenes $(75,16 \%)$ comprise the largest proportion of terpenes, while Penicillium (108, 23\%), Aspergillus (99, 21\%), and 
Trichoderma $(49,10 \%)$ are the dominant producers of terpenoids. The majority of the fungi producing these novel terpenes were isolated from live marine matter, marine animals (27\%), and aquatic plants (including mangrove plants) (38\%), while the remaining fungi were obtained from marine environments (i.e., deep-sea sediments $(15 \%)$, other marine sediments from the shallow sea or coast $(11 \%)$, and hydrothermal vents $(3 \%)$ ). Around $30 \%$ of the undescribed compounds displayed various activities, especially cytotoxicity against HTCLs, which was the case for 54 compounds. Interestingly, some of them with promising or high bioactivities deserve to be paid more attention (shown in Table S1); for example, cytotoxic compounds (chartarenes D (154) [46], 14,15-dehydro-6-epi-ophiobolin $\mathrm{K}$ (285), 14,15-dehydro-ophiobolins $\mathrm{K}(287)$ [84], $\left.\mathrm{IC}_{50}=0.14-0.68 \mu \mathrm{M}\right)$; lethally toxic compounds (phytoplankton toxicity), trichocarotins C/E (183/185) [54], 11R-methoxy-5,9,13-proharzitrien-3-ol (266) [50], $\mathrm{LD}_{50}=0.24-1.3 \mu \mathrm{g} / \mathrm{mL}$; brine shrimp lethal compounds, 19-hydroxypenitrem A (349) [112], $\mathrm{LD}_{50}=3.2 \mu \mathrm{M}$ ); antiviral compounds (aperterpenes $\mathrm{N}$ (334) [107], simpterpenoid (396) [128], $\mathrm{IC}_{50}=8.1-18 \mathrm{nM}$ ); anti-inflammatory compounds (13 $\beta$-hydroxy conidiogenone C (243) [67], amestolkolide B (464) [154], IC $50=1.6-2.2 \mu \mathrm{M}$ ); enzyme inhibitors ( $\alpha$-glucosidase inhibitor, isopimarane diterpene (239) [65]; protein tyrosine phosphatases inhibitors, penerpene A (437) [146]; human tumor-related protein kinases inhibitors, chartarolide A (460) [153], $\mathrm{IC}_{50}=1.7-5.0 \mu \mathrm{M}$ ); antibacterial compounds (7-O-methylhydroxysydonic acid (31) [10], dendry-phiellin I (53) [28], penijanthines C (435) [145], $\mathrm{MIC}=1.5-2.0 \mu \mathrm{g} / \mathrm{mL}$ or 3.1-6.3 $\mu \mathrm{M}$ ); and antifungal compounds (wentinoid A (212) [60], moriniafungin E (235) [64], MIC $=1.0 \mu \mathrm{g} / \mathrm{mL}$ or $2.9 \mu \mathrm{M}$ ). Due to the chemical diversity and biological activities of these terpenoids, it is worth studying marine fungi further to find promising lead compounds for the development of marine drugs.

Supplementary Materials: The following are available online at http://www.mdpi.com/1660-3397/18/6/321/s1. Table S1: Selective new terpenes with high bioactivities from marine-derived fungi in 2015-2019.

Author Contributions: S.C. conceived and designed the format of the manuscript. S.C., M.J., Z.W., and H.G. analyzed the data, and drafted and edited the manuscript. Z.W., M.J., and H.G. drew the chemical structures of the compounds. S.C. and L.L. reviewed the manuscript. All authors contributed to critically reading and discussing the manuscript. All authors have read and agreed to the published version of the manuscript.

Funding: This work was financially supported by the National Natural Science Foundation of China (grant number 41806155), the Guangdong MEPP Fund (NO.GDOE (2019) A21), and the Natural Science Foundation of Guangdong Province (grant number 2018A030310304).

Conflicts of Interest: The authors declare no conflict of interest.

\section{References}

1. Rateb, M.E.; Ebel, R. Secondary metabolites of fungi from marine habitats. Nat. Prod. Rep. 2011, 28, $290-344$. [CrossRef] [PubMed]

2. Bugni, T.S.; Ireland, C.M. Marine-derived fungi: A chemically and biologically diverse group of microorganisms. Nat. Prod. Rep. 2004, 21, 143-163. [CrossRef] [PubMed]

3. Imhoff, J.F. Natural products from marine fungi-Still an underrepresented resource. Mar. Drugs 2016, 14, 19. [CrossRef] [PubMed]

4. Deshmukh, S.K.; Prakash, V.; Ranjan, N. Marine fungi: A source of potential anticancer compounds. Front. Microbiol. 2018, 8, 2536-2559. [CrossRef]

5. Debbab, A.; Aly, A.H.; Proksch, P. Bioactive secondary metabolites from endophytes and associated marine derived fungi. Fungal Divers. 2011, 49, 19. [CrossRef]

6. Gross, H.; König, G.M. Terpenoids from marine organisms: Unique structures and their pharmacological potential. Phytochem. Rev. 2006, 5, 115-141. [CrossRef]

7. Ebel, R. Terpenes from marine-derived fungi. Mar. Drugs 2010, 8, 2340-2368. [CrossRef]

8. Elissawy, A.M.; El-Shazly, M.; Ebada, S.S.; Singab, A.B.; Proksch, P. Bioactive terpenes from marine-derived fungi. Mar. Drugs 2015, 13, 1966-1992. [CrossRef]

9. Blunt, J.W.; Copp, B.R.; Keyzers, R.A.; Munro, M.H.; Prinsep, M.R. Marine natural products. Nat. Prod. Rep. 2017, 34, 235-294. [CrossRef] 
10. Li, X.D.; Li, X.M.; Yin, X.L.; Li, X.; Wang, B.G. Antimicrobial Sesquiterpenoid derivatives and Monoterpenoids from the deep-sea sediment-derived fungus Aspergillus versicolor SD-330. Mar. Drugs 2019, 17, 563. [CrossRef]

11. Cheng, Z.; Xu, W.; Wang, Y.; Bai, S.; Liu, L.; Luo, Z.; Yuan, W.; Li, Q. Two new meroterpenoids and two new monoterpenoids from the deep sea-derived fungus Penicillium sp. YPGA11. Fitoterapia 2019, 133, 120-124. [CrossRef] [PubMed]

12. Liu, H.X.; Zhang, L.; Chen, Y.C.; Sun, Z.H.; Pan, Q.L.; Li, H.H.; Zhang, W.M. Monoterpenes and sesquiterpenes from the marine sediment-derived fungus Eutypella scoparia FS46. J. Asian Nat. Prod. Res. 2017, 19, 145-151. [CrossRef] [PubMed]

13. Gong, T.; Zhen, X.; Li, B.J.; Yang, J.L.; Zhu, P. Two new monoterpenoid alpha-pyrones from a fungus Nectria sp. HLS206 associated with the marine sponge Gelliodes carnosa. J. Asian Nat. Prod. Res. 2015, 17, 633-637. [CrossRef] [PubMed]

14. Song, Y.P.; Miao, F.P.; Fang, S.T.; Yin, X.L.; Ji, N.Y. Halogenated and Nonhalogenated metabolites from the marine-alga-endophytic fungus Trichoderma asperellum cf44-2. Mar. Drugs 2018, 16, 266. [CrossRef] [PubMed]

15. Yun, K.; Kondempudi, C.M.; Leutou, A.S.; Son, B.W. New production of a monoterpene glycoside, 1-O-( $\alpha$-D-Mannopyranosyl)-geraniol, by the marine-derived fungus Thielavia hyalocarpa. B Korean Chem. Soc. 2015, 36, 2391-2393. [CrossRef]

16. Wang, Y.; Li, D.H.; Li, Z.L.; Sun, Y.J.; Hua, H.M.; Liu, T.; Bai, J. Terpenoids from the marine-derived fungus Aspergillus fumigatus YK-7. Molecules 2015, 21,31-35. [CrossRef]

17. Li, Y.; Liu, W.; Xu, W.; Zeng, X.; Cheng, Z.; Li, Q. Aspterrics A and B, New Sesquiterpenes from Deep Sea-derived Fungus Aspergillus terreus YPGA10. Rec. Nat. Prod. 2019, 14, 18-22. [CrossRef]

18. Wang, L.; Li, M.; Tang, J.; Li, X. Eremophilane sesquiterpenes from a deep marine-derived fungus, Aspergillus sp. SCSIOW2, Cultivated in the presence of epigenetic modifying agents. Molecules 2016, 21, 473. [CrossRef]

19. Cui, H.; Liu, Y.; Li, T.; Zhang, Z.; Ding, M.; Long, Y.; She, Z. 3-Arylisoindolinone and sesquiterpene derivatives from the mangrove endophytic fungi Aspergillus versicolor SYSU-SKS025. Fitoterapia 2018, 124, 177-181. [CrossRef]

20. Wang, P.; Yu, J.H.; Zhu, K.; Wang, Y.; Cheng, Z.Q.; Jiang, C.S.; Dai, J.G.; Wu, J.; Zhang, H. Phenolic bisabolane sesquiterpenoids from a Thai mangrove endophytic fungus, Aspergillus sp. xy02. Fitoterapia 2018, 127, 322-327. [CrossRef]

21. Liu, Y.J.; Zhang, J.L.; Li, C.; Mu, X.G.; Liu, X.L.; Wang, L.; Zhao, Y.C.; Zhang, P.; Li, X.D.; Zhang, X.X. Antimicrobial secondary metabolites from the seawater-derived fungus Aspergillus sydowii SW9. Molecules 2019, 24, 4596. [CrossRef] [PubMed]

22. Li, X.D.; Li, X.; Li, X.M.; Yin, X.L.; Wang, B.G. Antimicrobial bisabolane-type sesquiterpenoids from the deep-sea sediment-derived fungus Aspergillus versicolor SD-330. Nat. Prod. Res. 2019. (online). [CrossRef]

23. Tan, Y.; Yang, B.; Lin, X.; Luo, X.; Pang, X.; Tang, L.; Liu, Y.; Li, X.; Zhou, X. Nitrobenzoyl sesquiterpenoids with cytotoxic activities from a marine-derived Aspergillus ochraceus fungus. J. Nat. Prod. 2018, 81, 92-97. [CrossRef] [PubMed]

24. Liu, Y.F.; Yue, Y.F.; Feng, L.X.; Zhu, H.J.; Cao, F. Asperienes A-D, Bioactive sesquiterpenes from the marine-derived fungus Aspergillus flavus. Mar. Drugs 2019, 17, 550. [CrossRef]

25. Huang, L.; Lan, W.J.; Deng, R.; Feng, G.K.; Xu, Q.Y.; Hu, Z.Y.; Zhu, X.F.; Li, H.J. Additional new cytotoxic triquinane-type sesquiterpenoids chondrosterins K-M from the marine fungus Chondrostereum sp. Mar. Drugs 2016, 14, 157. [CrossRef]

26. Hsiao, G.; Chi, W.C.; Pang, K.L.; Chen, J.J.; Kuo, Y.H.; Wang, Y.K.; Cha, H.J.; Chou, S.C.; Lee, T.H. Hirsutane-type sesquiterpenes with inhibitory activity of microglial nitric oxide production from the red alga-derived fungus Chondrostereum sp. NTOU4196. J. Nat. Prod. 2017, 80, 1615-1622. [CrossRef]

27. Huang, L.; Lan, W.J.; Li, H.J. Two new hirsutane-type sesquiterpenoids chondrosterins $\mathrm{N}$ and $\mathrm{O}$ from the marine fungus Chondrostereum sp. Nat. Prod. Res. 2018, 32, 1578-1582. [CrossRef] [PubMed]

28. Fang, W.; Wang, J.; Wang, J.; Shi, L.; Li, K.; Lin, X.; Min, Y.; Yang, B.; Tang, L.; Liu, Y.; et al. Cytotoxic and antibacterial eremophilane sesquiterpenes from the marine-derived fungus Cochliobolus lunatus SCSIO41401. J. Nat. Prod. 2018, 81, 1405-1410. [CrossRef]

29. Chen, L.-L.; Kong, F.-D.; Wang, P.; Yuan, J.-Z.; Guo, Z.-K.; Wang, H.; Dai, H.-F.; Mei, W.-L. Two new tremulane sesquiterpenes from a mangrove endophytic fungus, Coriolopsis sp. J5. Chin. Chem. Lett. 2017, 28, $222-225$. [CrossRef] 
30. Luo, X.W.; Chen, C.M.; Li, K.L.; Lin, X.P.; Gao, C.H.; Zhou, X.F.; Liu, Y.H. Sesquiterpenoids and meroterpenoids from a mangrove derived fungus Diaporthe sp. SCSIO 41011. Nat. Prod. Res. 2019. (online). [CrossRef]

31. Chen, C.-J.; Liu, X.-X.; Zhang, W.-J.; Zang, L.-Y.; Wang, G.; Ng, S.W.; Tan, R.-X.; Ge, H.-M. Sesquiterpenoids isolated from an endophyte fungus Diaporthe sp. RSC Adv. 2015, 5, 17559-17565. [CrossRef]

32. Niu, S.; Liu, D.; Shao, Z.; Proksch, P.; Lin, W. Eremophilane-type sesquiterpenoids in a deep-sea fungus Eutypella sp. activated by chemical epigenetic manipulation. Tetrahedron 2018, 74, 7310-7325. [CrossRef]

33. Niu, S.; Xie, C.-L.; Zhong, T.; Xu, W.; Luo, Z.-H.; Shao, Z.; Yang, X.-W. Sesquiterpenes from a deep-sea-derived fungus Graphostroma sp. MCCC 3A00421. Tetrahedron 2017, 73, 7267-7273. [CrossRef]

34. Zhang, P.; Li, J.; Lang, J.; Jia, C.; Niaz, S.I.; Chen, S.; Liu, L. Two new sesquiterpenes derivatives from marine fungus Leptosphaerulina Chartarum sp. 3608. Nat. Prod. Res. 2018, 32, 2297-2303. [CrossRef]

35. Zhang, L.H.; Chen, G.; Sun, Y.; Wang, H.F.; Bai, J.; Hua, H.M.; Pei, Y.H. Seven new drimane-type sesquiterpenoids from a marine-derived fungus Paraconiothyrium sporulosum YK-03. Molecules 2019, 24, 1817. [CrossRef]

36. Afiyatullov, S.S.; Leshchenko, E.V.; Sobolevskaya, M.P.; Antonov, A.S.; Denisenko, V.A.; Popov, R.S.; Khudyakova, Y.V.; Kirichuk, N.N.; Kuz'mich, A.S.; Pislyagin, E.A.; et al. New thomimarine E from marine isolate of the fungus Penicillium thomii. Chem. Nat. Compd. 2017, 53, 290-294. [CrossRef]

37. Afiyatullov, S.S.; Leshchenko, E.V.; Sobolevskaya, M.P.; Denisenko, V.A.; Kirichuk, N.N.; Khudyakova, Y.V.; Hoai, T.P.T.; Dmitrenok, P.S.; Menchinskaya, E.S.; Pislyagin, E.A.; et al. New eudesmane sesquiterpenes from the marine-derived fungus Penicillium thomii. Phytochem. Lett. 2015, 14, 209-214. [CrossRef]

38. Chen, H.Q.; Qiu, L.M.; Wang, P.; Cai, C.H.; Wang, H.; Dai, H.F.; Mei, W.L. Three new eudesmane-type sesquiterpenoids from the mangrove-derived endophytic fungus Penicillium sp. J-54. Phytochem. Lett. 2019, 33, 36-38. [CrossRef]

39. Xing, C.P.; Xie, C.L.; Xia, J.M.; Liu, Q.M.; Lin, W.X.; Ye, D.Z.; Liu, G.M.; Yang, X.W. Penigrisacids A-D, four new sesquiterpenes from the deep-sea-derived Penicillium griseofulvum. Mar. Drugs 2019, 17, 507. [CrossRef]

40. Afiyatullov, S.S.; Zhuravleva, O.I.; Antonov, A.S.; Leshchenko, E.V.; Pivkin, M.V.; Khudyakova, Y.V.; Denisenko, V.A.; Pislyagin, E.A.; Kim, N.Y.; Berdyshev, D.V.; et al. Piltunines A-F from the marine-derived fungus Penicillium piltunense KMM 4668. Mar. Drugs 2019, 17, 647. [CrossRef]

41. Liu, Y.; Li, X.M.; Meng, L.H.; Jiang, W.L.; Xu, G.M.; Huang, C.G.; Wang, B.G. Bisthiodiketopiperazines and acorane sesquiterpenes produced by the marine-derived fungus Penicillium adametzioides AS-53 on different culture media. J. Nat. Prod. 2015, 78, 1294-1299. [CrossRef] [PubMed]

42. Li, H.-J.; Jiang, C.-W.; Xu, M.-Y.; Yan, D.-F.; Xu, J.; Lan, W.-J. Pseudapenes A-C, sesquiterpenoids from the marine-derived fungus Pseudallescheria apiosperma F52-1. Tetrahedron Lett. 2019, 60, 15093-15096. [CrossRef]

43. Liu, S.; Zhao, Y.; Heering, C.; Janiak, C.; Muller, W.E.G.; Akone, S.H.; Liu, Z.; Proksch, P. Sesquiterpenoids from the Endophytic Fungus Rhinocladiella similis. J. Nat. Prod. 2019, 82, 1055-1062. [CrossRef] [PubMed]

44. Elnaggar, M.S.; Ebada, S.S.; Ashour, M.L.; Ebrahim, W.; Müller, W.E.G.; Mándi, A.; Kurtán, T.; Singab, A.; Lin, W.; Liu, Z.; et al. Xanthones and sesquiterpene derivatives from a marine-derived fungus Scopulariopsis sp. Tetrahedron 2016, 72, 2411-2419. [CrossRef]

45. Qin, C.; Lin, X.; Lu, X.; Wan, J.; Zhou, X.; Liao, S.; Tu, Z.; Xu, S.; Liu, Y. Sesquiterpenoids and xanthones derivatives produced by sponge-derived fungus Stachybotry sp. HH1 ZSDS1F1-2. J. Antibiot. 2015, 68, 121-125. [CrossRef]

46. Li, Y.; Liu, D.; Cheng, Z.; Proksch, P.; Lin, W. Cytotoxic trichothecene-type sesquiterpenes from the sponge-derived fungus Stachybotrys chartarum with tyrosine kinase inhibition. RSC Adv. 2017, 7, 7259-7267. [CrossRef]

47. Wang, W.; Wan, X.; Liu, J.; Wang, J.; Zhu, H.; Chen, C.; Zhang, Y. Two new terpenoids from Talaromyces purpurogenus. Mar. Drugs 2018, 16, 150. [CrossRef]

48. Ngokpol, S.; Suwakulsiri, W.; Sureram, S.; Lirdprapamongkol, K.; Aree, T.; Wiyakrutta, S.; Mahidol, C.; Ruchirawat, S.; Kittakoop, P. Drimane sesquiterpene-conjugated amino acids from a marine isolate of the fungus Talaromyces minioluteus (Penicillium Minioluteum). Mar. Drugs 2015, 13, 3567-3580. [CrossRef]

49. Rodriguez, J.P.G.; Williams, D.E.; Sabater, I.D.; Bonugli-Santos, R.C.; Sette, L.D.; Andersen, R.J.; Berlinck, R.G.S. The marine-derived fungus Tinctoporellus sp CBMAI 1061 degrades the dye Remazol Brilliant Blue R producing anthraquinones and unique tremulane sesquiterpenes. RSC Adv. 2015, 5, 66360-66366. [CrossRef]

50. Song, Y.P.; Fang, S.T.; Miao, F.P.; Yin, X.L.; Ji, N.Y. Diterpenes and Sesquiterpenes from the Marine Algicolous Fungus Trichoderma harzianum X-5. J. Nat. Prod. 2018, 81, 2553-2559. [CrossRef] 
51. Fang, S.T.; Wang, Y.J.; Ma, X.Y.; Yin, X.L.; Ji, N.Y. Two new sesquiterpenoids from the marine-sediment-derived fungus Trichoderma harzianum P1-4. Nat. Prod. Res. 2019, 33, 3127-3133. [CrossRef]

52. Song, Y.P.; Miao, F.P.; Liang, X.R.; Yin, X.L.; Ji, N.Y. Harziane and cadinane terpenoids from the alga-endophytic fungus Trichoderma asperellum A-YMD-9-2. Phytochem. Lett. 2019, 32, 38-41. [CrossRef]

53. Shi, Z.Z.; Miao, F.P.; Fang, S.T.; Yin, X.L.; Ji, N.Y. Trichobisabolins A-H, eight new bisabolane derivatives from the marine-alga-epiphytic fungus Trichoderma asperellum Y6-2. Fitoterapia 2019, 134, 372-377. [CrossRef]

54. Shi, Z.Z.; Fang, S.T.; Miao, F.P.; Yin, X.L.; Ji, N.Y. Trichocarotins A-H and trichocadinin A, nine sesquiterpenes from the marine-alga-epiphytic fungus Trichoderma virens. Bioorg. Chem. 2018, 81, 319-325. [CrossRef]

55. Zhou, Y.M.; Ju, G.L.; Xiao, L.; Zhang, X.F.; Du, F.Y. Cyclodepsipeptides and sesquiterpenes from marine-derived fungus Trichothecium roseum and their biological functions. Mar. Drugs 2018, 16, 519. [CrossRef]

56. Choodej, S.; Teerawatananond, T.; Mitsunaga, T.; Pudhom, K. Chamigrane sesquiterpenes from a basidiomycetous endophytic fungus XG8D associated with Thai mangrove xylocarpus granatum. Mar. Drugs 2016, 14, 132. [CrossRef]

57. Zeng, Y.B.; Gu, H.G.; Zuo, W.J.; Zhang, L.L.; Bai, H.J.; Guo, Z.K.; Proksch, P.; Mei, W.L.; Dai, H.F. Two new sesquiterpenoids from endophytic fungus J3 isolated from Mangrove Plant Ceriops tagal. Arch. Pharm. Res. 2015, 38, 673-676. [CrossRef]

58. Zhuravleva, O.I.; Antonov, A.S.; Oleinikova, G.K.; Khudyakova, Y.V.; Popov, R.S.; Denisenko, V.A.; Pislyagin, E.A.; Chingizova, E.A.; Afiyatullov, S.S. Virescenosides from the holothurian-associated fungus Acremonium Striatisporum Kmm 4401. Mar. Drugs 2019, 17, 616. [CrossRef]

59. Li, X.D.; Li, X.; Li, X.M.; Xu, G.M.; Zhang, P.; Meng, L.H.; Wang, B.G. Tetranorlabdane diterpenoids from the deep sea sediment-derived fungus Aspergillus wentii SD-310. Planta Med. 2016, 82, 877-881. [CrossRef]

60. Li, X.; Li, X.-D.; Li, X.-M.; Xu, G.-M.; Liu, Y.; Wang, B.-G. Wentinoids A-F, six new isopimarane diterpenoids from Aspergillus wentii SD-310, a deep-sea sediment derived fungus. RSC Adv. 2017, 7, 4387-4394. [CrossRef]

61. Li, X.D.; Li, X.; Li, X.M.; Xu, G.M.; Liu, Y.; Wang, B.G. 20-nor-isopimarane epimers produced by Aspergillus wentii SD-310, a fungal strain obtained from deep sea sediment. Mar. Drugs 2018, 16, 440. [CrossRef] [PubMed]

62. Niu, S.; Peng, G.; Xia, J.M.; Xie, C.L.; Li, Z.; Yang, X.W. A new pimarane diterpenoid from the Botryotinia fuckeliana fungus isolated from deep-sea water. Chem. Biodivers. 2019, 16, e1900519. [CrossRef] [PubMed]

63. Niu, S.; Xie, C.L.; Xia, J.M.; Liu, Q.M.; Peng, G.; Liu, G.M.; Yang, X.W. Botryotins A-H, tetracyclic diterpenoids representing three carbon skeletons from a deep-sea-derived Botryotinia fuckeliana. Org. Lett. 2020, 22, 580-583. [CrossRef]

64. Zhang, M.Q.; Xu, K.X.; Xue, Y.; Cao, F.; Yang, L.J.; Hou, X.M.; Wang, C.Y.; Shao, C.L. Sordarin diterpene glycosides with an unusual 1,3-Dioxolan-4-one ring from the zoanthid-derived fungus Curvularia hawaiiensis TA26-15. J. Nat. Prod. 2019, 82, 2477-2482. [CrossRef] [PubMed]

65. Xia, X.; Qi, J.; Liu, Y.; Jia, A.; Zhang, Y.; Liu, C.; Gao, C.; She, Z. Bioactive isopimarane diterpenes from the fungus, Epicoccum sp. HS-1, associated with Apostichopus japonicus. Mar. Drugs 2015, 13, 1124-1132. [CrossRef] [PubMed]

66. Niu, S.; Fan, Z.; Tang, X.; Liu, Q.; Shao, Z.; Liu, G.; Yang, X.-W. Cyclopiane-type diterpenes from the deep-sea-derived fungus Penicillium commune MCCC 3A00940. Tetrahedron Lett. 2018, 59, 375-378. [CrossRef]

67. Li, F.; Sun, W.; Zhang, S.; Gao, W.; Lin, S.; Yang, B.; Chai, C.; Li, H.; Wang, J.; Hu, Z.; et al. New cyclopiane diterpenes with anti-inflammatory activity from the sea sediment-derived fungus Penicillium sp. TJ403-2. Chin. Chem. Lett. 2020, 31, 197-201. [CrossRef]

68. Niu, S.; Fan, Z.W.; Xie, C.L.; Liu, Q.; Luo, Z.H.; Liu, G.; Yang, X.W. Spirograterpene A, a tetracyclic spiro-diterpene with a fused 5/5/5/5 ring system from the deep-sea-derived fungus Penicillium granulatum MCCC 3A00475. J. Nat. Prod. 2017, 80, 2174-2177. [CrossRef]

69. Cheng, Z.; Li, Y.; Xu, W.; Liu, W.; Liu, L.; Zhu, D.; Kang, Y.; Luo, Z.; Li, Q. Three new cyclopiane-type diterpenes from a deep-sea derived fungus Penicillium sp. YPGA11 and their effects against human esophageal carcinoma cells. Bioorg. Chem. 2019, 91, 103129-103133. [CrossRef]

70. Wang, C.; Gao, Y.K.; Lei, F.H.; Tan, X.C.; Shen, L.Q.; Gao, C.H.; Yi, X.X.; Li, X.Y. A new glycosyl ester isolated from marine-derived Penicillium sp. Chin. Herb. Med. 2019, 50, 2518-2523. 
71. Liang, X.R.; Miao, F.P.; Song, Y.P.; Guo, Z.Y.; Ji, N.Y. Trichocitrin, a new fusicoccane diterpene from the marine brown alga-endophytic fungus Trichoderma citrinoviride cf-27. Nat. Prod. Res. 2016, 30, 1605-1610. [CrossRef] [PubMed]

72. Liang, X.R.; Miao, F.P.; Song, Y.P.; Liu, X.H.; Ji, N.Y. Citrinovirin with a new norditerpene skeleton from the marine algicolous fungus Trichoderma citrinoviride. Bioorg. Med. Chem. Lett. 2016, 26, 5029-5031. [CrossRef]

73. Zhang, M.; Liu, J.-M.; Zhao, J.-L.; Li, N.; Chen, R.-D.; Xie, K.-B.; Zhang, W.-J.; Feng, K.-P.; Yan, Z.; Wang, N.; et al. Two new diterpenoids from the endophytic fungus Trichoderma sp. Xy24 isolated from mangrove plant Xylocarpus granatum. Chin. Chem. Lett. 2016, 27, 957-960. [CrossRef]

74. Zou, J.X.; Song, Y.P.; Ji, N.Y. Deoxytrichodermaerin, a harziane lactone from the marine algicolous fungus Trichoderma longibrachiatum A-WH-20-2. Nat. Prod. Res. 2019. (online). [CrossRef] [PubMed]

75. Zhao, D.L.; Yang, L.J.; Shi, T.; Wang, C.Y.; Shao, C.L.; Wang, C.Y. Potent Phytotoxic Harziane Diterpenes from a Soft Coral-Derived Strain of the Fungus Trichoderma harzianum XS-20090075. Sci. Rep. 2019, 9, 13345-13353. [CrossRef] [PubMed]

76. Yamada, T.; Suzue, M.; Arai, T.; Kikuchi, T.; Tanaka, R. Trichodermanins C-E, new diterpenes with a fused 6-5-6-6 ring system produced by a marine sponge-derived fungus. Mar. Drugs 2017, 15, 169. [CrossRef]

77. Liang, X.R.; Miao, F.P.; Song, Y.P.; Guo, Z.Y.; Ji, N.Y. Diterpenes and steroids from marine alga-endophytic fungus Trichoderma Asperellum dl-34. Chem. Bioeng. 2016, 33, 32-36.

78. Liang, X.R.; Ma, X.Y.; Ji, N.Y. Trichosordarin A, a norditerpene glycoside from the marine-derived fungus Trichoderma harzianum R5. Nat. Prod. Res. 2019. (online). [CrossRef]

79. Ishino, M.; Kamauchi, H.; Takatori, K.; Kinoshita, K.; Sugita, T.; Koyama, K. Three novel phomactin-type diterpenes from a marine-derived fungus. Tetrahedron Lett. 2016, 57, 4341-4344. [CrossRef]

80. Shi, Z.Z.; Miao, F.P.; Fang, S.T.; Liu, X.H.; Yin, X.L.; Ji, N.Y. Sesteralterin and tricycloalterfurenes A-D: Terpenes with rarely occurring frameworks from the marine-alga-epiphytic fungus Alternaria alternata k21-1. J. Nat. Prod. 2017, 80, 2524-2529. [CrossRef]

81. Ye, B.; Ding, W.; Wang, P.-M.; Xu, J. Two new sesterterpenes from marine-derived fungus Arthrinium sp. Chem. Nat. Compd. 2019, 55, 281-284. [CrossRef]

82. Chai, H.; Yin, R.; Liu, Y.; Meng, H.; Zhou, X.; Zhou, G.; Bi, X.; Yang, X.; Zhu, T.; Zhu, W.; et al. Sesterterpene ophiobolin biosynthesis involving multiple gene clusters in Aspergillus ustus. Sci. Rep. 2016, 6, 27181-27191. [CrossRef] [PubMed]

83. Zhu, T.; Lu, Z.; Fan, J.; Wang, L.; Zhu, G.; Wang, Y.; Li, X.; Hong, K.; Piyachaturawat, P.; Chairoungdua, A.; et al. Ophiobolins from the mangrove fungus Aspergillus ustus. J. Nat. Prod. 2018, 81, 2-9. [CrossRef] [PubMed]

84. Choi, B.K.; Trinh, P.T.H.; Lee, H.S.; Choi, B.W.; Kang, J.S.; Ngoc, N.T.D.; Van, T.T.T.; Shin, H.J. New ophiobolin derivatives from the marine fungus Aspergillus flocculosus and their cytotoxicity against cancer cells. Mar. Drugs 2019, 17, 346. [CrossRef]

85. Cai, R.; Jiang, H.; Mo, Y.; Guo, H.; Li, C.; Long, Y.; Zang, Z.; She, Z. Ophiobolin-type sesterterpenoids from the mangrove endophytic fungus Aspergillus sp. ZJ-68. J. Nat. Prod. 2019, 82, 2268-2278. [CrossRef]

86. Tian, W.; Deng, Z.; Hong, K. The biological activities of sesterterpenoid-type ophiobolins. Mar. Drugs 2017, 15, 229. [CrossRef]

87. Zhao, Y.; Zhao, C.; Lu, J.; Wu, J.; Li, C.; Hu, Z.; Tian, W.; Yang, L.; Xiang, J.; Zhou, H.; et al. Sesterterpene MHO7 suppresses breast cancer cells as a novel estrogen receptor degrader. Pharmacol. Res. 2019, 146, 104294. [CrossRef]

88. Tian, W.; Yang, L.; Wu, D.; Deng, Z.; Hong, K. Toxicity, pharmacokinetics, and gut microbiome of oral administration of sesterterpene MHO7 derived from a marine fungus. Mar. Drugs 2019, 17, 667. [CrossRef]

89. Lv, C.; Qin, W.; Zhu, T.; Wei, S.; Hong, K.; Zhu, W.; Chen, R.; Huang, C. Ophiobolin O isolated from Aspergillus ustus induces G1 arrest of MCF-7 cells through interaction with AKT/GSK3beta/cyclin D1 signaling. Mar. Drugs 2015, 13, 431-443. [CrossRef]

90. Liu, Z.; Chen, Y.; Chen, S.; Liu, Y.; Lu, Y.; Chen, D.; Lin, Y.; Huang, X.; She, Z. Aspterpenacids A and B, Two Sesterterpenoids from a Mangrove Endophytic Fungus Aspergillus terreus H010. Org. Lett. 2016, 18, 1406-1409. [CrossRef]

91. Intaraudom, C.; Nitthithanasilp, S.; Rachtawee, P.; Boonruangprapa, T.; Prabpai, S.; Kongsaeree, P.; Pittayakhajonwut, P. Phenalenone derivatives and the unusual tricyclic sesterterpene acid from the marine fungus Lophiostoma bipolare BCC25910. Phytochemistry 2015, 120, 19-27. [CrossRef] [PubMed] 
92. Nazir, M.; Harms, H.; Loef, I.; Kehraus, S.; El Maddah, F.; Arslan, I.; Rempel, V.; Muller, C.E.; Konig, G.M. GPR18 inhibiting amauromine and the novel triterpene glycoside auxarthonoside from the sponge-derived fungus Auxarthron reticulatum. Planta Med. 2015, 81, 1141-1145. [CrossRef]

93. Elnaggar, M.S.; Ebada, S.S.; Ashour, M.L.; Ebrahim, W.; Singab, A.; Lin, W.; Liu, Z.; Proksch, P. Two new triterpenoids and a new naphthoquinone derivative isolated from a hard coral-derived fungus Scopulariopsis sp. Fitoterapia 2017, 116, 126-130. [CrossRef] [PubMed]

94. Shi, Z.Z.; Fang, S.T.; Miao, F.P.; Ji, N.Y. Two new tricycloalternarene esters from an alga-epiphytic isolate of Alternaria alternata. Nat. Prod. Res. 2018, 32, 2523-2528. [CrossRef] [PubMed]

95. Shi, Z.Z.; Yin, X.L.; Fang, S.T.; Miao, F.P.; Ji, N.Y. Two new isomeric tricycloalternarenes from the marine alga-epiphytic fungus Alternaria alternata k23-3. Magn. Reson. Chem. 2018, 56, 210-215. [CrossRef] [PubMed]

96. Fang, S.-T.; Miao, F.-P.; Liu, X.-H.; Song, Y.-P.; Ji, N.-Y. Two new tricycloalternarene acids from the marine-derived fungus Alternaria alternata ICD5-11. Phytochem. Lett. 2018, 23, 185-188. [CrossRef]

97. Shen, L.; Tian, S.J.; Song, H.L.; Chen, X.; Guo, H.; Wan, D.; Wang, Y.R.; Wang, F.W.; Liu, L.J. Cytotoxic tricycloalternarene compounds from endophyte Alternaria sp. W-1 Associated with Laminaria japonica. Mar. Drugs 2018, 16, 402. [CrossRef]

98. Peng, J.; Zhang, X.; Wang, W.; Zhu, T.; Gu, Q.; Li, D. Austalides S-U, new meroterpenoids from the sponge-derived fungus Aspergillus aureolatus HDN14-107. Mar. Drugs 2016, 14, 131. [CrossRef]

99. Wang, Y.; Qi, S.; Zhan, Y.; Zhang, N.; Wu, A.A.; Gui, F.; Guo, K.; Yang, Y.; Cao, S.; Hu, Z.; et al. Aspertetranones A-D, putative meroterpenoids from the marine algal-associated fungus Aspergillus sp. ZL0-1b14. J. Nat. Prod. 2015, 78, 2405-2410. [CrossRef]

100. Yurchenko, A.N.; Trinh, P.T.H.; Girich Ivanets, E.V.; Smetanina, O.F.; Rasin, A.B.; Popov, R.S.; Dyshlovoy, S.A.; von Amsberg, G.; Menchinskaya, E.S.; Thanh Van, T.T.; et al. Biologically active metabolites from the marine sediment-derived fungus Aspergillus flocculosus. Mar. Drugs 2019, 17, 579. [CrossRef]

101. Long, Y.; Cui, H.; Liu, X.; Xiao, Z.; Wen, S.; She, Z.; Huang, X. Acetylcholinesterase inhibitory meroterpenoid from a mangrove endophytic fungus Aspergillus sp. 16-5c. Molecules 2017, 22, 727. [CrossRef]

102. Liu, Z.; Liu, H.; Chen, Y.; She, Z. A new anti-inflammatory meroterpenoid from the fungus Aspergillus terreus H010. Nat. Prod. Res. 2018, 32, 2652-2656. [CrossRef] [PubMed]

103. Wen, H.; Yang, X.; Liu, Q.; Li, S.; Li, Q.; Zang, Y.; Chen, C.; Wang, J.; Zhu, H.; Zhang, Y. Structurally diverse meroterpenoids from a marine-derived Aspergillus sp. Fungus. J. Nat. Prod. 2020, 83, 99-104. [CrossRef] [PubMed]

104. Chooi, Y.H.; Tang, Y. Navigating the fungal polyketide chemical space: From genes to molecules. J. Org. Chem. 2012, 77, 9933-9953. [CrossRef]

105. Oleinikova, G.K.; Denisenko, V.A.; Berdyshev, D.V.; Pushilin, M.A.; Kirichuk, N.N.; Menzorova, N.I.; Kuzmich, A.S.; Yurchenko, E.A.; Zhuravleva, O.I.; Afiyatullov, S.S. Two new sesterterpenoids, terretonins H and I, from the marine-derived fungus Aspergillus ustus. Phytochem. Lett. 2016, 17, 135-139. [CrossRef]

106. Wu, C.J.; Cui, X.; Xiong, B.; Yang, M.S.; Zhang, Y.X.; Liu, X.M. Terretonin D1, a new meroterpenoid from marine-derived Aspergillus terreus ML-44. Nat. Prod. Res. 2019, 33, 2262-2265. [CrossRef]

107. Li, H.-L.; Li, X.-M.; Li, X.; Yang, S.-Q.; Wang, B.-G. Structure, absolute configuration and biological evaluation of polyoxygenated meroterpenoids from the marine algal-derived Aspergillus terreus EN-539. Phytochem. Lett. 2019, 32, 138-142. [CrossRef]

108. Bai, Z.Q.; Lin, X.; Wang, J.; Zhou, X.; Liu, J.; Yang, B.; Yang, X.; Liao, S.; Wang, L.; Liu, Y. New meroterpenoids from the endophytic fungus Aspergillus flavipes AIL8 derived from the mangrove plant Acanthus ilicifolius. Mar. Drugs 2015, 13, 237. [CrossRef] [PubMed]

109. Zhang, H.; Zhao, Z.; Chen, J.; Bai, X.; Wang, H. Tricycloalternarene analogs from a symbiotic fungus aspergillus sp. D and their antimicrobial and cytotoxic effects. Molecules 2018, 23, 855. [CrossRef]

110. Li, H.; Sun, W.; Deng, M.; Qi, C.; Chen, C.; Zhu, H.; Luo, Z.; Wang, J.; Xue, Y.; Zhang, Y. Asperversins A and B, Two novel meroterpenoids with an Unusual 5/6/6/6 ring from the marine-derived fungus Aspergillus versicolor. Mar. Drugs 2018, 16, 177. [CrossRef] [PubMed]

111. Ding, C.; Wu, X.; Auckloo, B.; Chen, C.-T.; Ye, Y.; Wang, K.; Wu, B. An unusual stress metabolite from a hydrothermal vent fungus Aspergillus sp. WU 243 induced by cobalt. Molecules 2016, 21, 105. [CrossRef] [PubMed]

112. Zhang, P.; Li, X.-M.; Li, X.; Wang, B.-G. New indole-diterpenoids from the algal-associated fungus Aspergillus nidulans. Phytochem. Lett. 2015, 12, 182-185. [CrossRef] 
113. Gu, B.-B.; Wu, W.; Liu, L.-Y.; Tang, J.; Zeng, Y.-J.; Wang, S.-P.; Sun, F.; Li, L.; Yang, F.; Lin, H.-W. 3,5-dimethylorsellinic acid derived meroterpenoids from Eupenicillium sp. 6A-9, a fungus isolated from the marine sponge Plakortis simplex. Eur. J. Org. Chem. 2018, 2018, 48-59. [CrossRef]

114. Zheng, C.J.; Bai, M.; Zhou, X.M.; Huang, G.L.; Shao, T.M.; Luo, Y.P.; Niu, Z.G.; Niu, Y.Y.; Chen, G.Y.; Han, C.R. Penicilindoles A-C, Cytotoxic indole diterpenes from the mangrove-derived fungus Eupenicillium sp. HJ002. J. Nat. Prod. 2018, 81, 1045-1049. [CrossRef]

115. Zheng, C.J.; Shao, C.L.; Chen, M.; Niu, Z.G.; Zhao, D.L.; Wang, C.Y. Merosesquiterpenoids and ten-membered macrolides from a soft coral-derived Lophiostoma sp. fungus. Chem. Biodivers. 2015, 12, 1407-1414. [CrossRef]

116. Gao, S.S.; Li, X.M.; Williams, K.; Proksch, P.; Ji, N.Y.; Wang, B.G. Rhizovarins A-F, indole-diterpenes from the mangrove-derived endophytic fungus Mucor irregularis QEN-189. J. Nat. Prod. 2016, 79, 2066-2074. [CrossRef]

117. Xu, Y.; Wang, C.; Liu, H.; Zhu, G.; Fu, P.; Wang, L.; Zhu, W. Meroterpenoids and isocoumarinoids from a myrothecium fungus associated with apocynum venetum. Mar. Drugs 2018, 16, 363. [CrossRef]

118. Lan, W.J.; Fu, S.J.; Xu, M.Y.; Liang, W.L.; Lam, C.K.; Zhong, G.H.; Xu, J.; Yang, D.P.; Li, H.J. Five new cytotoxic metabolites from the marine fungus Neosartorya pseudofischeri. Mar. Drugs 2016, 14, 18. [CrossRef]

119. Zin, W.W.; Buttachon, S.; Buaruang, J.; Gales, L.; Pereira, J.A.; Pinto, M.M.; Silva, A.M.; Kijjoa, A. A new meroditerpene and a new tryptoquivaline analog from the algicolous fungus Neosartorya takakii KUFC 7898. Mar. Drugs 2015, 13, 3776-3790. [CrossRef]

120. Pan, C.; Shi, Y.; Auckloo, B.N.; Hassan, S.S.U.; Akhter, N.; Wang, K.; Ye, Y.; Arthur Chen, C.T.; Tao, X.; Wu, B. Isolation and antibiotic screening of fungi from a hydrothermal vent site and characterization of secondary metabolites from a Penicillium isolate. Marine Biotechnol. 2017, 19, 469-479. [CrossRef]

121. Zhang, J.; Yuan, B.; Liu, D.; Gao, S.; Proksch, P.; Lin, W. Brasilianoids A-F, new meroterpenoids from the sponge-associated fungus Penicillium brasilianum. Front. Chem. 2018, 6, 314-326. [CrossRef]

122. Zhang, J.; Wu, Y.; Yuan, B.; Liu, D.; Zhu, K.; Huang, J.; Proksch, P.; Lin, W. DMOA-based meroterpenoids with diverse scaffolds from the sponge-associated fungus Penicillium brasilianum. Tetrahedron 2019, 75, 2193-2205. [CrossRef]

123. Hwang, J.-Y.; You, M.J.; Oh, D.-C.; Oh, K.-B.; Shin, J. New meroterpenoids from a Penicillium sp. fungus. Nat. Prod. Sci. 2018, 24, 253-258. [CrossRef]

124. Park, J.S.; Quang, T.H.; Yoon, C.S.; Kim, H.J.; Sohn, J.H.; Oh, H. Furanoaustinol and 7-acetoxydehydroaustinol: New meroterpenoids from a marine-derived fungal strain Penicillium sp. SF-5497. J. Antibiot. 2018, 71, 557-563. [CrossRef]

125. Park, J.S.; Quang, T.H.; Thi Thanh Ngan, N.; Sohn, J.H.; Oh, H. New preaustinoids from a marine-derived fungal strain Penicillium sp. SF-5497 and their inhibitory effects against PTP1B activity. J. Antibiot. 2019, 72, 629-633. [CrossRef] [PubMed]

126. Bai, M.; Zheng, C.J.; Huang, G.L.; Mei, R.Q.; Wang, B.; Luo, Y.P.; Zheng, C.; Niu, Z.G.; Chen, G.Y. Bioactive meroterpenoids and isocoumarins from the mangrove-derived fungus Penicillium sp. TGM112. J. Nat. Prod. 2019, 82, 1155-1164. [CrossRef]

127. Xie, C.L.; Xia, J.M.; Lin, T.; Lin, Y.J.; Lin, Y.K.; Xia, M.L.; Chen, H.F.; Luo, Z.H.; Shao, Z.Z.; Yang, X.W. Andrastone A from the deep-sea-derived fungus Penicillium allii-sativi acts as an inducer of caspase and RXRalpha-dependent apoptosis. Front. Chem. 2019, 7, 692-698. [CrossRef] [PubMed]

128. Li, H.L.; Xu, R.; Li, X.M.; Yang, S.Q.; Meng, L.H.; Wang, B.G. Simpterpenoid A, a meroterpenoid with a Highly functionalized cyclohexadiene moiety featuring Gem-Propane-1,2-Dione and methylformate groups, from the mangrove-derived Penicillium simplicissimum MA-332. Org. Lett. 2018, 20, 1465-1468. [CrossRef]

129. Ozkaya, F.C.; Ebrahim, W.; Klopotowski, M.; Liu, Z.; Janiak, C.; Proksch, P. Isolation and X-ray structure analysis of citreohybridonol from marine-derived Penicillium atrovenetum. Nat. Prod. Res. 2018, 32, 840-843. [CrossRef]

130. Cho, K.H.; Kim, D.C.; Yoon, C.S.; Ko, W.M.; Lee, S.J.; Sohn, J.H.; Jang, J.H.; Ahn, J.S.; Kim, Y.C.; Oh, H. Anti-neuroinflammatory effects of citreohybridonol involving TLR4-MyD88-mediated inhibition of NF-small ka, CyrillicB and MAPK signaling pathways in lipopolysaccharide-stimulated BV2 cells. Neurochem. Int. 2016, 95, 55-62. [CrossRef]

131. Cheng, Z.; Xu, W.; Liu, L.; Li, S.; Yuan, W.; Luo, Z.; Zhang, J.; Cheng, Y.; Li, Q. Peniginsengins B-E, new farnesylcyclohexenones from the deep sea-derived fungus Penicillium sp. YPGA11. Mar. Drugs 2018, 16, 358. [CrossRef] 
132. Liu, S.; Su, M.; Song, S.J.; Hong, J.; Chung, H.Y.; Jung, J.H. An anti-inflammatory PPAR-gamma agonist from the jellyfish-derived fungus Penicillium chrysogenum J08NF-4. J. Nat. Prod. 2018, 81, 356-363. [CrossRef] [PubMed]

133. Hoang, T.P.T.; Roullier, C.; Boumard, M.C.; Robiou du Pont, T.; Nazih, H.; Gallard, J.F.; Pouchus, Y.F.; Beniddir, M.A.; Grovel, O. Metabolomics-driven discovery of meroterpenoids from a mussel-derived Penicillium ubiquetum. J. Nat. Prod. 2018, 81, 2501-2511. [CrossRef] [PubMed]

134. Ding, Z.; Zhang, L.; Fu, J.; Che, Q.; Li, D.; Gu, Q.; Zhu, T. Phenylpyropenes E and F: New meroterpenes from the marine-derived fungus Penicillium concentricum ZLQ-69. J. Antibiot. 2015, 68, 748-751. [CrossRef] [PubMed]

135. Ding, B.; Wang, Z.; Huang, X.; Liu, Y.; Chen, W.; She, Z. Bioactive alpha-pyrone meroterpenoids from mangrove endophytic fungus Penicillium sp. Nat. Prod. Res. 2016, 30, 2805-2812. [CrossRef] [PubMed]

136. Li, X.; Li, X.M.; Zhang, P.; Wang, B.G. A new phenolic enamide and a new meroterpenoid from marine alga-derived endophytic fungus Penicillium oxalicum EN-290. J Asian Nat. Prod. Res. 2015, 17, 1204-1212. [CrossRef]

137. Liu, H.; Li, X.M.; Liu, Y.; Zhang, P.; Wang, J.N.; Wang, B.G. Chermesins A-D: Meroterpenoids with a drimane-type spirosesquiterpene skeleton from the marine algal-derived endophytic fungus Penicillium chermesinum EN-480. J. Nat. Prod. 2016, 79, 806-811. [CrossRef]

138. Sobolevskaya, M.P.; Zhuravleva, O.I.; Leshchenko, E.V.; Zakharenko, A.M.; Denisenko, V.A.; Kirichuk, N.N.; Popov, R.S.; Berdyshev, D.V.; Pislyagin, E.A.; Pivkin, M.V.; et al. New metabolites from the alga-derived fungi Penicillium thomii Maire and Penicillium lividum Westling. Phytochem. Lett. 2016, 15, 7-12. [CrossRef]

139. Chen, S.; Wang, J.; Wang, Z.; Lin, X.; Zhao, B.; Kaliaperumal, K.; Liao, X.; Tu, Z.; Li, J.; Xu, S.; et al. Structurally diverse secondary metabolites from a deep-sea-derived fungus Penicillium chrysogenum SCSIO 41001 and their biological evaluation. Fitoterapia 2017, 117, 71-78. [CrossRef]

140. Lin, X.; Wu, Q.; Yu, Y.; Liang, Z.; Liu, Y.; Zhou, L.; Tang, L.; Zhou, X. Penicilliumin B, a novel sesquiterpene methylcyclopentenedione from a deep sea-derived Penicillium strain with renoprotective activities. Sci. Rep. 2017, 7, 10757-10763. [CrossRef]

141. Yamazaki, H.; Nakayama, W.; Takahashi, O.; Kirikoshi, R.; Izumikawa, Y.; Iwasaki, K.; Toraiwa, K.; Ukai, K.; Rotinsulu, H.; Wewengkang, D.S.; et al. Verruculides A and B, two new protein tyrosine phosphatase 1B inhibitors from an Indonesian ascidian-derived Penicillium verruculosum. Bioorg. Med. Chem. Lett. 2015, 25, 3087-3090. [CrossRef] [PubMed]

142. Kong, F.D.; Ma, Q.Y.; Huang, S.Z.; Wang, P.; Wang, J.F.; Zhou, L.M.; Yuan, J.Z.; Dai, H.F.; Zhao, Y.X. Chrodrimanins K-N and related meroterpenoids from the fungus Penicillium sp. SCS-KFD09 isolated from a marine worm, Sipunculus nudus. J. Nat. Prod. 2017, 80, 1039-1047. [CrossRef] [PubMed]

143. Kong, F.D.; Zhang, R.S.; Ma, Q.Y.; Xie, Q.Y.; Wang, P.; Chen, P.W.; Zhou, L.M.; Dai, H.F.; Luo, D.Q.; Zhao, Y.X. Chrodrimanins O-S from the fungus Penicillium sp. SCS-KFD09 isolated from a marine worm, Sipunculusnudus. Fitoterapia 2017, 122, 1-6. [CrossRef] [PubMed]

144. Hu, X.Y.; Meng, L.H.; Li, X.; Yang, S.Q.; Li, X.M.; Wang, B.G. Three new indole diterpenoids from the sea-anemone-derived fungus Penicillium sp. AS-79. Mar. Drugs 2017, 15, 137. [CrossRef] [PubMed]

145. Guo, X.C.; Xu, L.L.; Yang, R.Y.; Yang, M.Y.; Hu, L.D.; Zhu, H.J.; Cao, F. Anti-vibrio indole-diterpenoids and C-25 epimeric steroids from the marine-derived fungus Penicillium janthinellum. Front. Chem. 2019, 7, 80-86. [CrossRef]

146. Kong, F.D.; Fan, P.; Zhou, L.M.; Ma, Q.Y.; Xie, Q.Y.; Zheng, H.Z.; Zheng, Z.H.; Zhang, R.S.; Yuan, J.Z.; Dai, H.F.; et al. Penerpenes A-D, four indole terpenoids with potent protein tyrosine phosphatase inhibitory activity from the marine-derived fungus Penicillium sp. KFD28. Org. Lett. 2019, 21, 4864-4867. [CrossRef]

147. Zhou, L.M.; Kong, F.D.; Fan, P.; Ma, Q.Y.; Xie, Q.Y.; Li, J.H.; Zheng, H.Z.; Zheng, Z.H.; Yuan, J.Z.; Dai, H.F.; et al. Indole-diterpenoids with protein tyrosine phosphatase inhibitory activities from the marine-derived fungus Penicillium sp. KFD28. J. Nat. Prod. 2019, 82, 2638-2644. [CrossRef]

148. Liu, L.; Xu, W.; Li, S.; Chen, M.; Cheng, Y.; Yuan, W.; Cheng, Z.; Li, Q. Penicindopene A, a new indole diterpene from the deep-sea fungus Penicillium sp. YPCMAC1. Nat. Prod. Res. 2019, 33, 2988-2994. [CrossRef]

149. Arunpanichlert, J.; Rukachaisirikul, V.; Phongpaichit, S.; Supaphon, O.; Sakayaroj, J. Meroterpenoid, isocoumarin, and phenol derivatives from the seagrass-derived fungus Pestalotiopsis sp. PSU-ES194. Tetrahedron 2015, 71, 882-888. [CrossRef] 
150. Chen, C.J.; Zhou, Y.Q.; Liu, X.X.; Zhang, W.J.; Hu, S.S.; Lin, L.P.; Huo, G.M.; Jiao, R.H.; Tan, R.X.; Ge, H.M. Antimicrobial and anti-inflammatory compounds from a marine fungus Pleosporales sp. Tetrahedron Lett. 2015, 56, 6183-6189. [CrossRef]

151. Ma, X.; Wang, H.; Li, F.; Zhu, T.; Gu, Q.; Li, D. Stachybotrin G, a sulfate meroterpenoid from a sponge derived fungus Stachybotrys chartarum MXH-X73. Tetrahedron Lett. 2015, 56, 7053-7055. [CrossRef]

152. Zhang, P.; Li, Y.; Jia, C.; Lang, J.; Niaz, S.-I.; Li, J.; Yuan, J.; Yu, J.; Chen, S.; Liu, L. Antiviral and anti-inflammatory meroterpenoids: Stachybonoids A-F from the crinoid-derived fungus Stachybotrys chartarum 952. RSC Adv. 2017, 7, 49910-49916. [CrossRef]

153. Liu, D.; Li, Y.; Li, X.; Cheng, Z.; Huang, J.; Proksch, P.; Lin, W. Chartarolides A-C, novel meroterpenoids with antitumor activities. Tetrahedron Lett. 2017, 58, 1826-1829. [CrossRef]

154. Chen, S.; Ding, M.; Liu, W.; Huang, X.; Liu, Z.; Lu, Y.; Liu, H.; She, Z. Anti-inflammatory meroterpenoids from the mangrove endophytic fungus Talaromyces amestolkiae YX1. Phytochemistry 2018, 146, 8-15. [CrossRef] [PubMed]

155. Cao, X.; Shi, Y.; Wu, X.; Wang, K.; Huang, S.; Sun, H.; Dickschat, J.S.; Wu, B. Talaromyolides A-D and Talaromytin: Polycyclic Meroterpenoids from the Fungus Talaromyces sp. CX11. Org. Lett. 2019, 21, 6539-6542. [CrossRef]

(C) 2020 by the authors. Licensee MDPI, Basel, Switzerland. This article is an open access article distributed under the terms and conditions of the Creative Commons Attribution (CC BY) license (http://creativecommons.org/licenses/by/4.0/). 